UIII norden

Nordic Council of Ministers

Nordic intercalibration of hard bottom macroalgae monitoring methodologies

Algamony 

4 norden 



\title{
Nordic intercalibration of hard bottom macroalgae monitoring methodologies
}

\author{
Algamony \\ Frithjof E Moy, NIVA, Norway, \\ Karsten Dahl, National Environmental Research Institute, \\ Aarhus University, Denmark \\ Jan Karlsson, University of Göteborg, Sweden \\ Hans Kautsky, University of Stockholm, Sweden \\ Ari Ruuskanen, University of Helsinki, Finland and \\ Jacob Carstensen, National Environmental Research Institute, \\ Aarhus University, Denmark
}


Nordic intercalibration of hard bottom macroalgae monitoring methodologies

Algamony

TemaNord 2010:543

(c) Nordic Council of Ministers, Copenhagen 2010

ISBN 978-92-893-2062-7

This publication is available as Print on Demand (PoD) and can be ordered on

www.norden.org/order. Other Nordic publications are available at www.norden.org/en/publications

Printed on environmentally friendly paper

This publication can be ordered on www.norden.org/order. Other Nordic publications are available at www.norden.org/publications

Printed in Denmark

Nordic Council of Ministers

Ved Stranden 18

DK-1061 København K

Phone (+45) 33960200

Fax (+45) 33960202
Nordic Council

Ved Stranden 18

DK-1061 København K

Phone (+45) 33960400

Fax (+45) 33111870

www.norden.org

\section{Nordic co-operation}

Nordic co-operation is one of the world's most extensive forms of regional collaboration, involving Denmark, Finland, Iceland, Norway, Sweden, and three autonomous areas: the Faroe Islands, Greenland, and Åland.

Nordic co-operation has firm traditions in politics, the economy, and culture. It plays an important role in European and international collaboration, and aims at creating a strong Nordic community in a strong Europe.

Nordic co-operation seeks to safeguard Nordic and regional interests and principles in the global community. Common Nordic values help the region solidify its position as one of the world's most innovative and competitive. 


\section{Content}

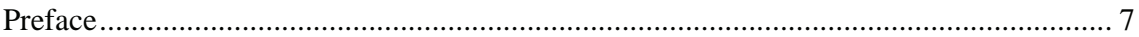

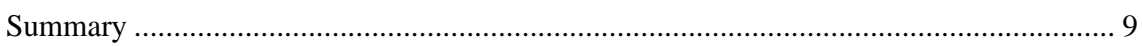

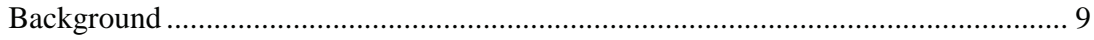

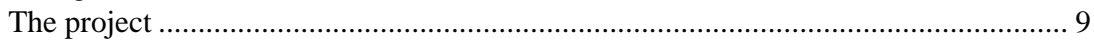

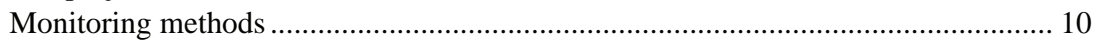

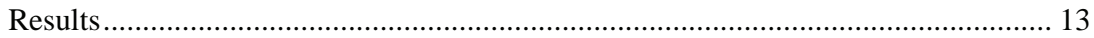

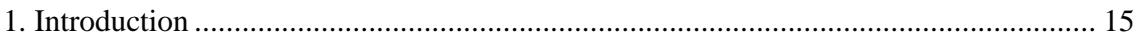

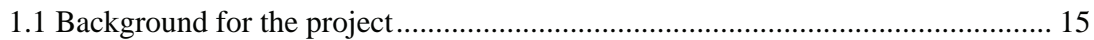

1.2 Description of national macroalgal monitoring guidelines................................... 19

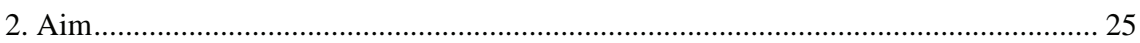

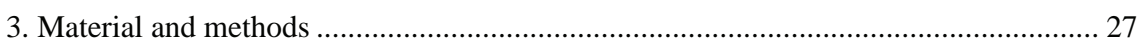

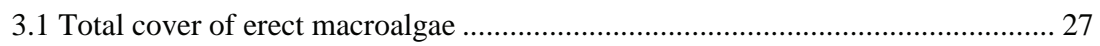

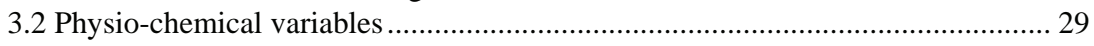

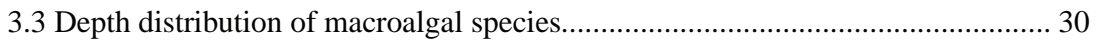

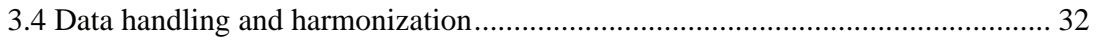

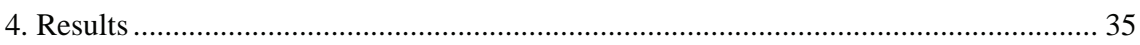

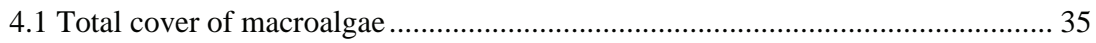

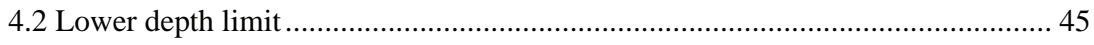

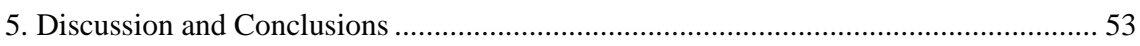

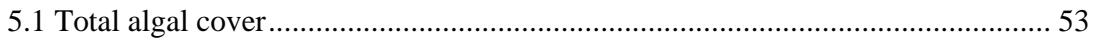

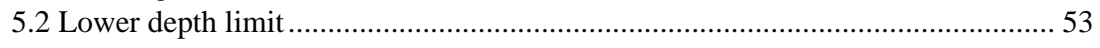

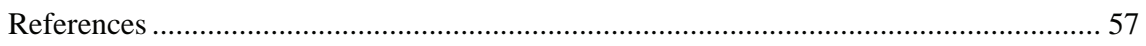

Appendix 1: Technical Guideline for collecting “total erect macroalgal cover” ............... 61

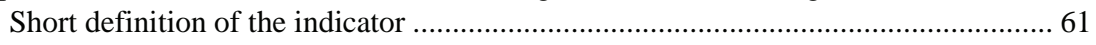

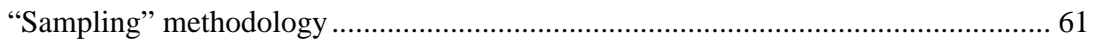

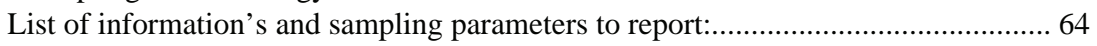

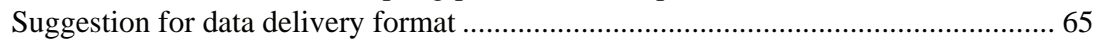

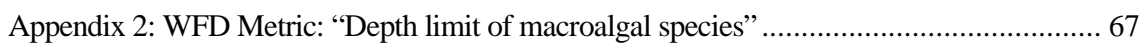

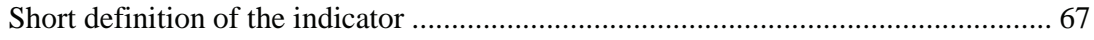

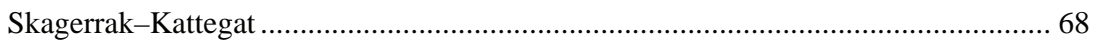

The Baltic Sea - Finland and Sweden ................................................................... 72

Appendix 3: Tables of algal depth distribution (average, maximum and variance)........... 75 



\section{Preface}

The ALGOMONY project - which aim is harmony in Nordic macroalgae monitoring methodologies - was conceived during the work of RETRO another valuable project funded by the Nordic Council of Ministers.

RETRO (Reference conditions and EQO's for aquatic vegetation and macrozoobenthos, 2002-2004) clearly demonstrated the major impact of methodology on evaluation and modelling of reference conditions of Skagerrak/Kattegat. There was a general need for development and intercalibration of common marine ecological quality objectives among the Nordic countries as well for the EU member states to fulfil the obligations according to a number of EU directives.

ALGONOMY have had a 2 year funding by the NCM. The first year (2007) a practical workshop with diving exercise was arranged in Norway, to get hands-on information about the monitoring methodologies used in Finland, Sweden, Denmark and Norway. The second year (2008) an analytical workshop was arranged in Sweden with the aim to intercalibrate Nordic monitoring data. The difficulties of intercalibration across nations and methodologies was underestimated and the ALGONOMY project needed a third year (without funding) to write the consensus report from the project.

We believe the results from the project will bring Nordic marine monitoring a step forward through the good work and learned skills of the participants and through further use of results and experience in new projects, like the NCM funded project MOPODECO.

Thanks to Karsten Dahl (kda@dmu.dk), Kim Lundshøj (DK), Jacob Carstensen (jac@dmu.dk), Janne Gitmark (jkg@niva.no), Kjell Magnus Norderhaug (kmn@niva.no), Are Pedersen (are@niva.no), Lise Tveiten (lis@niva.no), Jan Karlsson (Jan.Karlsson@marecol.gu.se), Hans Kautsky (hassek@ecology.su.se), Susanne Qvarfordt (susanne@ecology.su.se), Anders Wallin (anders@ecology.su.se), Ari Ruuskanen (aruuskan@ mappi.helsinki.fi), Henna Piekäinen (Henna.Piekainen@ymparisto.fi)

Norway, 1 March 2010

Frithjof E Moy

moy@niva.no

ALGONOMY project leader 

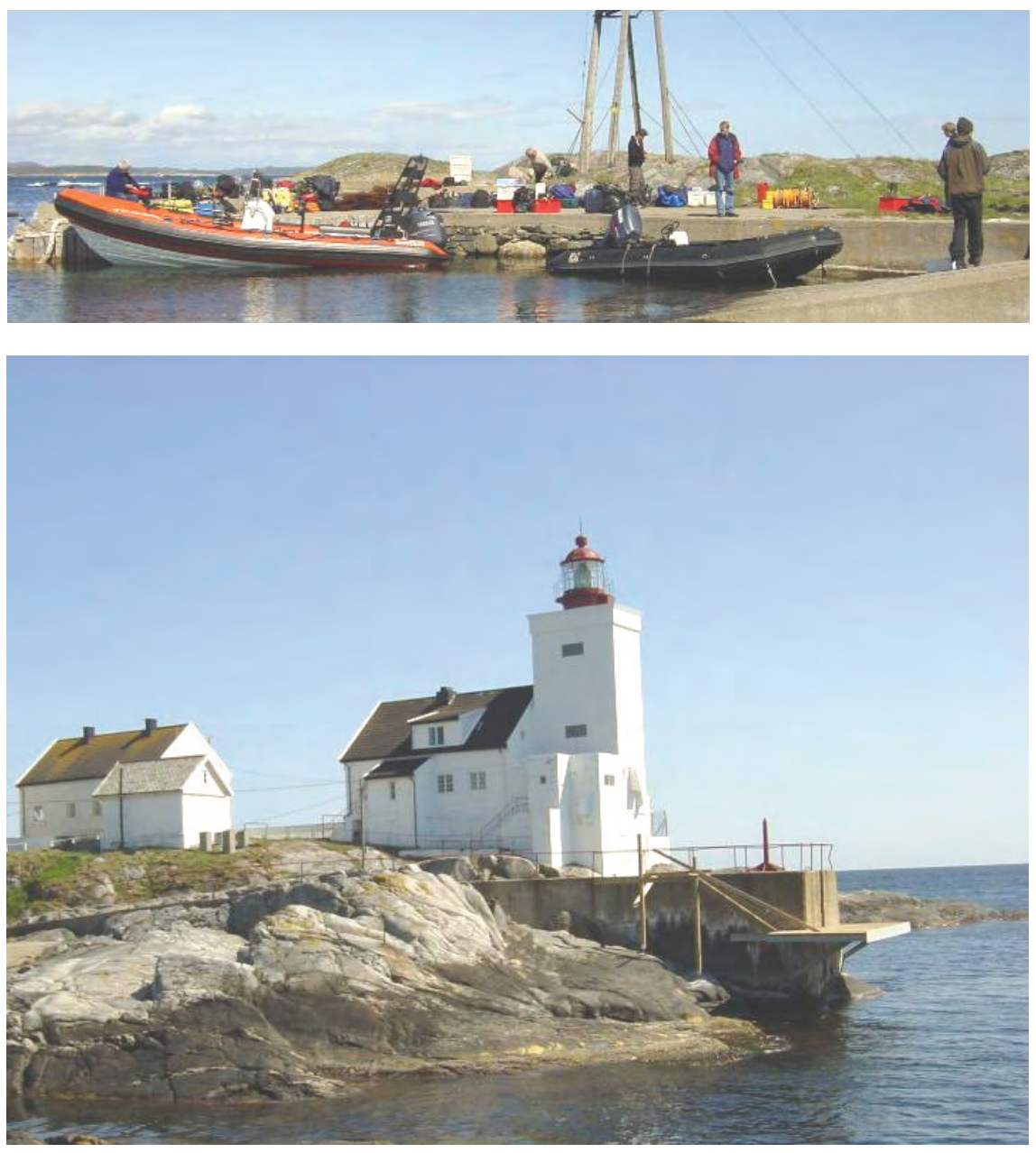

Workshop at Homborund lighthouse outside Grimstad, Norway, the first year of the project.
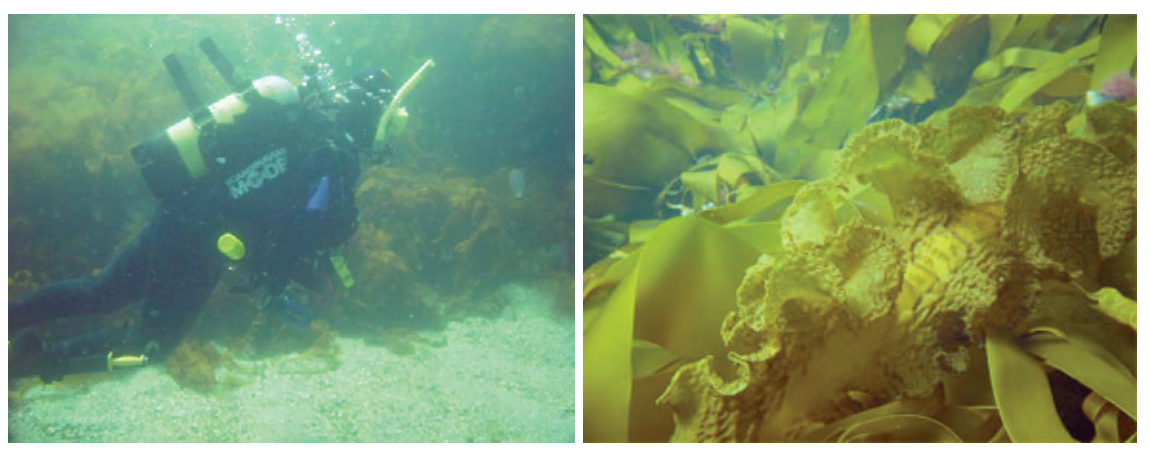

Monitoring methods and common metrics were tested and discussed. 


\section{Summary}

\section{Background}

There is a general need for development and intercalibration of common marine ecological quality objectives among the EU member states to fulfil the obligations according to a number of EU directives. The process of intercalibration within the Water Framework Directive (WFD) has proven the difficulties of calibration across nations and methodologies.

The RETRO project (Reference conditions and EQO's for aquatic vegetation and macrozoobenthos, 2002-2004) funded by the Nordic Council of Ministers (NCM) also clearly demonstrated the major impact of methodology on common evaluation and modelling of reference conditions of Skagerrak/Kattegat.

Macroalgal vegetation is an important quality element in assessing the quality status of marine ecosystems in the euphotic zone. Macroalgae is a mandatory biological quality element (BQE) in assessing the quality of coastal waters (waterbodies) according to the Water Framework Directive. It is also a biological feature explicitly mentioned in annex III of the new EU Marine Strategy Framework Directive. In addition macroalgae is an important element describing conservation status of several habitats included in the EU's Habitats Directive.

\section{The project}

The aim of the ALGONOMY project was to bring Nordic macroalgae monitoring scientists together to harmonise monitoring methodologies and to agree on common metrics that without extensive cost could be implemented in the different national monitoring programmes.

ALGONOMY have had a 2 year funding (2007-2008) by the NCM. The first year a practical workshop with diving exercise was arranged in Norway, to get hands-on information about the different monitoring methodologies used in Finland, Sweden, Denmark and Norway, and to agree upon common metrics to harmonize national monitoring data. Based on this exercise two common metrics was chosen for further common work:

1) Total cover of erect macroalgae species (method by NERI. A technical guideline for this indicator was elaborated and given in Annex 1).

2) Lower depth distribution limit of selected macroalgae species (suggested WFD intercalibration metric. Guideline is given in Annex 2). 
These two methods were added to the national monitoring works in 2007 and 2008. The data were analysed in a second workshop arranged in autumn the second year. The difficulties of intercalibration across nations and methodologies should not be underestimated in the work of implementation of the Water Framework directive and the ALGONOMY project needed a third year (without funding) to write the consensus report from the project. Results and experience of ALGONOMY will be used further in new Nordic projects, like the NCM funded project MOPODECO.

\section{Personnel}

ALGONOMY core group: Ari Ruuskanen (Univ of Helsinki, SF), Karsten Dahl (DMU, DK), Hans Kautsky (Univ of Stockholm, S), Jan Karlsson (Univ of Göteborg, S), and Frithjof Moy (NIVA, NO).

Project participants: Henna Piekäinen (SYKE, SF); Jacob Carstensen and Kim Lundshøj (DMU, DK); Are Pedersen, Janne Gitmark, Kjell Magnus Norderhaug and Lise Tveiten (NIVA, NO); Anders Wallin and Susanne Qvarfordt (Univ of Stockholm, S).

\section{Monitoring methods}

\section{Finland}

Macroalgae vegetation and bottom substrate quality is recorded by a taxonomic skilled diver along a measurement line perpendicular to the shoreline. (1993-2007: Length of rope $=50 \mathrm{~m}$. From 2008: Length of rope $=$ until lower growth limit of vegetation is reached.) Depth and bottom substrate (percentage of rock, boulder, stone, gravel, sand, mud) is recorded on each meter mark on the rope. Macroalgae species composition and abundance (\% cover degree using $1 \mathrm{~m} \times 1 \mathrm{~m}$ frame) is recorded on depth intervals of $0-1 \mathrm{~m}, 1-2 \mathrm{~m}, 2-4 \mathrm{~m}, 4-6 \mathrm{~m}, 6-8 \mathrm{~m}$. Since 2000 percent cover degree is measured in related to potential available macroalgae growth substrate.

\section{Sweden, east coast}

Vegetation, animals and bottom substrate quality is recorded in situ by two taxonomic skilled divers simultaneously in a 6-10 m wide transect along a measurement line with a given bearing from a fixed point on the shore (usually perpendicular). The maximum depth is set by the species distribution and/or type of substrate. Species composition, abundance, substrate type (percentage of boulders, stones, gravel, sand, soft bottom or mussels etc.), depth and distance from the shore are recorded whenever the substrate changes and/or new species occur or changes in their cover- 
age. Abundance (cover degree) is given according to a 7-grade percent scale: 100, 75, 50, 25, 10, 5 and 1 (for occurrence). The accumulated coverage of species may exceed $100 \%$ as species grows in several layers. Abundance of mobile animals is given according to the scale: 1 for occurrence, 2 for frequent and 3 for common. On selected stations quantitative samples are collected (three replicate $0.2 \times 0.2 \mathrm{~cm}$ frames).

\section{Sweden, west coast}

(National Monitoring Programme, SEPA): Photo-monitoring technique on step bedrock used since 1993. At each station, surveyed once a year from late July to mid August, five transects are deployed randomly perpendicular to the shore within a fixed section of the shore. For each transect, at fixed depths between 0 to $20 \mathrm{~m}$, two digital photos are taken, giving a total of 10 replicates per depth interval at each locality. Each replicate covers an area of $0.25 \mathrm{~m}^{2}$. If necessary, multiple photos are taken after unfolding the canopy. In addition, the diver record in situ (on a plastic sheet) the upper and lower growth limit of the dominating macroalgae along each transects. In the laboratory, the number of species, the total area covered, the area covered by individual taxa, and for species with distinct individuals, their abundances are retrieved from the digital pictures using an interactive pen display computer system.

\section{Denmark}

(The national monitoring programme): Selected stone reefs on general sandy bottom are surveyed 1-2 times annually in June and August since 1994 by taxonomic skilled divers. Percent cover of erect macroalgae species, dominate animals and the total cover of the erect macroalgal community on hard stable substrate are recorded along a depth gradient with 2-3 m intervals. The selected stations had at least $10 \%$ cover of hard stable substrate and $10-25 \mathrm{~m}^{2}$ of the stone reef are inspected. The diver is connected to the research vessel with communication and online video for biological registration, documentation and safety. In addition samples are collection for later taxonomic work up in the laboratory.

\section{Norway}

(Norwegian Coastal Monitoring Programme): Hard bottom communities on selected fixed stations are monitored annually in June since 1990. Species composition and abundance of macroalgae and animals (sessile or slow moving) are recorded by taxonomic skilled divers (botanist and zoologist) along an approx $8 \mathrm{~m}$ wide, vertical transects from maximum $30 \mathrm{~m}$ depth and towards the surface along fixed transect routes. Species abundance is visually judged for every 2 depth $\mathrm{m}$ (or at marked changes 
in composition) according to a semi-quantitative 4 level scale: rare, frequent, common and dominant, relative to suitable substrate. The divers are connected to the surface team with a communication and safety cable and all observations are noted by the surface crew. Samples for taxonomic work up are collected and abundances on between depths are added by the diver.

\section{Total algal cover}

Total algal vegetation cover is the overall cover of all erect macrophyte species (not crusts) fixed to stable, hard substrate. The value of the indicator has a range from 0 to $100 \%$ of available substrate. The cover is judged by divers looking at the seabed in a more or less 90 degree angle from the water surface. Multiple layers of algae (primary cover, understory and canopy) will only be expressed as on cover and maximum $100 \%$. This is different to the cumulative sum of individual species cover, which could exceed $100 \%$.

Total algal cover is measured at a specific depth (adjusted for changing water levels like tides) or better at each registration depth on deeper water giving cover data within the interval $15 \%-85 \%$ or larger range as it allows detection of both improvements and loss in algal cover due to changing levels of eutrophication.

A sampling area of $>10 \mathrm{~m}^{2}$ is recommended however the area should reflect patchiness in the vegetation. The sampling area at the locations/ stations should preferably have a slope of $<30$ degree average angle to the horizontal axis to avoid influencing shading effects due to the topography.

Biological factors interacting with the total algal cover like presents of sea urchins, drifting algal mats or space competing animals like mussels and sea anemones, must be recorded and compensated for.

\section{Lower depth distribution limit}

The WFD intercalibration metric "Depth limit of macroalgal species" use the depth extension of selected perennial macroalgal species as the biological quality element in response to environmental impacts. The selected species should be selected based on 1) perennial, 2) commonly occurring in the type and 3) easy to determine. We selected 8 species: Chondrus crispus, Phycodrys rubens, Furcellaria lumbricalis, Coccotylus/Phyllophora, Delesseria sanguinea, Rhodomela confervoides, Halidrys siliquosa and Saccharina latissima (Laminaria saccharina)

The Nordic NEA-GIG group have suggested good-moderate boundaries (species lower depth distribution limit) for Skagerrak water types based on historical reference data on species depth distribution and expert judgement (Boundary setting protocol for intercalibration of macroalgae). 
Although the relationship between water transparency and the depth limit of perennial macroalgal species is obvious, so far, poor doseresponse relationships between water quality expressed as either nutrient concentration or water transparency and lower depth limit of the selected macroalgal species have been found. In the ALGONOMY project we decided to test lower depth distribution of $5 \%$ cover degree (frequent occurrence) which was assumed easier to locate than the absolute depth distribution limit defined by (Boundary setting protocol).

Water quality is classified by evaluating the recorded lower depth distribution limit with the boundaries given in the boundary setting protocol.

\section{Results}

\section{Total algae cover}

Data on total algal cover estimates (including direct measurements in 2007-2008) resulted in 239 annual means representing 46 areas and 21 years. These were quite heterogeneously distributed between study sites. The parameters for the depth gradient varied by a factor of 2, with the steepest gradients observed at the Swedish west coast. Total cover estimations were most uncertain for Askö and also the Finnish archipelago, because total cover had to be normalised to the fraction of suitable substrate at these study sites. The uncertainty of the Finnish depth gradient was large due to lack of deeper observations and therefore a limited range for estimating the depth gradient. The most precise depth-specific estimate of total cover is obtained from photo method carried out within a small geographic area on the Swedish west coast.

Total cover estimates were significantly related to Secchi depths, but significant differences were found in this relationship between study sites. Though, there were no significant differences between the Danish, Norwegian and Swedish west coast relationships (Skagerrak region). The differences might be caused by a combination of different methodologies for assessing total cover and differences how well water quality can be estimated for the macroalgae transects.

Long-term trends in total cover suggest that macroalgae have a relatively fast response to changing water quality, and as such provide a good ecological indicator for assessing the effects of nutrient management.

Water quality (supporting parameters) and macroalgae monitoring stations should be better coordinated within the national monitoring programmes with a close distance between biological and water quality stations. The pelagic sampling frequency should reflect the dynamic processes in the water column such that more precise functional relationships can be estimated. 


\section{Lower depth distribution limit}

Lower depth distribution limit of 5\% cover degree and maximum depth limit was assembled for the 8 selected species for the period 1995-2008 from the national monitoring programmes (6,020 records, including direct measurements in 2007-2008).

Results from the Skagerrak region may be compared to the NEA-GIG boundary setting protocol criteria for the Skagerrak region water types 8 (archipelago), 9 (fjords) and 10 (open coast). The work in this project has focused on the usefulness of this metric.

Large year to year variations found in the data sets, especially in the Norwegian data, clearly indicate that the water quality cannot be judge by a single year alone but should be based on three or more years. The large variation may be due to natural variation in factors influencing the depth distribution other than direct water quality. In the Norwegian data, the variation may be due to competing species like dominate canopying kelp Laminaria hyperborea depriving understory species (like Chondrus crispus, Furcellaria lumbricalis, and Rhodomela confervoides) from natural light. Biological factors like competition for space and light must be considered before use of this metric and likewise possible grazing from e.g. sea-urchins. We therefore recommend that species composition and abundance is measured according to the WFD to be able to evaluate lower depth limit in light of community structure and water quality.

Species like Coccotylus/Phyllophora and Delesseria sanguinea grows deeper with less light than most other macroalgae species and lower depth limit is therefore less influenced by abundance of kelp or other competing species. It is advisable to select two or more species common to the geographical region and water type based on knowledge of species composition and abundance.

With the Norwegian data set subtracted (due to the large variance) the variance in the data is generally slightly greater for maximum depth distribution compared to 5\% cover degree depth distribution limit. This support the hypothesis that $5 \%$ cover degree is easier to obtain than the maximum depth which could be more incidental. 


\section{Introduction}

\subsection{Background for the project}

There is a general need for development and intercalibration of common marine ecological quality objectives among the EU member states to fulfil the obligations according to a number of EU directives.

Macroalgal vegetation is an important quality element in assessing the quality status of marine ecosystems in the photic zone and it is a mandatory biological quality element (BQE) in assessing the quality of coastal waters according to the Water Framework Directive. It is also a biological feature explicitly mentioned in annex III of the new EU Marine Strategy Framework Directive. In addition macroalgae is an important element describing conservation status of several habitats included in the EU's Habitats Directive like "reefs", "bobbling reefs" and "shallow bays and lagoons" including "hard substrate".

The national coastal monitoring programmes of the Nordic countries cover a wide range from Skagerrak to the Baltic Sea. They include different methodologies for registration and classification of hard bottom aquatic vegetation. Problems with intercalibration of data describing macroalgal communities in Kattegat and Skagerrak between Norway, Sweden and Denmark were well documented in the NMR project RETRO (Reference conditions and EQO's for aquatic vegetation and macrozoobenthos). In this case differences in algal communities was clearly demonstrated which could not be justified by natural or human impact alone (figure 1.1).

The intercalibration work done so far (by 2009) for the NE Atlantic and the Baltic coastal and transitional waters has focused on depth distribution of selected species. Based on historical data and expert judgement reference values of lower depth distribution limit for 8 selected macroalgae species has been set for defined water types of intercalibration (see Appendix 2). The species chosen are common in Skagerrak-Kattegat, are easily recognisable, and monitoring and historical data were available. But still intercalibration has shown urgent need for harmonizing monitoring methods and defining the lower depth limit.

In the Baltic (Sweden-Finland) bladderwrack (Fucus vesiculosus) is the only species selected for the lower depth limit quality matrix. Reference depth distribution is based on literature surveys of historical data. With the expert judgements the reference condition was established (See Appendix 2).

In Denmark other algal metrics (indicators) and methodologies have been developed and used to describe reference conditions and present 
ecological status. Empirical models have been developed for Nature-2000 reef sites in the open part of Kattegat describing "Total vegetation cover" and "cumulative vegetation cover" as function of locality, solar radiation, depth, grassing pressure of sea-urchin and total load of nutrient to Kattegat (Dahl \& Carstensen, 2008). Both models are statistically well founded. Lacking historic information on the vegetation cover in Danish waters the two models have been used to describe reference conditions and other scenarios of vegetation cover at different estimates of nitrogen loads to Kattegat, as seen in the example in figure 1.2.

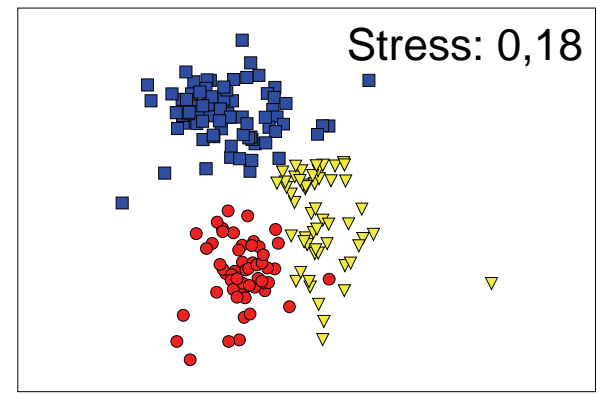

- DK

$\nabla \quad$ SWE

- NOR

Figure 1.1. Multi dimensional scaling plot (MDS) showing the similarity between samples describing the algal community at 18-20m depth in Kattegat-Skagerrak (from Petersen et al, 2006).
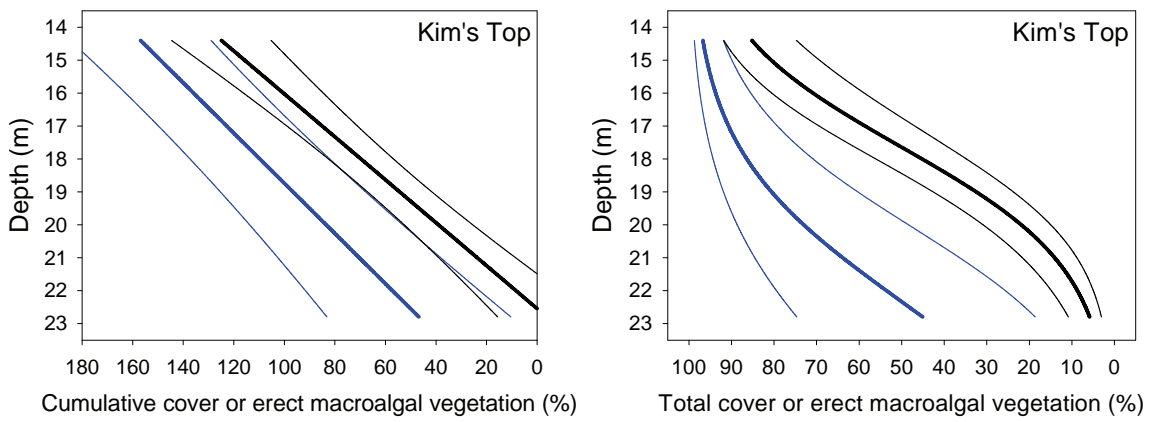

Figure 1.2 total cover (left) and cumulative cover (right) of macrophytes at different depth and at different nutrient load scenarios at the reef Kim's Top in the central part of Kattegat. The thick blue line describe a reference load scenario with 10,000 tons from rivers and point sources in January-June and the thick blue line describe an average load scenario equal to the period 1999-2007 on 48,000 tons in the same 6 month. The thin line describes the upper and lover 95\% confidence interval on the estimated covers. From Dahl \& Carstensen, 2008

Empirical modelling on algal datasets collected on hard stable substrate in coastal areas of Denmark has also been done recently (Carstensen et al, 2008). More or less all datasets collected as part of the national monitoring program in 2001, 2003 and 2005 have been included in the work.

Six different indicators have been tested and important structuring factors identified and quantified. Common for all indicators are that data has been normalised for differences in sampling depth, spatial variation within a waterbody and time within the summer period by an "underlying 
model". The resulting algal indicators are expressed as an average value and variance representing $7 \mathrm{~m}$ water depth in each selected waterbody. The indicators and the structuring factors are shown in table 1.1.

Tabel 1.1 Macroalgal indicators and those factors that was identified as significantly structuring each indicator as well as the overall model correlations.

\begin{tabular}{lcccc}
\hline Variabel & TN & Salinitet & TN salinitet & R2 \\
\hline Total algal cover & & $\uparrow$ & $\downarrow$ & 0.68 \\
Cummulated algal cover & & $\uparrow$ & $\downarrow$ & 0.70 \\
Cummulated cover of per-annual species & $\downarrow$ & $\uparrow$ & & \\
Cummulated cover of opportunistic species & & & $\downarrow$ & 0.71 \\
Fraction of opportunistis algalspecies & $\uparrow$ & & $\downarrow$ & 0.69 \\
Number of per-annual species makroalgearter & & $\uparrow$ & $\downarrow$ & 0.79 \\
\hline
\end{tabular}

TN =Total Nitrogen TN*salinity means that the effect of TN was dependent on salinity. The arrows indicate positive (up) or negative (down) effects of TN and salinity (from Carstensen et al. 2008).

All macroalgal variables responded significantly ( $>>0.05$ ) to a combination to changes in total nitrogen and to changes in salinity which emphasises the need for setting different targets depending on salinity. The strongest responses to changes in nitrogen concentration and the least variability were found for the indicators "total algal cover", "number of late-successional species" and "fraction of opportunists" less saline waters.

As was the case with reef vegetation in open waters no reference data is available for macroalgal vegetation in coastal Danish waters. Reference conditions for each algal indicators and ecological status class boundaries were established for all the macroalgal variables in a large number of waterbodies, considerably smaller than prescribed in the Water Framework Directive. The boundaries were established based on estimates on pristine load scenarios and site-specific relations between load and concentrations in the recipient waterbodies. Figure 1.3 gives an example of all indicators from the north-western part of Limfjorden, a water body with excellent datasets of both hydrography and algal stations. 
A

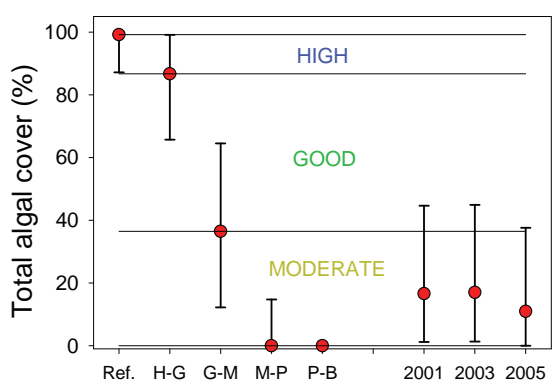

C

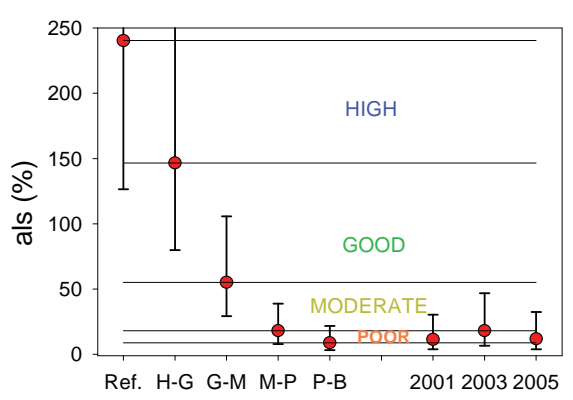

$\mathrm{E}$

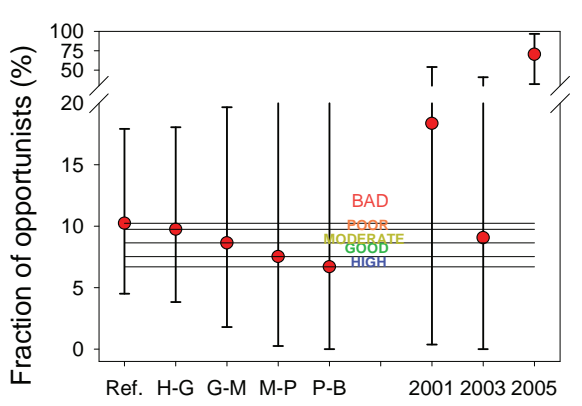

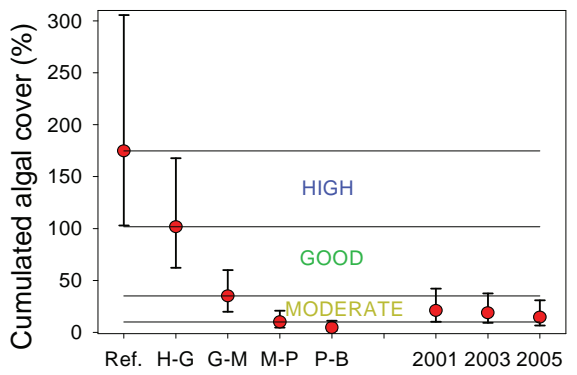

D

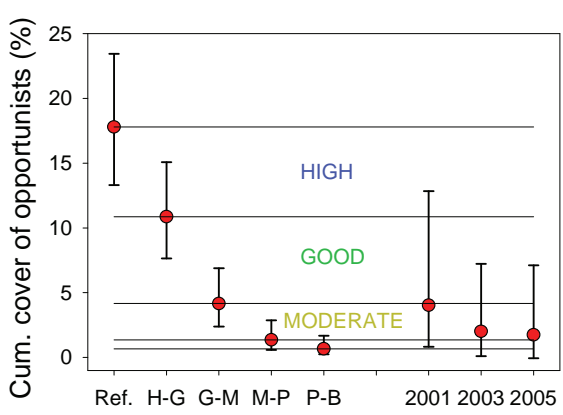

$\mathrm{F}$

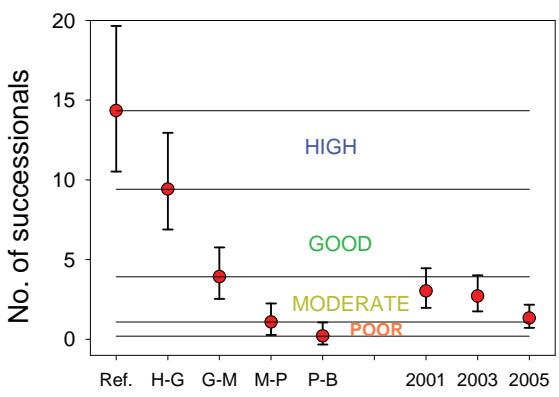

Figure 1.3 Reference levels, class borders and actual levels of various algal variables in Limfjorden west of Mors.) Total algal cover (A), Cumulated algal cover (B), Cumulated cover of late-successionals (C), Cumulated cover of opportunists (D), fraction of opportunists $(E)$ and number of late-successional algal species $(F)$. Algal variables are modelled for a water depth of $7 \mathrm{~m}$.

The methodology of linking macroalgal covers to water chemistry used in Danish waters has also been tested on a dataset from Finland. KrauseJensen et al. 2009 found that Finnish and Danish coastal monitoring data of cumulative cover (sum of all species-specific cover) had a similar functional relationship to Secchi depths. In this study we hypothesise that a common functional relationship of total cover to Secchi depths can be obtained across differences in the national monitoring programs. 


\subsection{Description of national macroalgal monitoring guidelines}

National monitoring programs in Denmark, Finland, Norway and Sweden have aimed at studying the trends of macroalgae composition and abundance in responses to changing status of eutrophication and other factors. Eutrophication load influence the light penetration supporting different cover and communities of macroalgae with depth. In the national monitoring programs different methods have been employed to collect data of macroalgal community cover. A short introduction to the different national monitoring methods is given below

\subsubsection{Finish algal monitoring (Baltic proper)}

The monitoring from 1993 to 2007 has used the following guideline.

Line measurements:

A 50 meter long measurement line is drawn on the bottom outward from the shore line until the line or the vegetation ends. In some cases a $50 \mathrm{~m}$ line is too short and the end of the line does not exceed lower growth limit of vegetation. However, methods have been renewed in 2008 and today a line is drawn until lower growth limit of vegetation is reached. The end of the measurement line is anchored in the sea floor. The measurement line is marked every meter (numbers $1-50$ ).

Monitoring (by diver):

Both bottom substrate quality and macrophyte vegetation is monitored by a taxonomic skilled diver. The bottom substrate quality is monitored along the bottom measurement line on each meter mark. Depth and quality of bottom (percentage of rock, boulder, stone, gravel, sand, mud) is measured. Macropytes are monitored on depth intervals of 0-1 m, 1-2 m, 2-4 m, 4-6 m, 6-8 m. On each interval, vegetation is measured by using $1 \mathrm{~m} \times 1 \mathrm{~m}$ frame. The frame is placed on randomly chosen meter mark of the measurement line (years 1993-1999). Since year 2000 the frame is placed on the same depth on each depth intervals. All species, their percentage and their canopy height are measured.

Percentage coverage of vegetation is measured in related to whole measurement area $(1 \mathrm{~m} \mathrm{x} \mathrm{1m)} \mathrm{in} \mathrm{1993-1999.} \mathrm{For} \mathrm{example,} \mathrm{if} \mathrm{there} \mathrm{is} \mathrm{a}$ stone which covers $10 \%$ of the total area ( $90 \%$ of the area is mud), and that stone is covered $50 \%$ of macrophytes, then the percentage coverage is $5 \%$. Since 2000 percentage coverage is measured in related to "potential" growth substrata. For example, if there is a stone which covers $10 \%$ of the total area ( $90 \%$ of the area is mud), and that stone is covered $50 \%$ of macrophytes, then the percentage coverage is $50 \%$. 


\subsubsection{Swedish east coast algal monitoring (Baltic proper)}

Along the Swedish Baltic Sea coast, two SCUBA-divers estimate the plant and animal depth distribution and percent coverage of the substrate. The monitoring is performed using line transects. From a fixed starting point on the shore (drilled holes in the rock or boulder) divers swim in a fixed compass direction towards depth. The compass direction was decided upon at the start of the project and usually goes perpendicular to the depth curve. The maximum depth is set by the species distribution and/or type of substrate. Swimming towards the shore again, the divers note distance from shore (measurement line) and the depth as well as type of substrate. The type of substrate (more or less suitable for algal growth) is categorized (boulders, stones, gravel, sand, soft bottom or mussels etc.) and percent coverage of substrate type is noted. Also, all identified plants and the blue mussel (Mytilus edulis) occurrence and percent coverage of the substrate is noted. The estimates are done continuously along the transect line in a 6-10 m wide corridor and with the eye a few $\mathrm{m}$ along the line. A new note is taken whenever the substrate changes and/or new species occur or changes in their coverage. A rough estimate of siltation is also done (4-grade scale where $1=$ no silt, 2 = low amount, 3 = stirs up but settles within a short time, 4 = the visibility is destroyed for the rest of the dive). Notes are done in situ by the divers simultaneously as the observation is done.

The cover degree of the substrate and the cover degree of plants and animals is given in a 7-grade percent scale: 100, 75, 50, 25, 10, 5 and 1 $(+)$ for occurrence. I practice, ranges are used (approximately 100-90, 90-65, 65-40, 40-15, 15-7.5, 7.5-3 and 3-1\%). When species are estimated, one or few $(<3)$ single individuals are given the coverage of $1(+)$ and $5 \%$ is used to indicate the occurrence of more than a few individuals. The accumulated coverage of species may exceed $100 \%$ as species grows in several layers (primary cover, understory species, canopy layer) and as epiphytes and epizoans. Abundance of mobile animals is given according to the scale: 1 for occurrence, 2 for frequent and 3 for common.

On selected stations, in addition of the species depth distribution and percentage cover, at given distance from shore quantitative samples are collected by tossing by haphazard quadrangular frames with the side length of $0.2 \mathrm{~m}$ (three replicate per chosen distance/depth). Usually, 12 to 15 quantitative samples are collected from each transect. The samples are sorted for all macroscopic plant and animal determined to species or in some cases to nearest higher taxon. Species are counted (animals) and dried separately in $60^{\circ} \mathrm{C}$ for at least two weeks to constant weight. Shells are included when present. 
For more detailed information on the Swedish east coast monitoring methods, see:

- [http://www.naturvardsverket.se/sv/Tillstandet-i-miljon/ Miljoovervakning/Handledning-for-miljoovervakning/Metoder/ Undersokningstyper/Undersokningstyp-Kust-och-hav/]

- [http://www.naturvardsverket.se/upload/02_tillstandet_i_miljon/Milj oovervakning/undersokn_typ/hav/vegbotos.pdf]

- [http://www.naturvardsverket.se/upload/02_tillstandet_i_miljon/Milj oovervakning/undersokn_typ/hav/rigadyk.pdf]

- [http://www.naturvardsverket.se/upload/02_tillstandet_i_miljon/Milj oovervakning/undersokn_typ/hav/fytalmetod.pdf]

\subsubsection{Swedish west-coast algal monitoring (Skagerrak and Kattegat)}

The Swedish west-coast datasets from the Kattegat and Skagerrak area originate from six localities within the Swedish National Monitoring programme run by SEPA. Starting in 1993, the localities have been surveyed once a year from late July to mid August. The localities, of which three represent exposed conditions, the other three semi-exposed, are situated in the middle part of the Swedish Skagerrak coast (Figure 3.1). The bottom substrate consists merely of bedrock, although sections with boulders may occur.

At each visit, five transects are deployed perpendicular to the shore, their starting points being chosen by random along a fixed section of the shore.

Along each transect the upper and lower growth limit of the dominating macroalgae are recorded in situ by diver (on a plastic sheet).

For each transect, at fixed depths between 0 to $20 \mathrm{~m}$, two digital photos are taken, giving a total of 10 replicates per depth interval at each locality. Each replicate covers an area of $0.25 \mathrm{~m}^{2}$. If necessary, multiple photos are taken after unfolding the canopy.

At the laboratory, the number of species, the total area covered, the area covered by individual taxa, and for species with distinct individuals, their abundances are retrieved from the digital pictures using an interactive pen display computer system.

In this analysis only datasets from 2007 were included, because the measurements from the previous years did not include the parameter "Total vegetation cover". The entry "Max depth" is based on merged data from field records and image analysis. The " $5 \%$ vegetation lower limit" was calculated by linear interpolating a depletion curve for area covered between the fixed depths used for area measurements. Both entries are given as mean values of transect occurrences. 


\subsubsection{Danish algal monitoring}

The Danish dataset is based on the sampling programme carried out on reefs located within Nature-2000 areas. The sampling is done by National Environmental research Institute (NERI) as part of the national monitoring programme.

Macroalgal vegetation has been monitored at selected stations (point samples) along a depth gradient with 2-3 m intervals since 1994 using the same methodology. Some reefs have been visited 1-2 times annually and a few reefs only once in the period. All monitoring cruises were carried out between June and August.

Taxonomic skilled divers visually judged the species specific percent cover of erect algae and the cover percent of the total erect macroalgal community on hard stable substrate. The selected stations had at least $10 \%$ cover of hard stable substrate and $10-25 \mathrm{~m}^{2}$ of the stone reef was inspected.

To minimize the effect of divers and for general documentation online video and communication equipment is used during the dives, showing the same algal community onboard the research vessel as the diver observe and describe at the bottom.

Along with the collection of algal data, divers visually recorded the cover of important fauna species as well as floating algal mats if present. The four different species of sea urchins present in Danish waters: northern sea urchin (Strongylocentrotus droebachiensis), green sea urchin (Psammechinus miliaris), common sea urchin (Echinus esculentus) and long spine sea urchin (Echinus acutus) is not surprisingly documented to have a negative impact on the algal community (Dahl \& Carstensen 2008). Massive settlement of blue mussels (Mytilus edulis) and space competition with sea-anemones might affect the benthos algal vegetation.

A detailed guideline describing the Danish National Monitoring programme on open water reef locations can be found on [http://www. dmu.dk/Overvaagning/Fagdatacentre/Det+Marine+Fagdatacenter/Teknis ke+anvisninger+NOVANA+2004-2009/] as well as guidelines for the rest of the monitoring programme.

\subsubsection{Norwegian algal monitoring}

The Norwegian dataset is based on the Norwegian Coastal Monitoring Programme that focuses on Skagerrak and the North Sea. The monitoring programme was established by the Norwegian State Pollution Authorities (SFT) in 1989, and has been running continually since 1990. The programme has been operated by Norwegian Water Research Institute (NIVA) in co-operation with Institute for Marine Research (IMR). It is a comprehensive monitoring programme that integrates oceanography, chemistry and biological measurements. Oceanography and macroalgal stations included are shown in fig 1. 
Macroalgal communities on hard bottom are monitored regularly at 16 stations, with 8 stations in Skagerrak and 8 stations on the North Sea coastline. The sites are surveyed annually in June. Abundance and species composition of macroalgae and animals (sessile or slow moving) are monitored along vertical transects from approx $30 \mathrm{~m}$ depth and towards the surface. The vertical transects are approx $8 \mathrm{~m}$ wide and follows fixed transect routes. Taxonomic skilled divers visually judged for every $2 \mathrm{~m}$ of depth the species specific cover according to a semi-quantitative 4 level scale: rare, frequent, common and dominant. Cover degree is measured on suitable substrate (rock). If the community change markedly in between the fixed depths recordings, the changes in species composition is recorded. The method is in accordance with the Norwegian Standard NS9424 (1996) and ISO 19493:2007 (Water quality - Guidance on marine biological surveys of hard-substrate communities).

Additional methods used in the monitoring programme are stereo photography of fixed areas of rocky bottom, demographic kelp forest measurements and underwater video documentation.

Lower growth limit of species defined as " $5 \%$ cover" was set be equal to the cover class "frequent". The lowest observation depth with at least frequent abundance was recorded as the "depth limit" of the species.

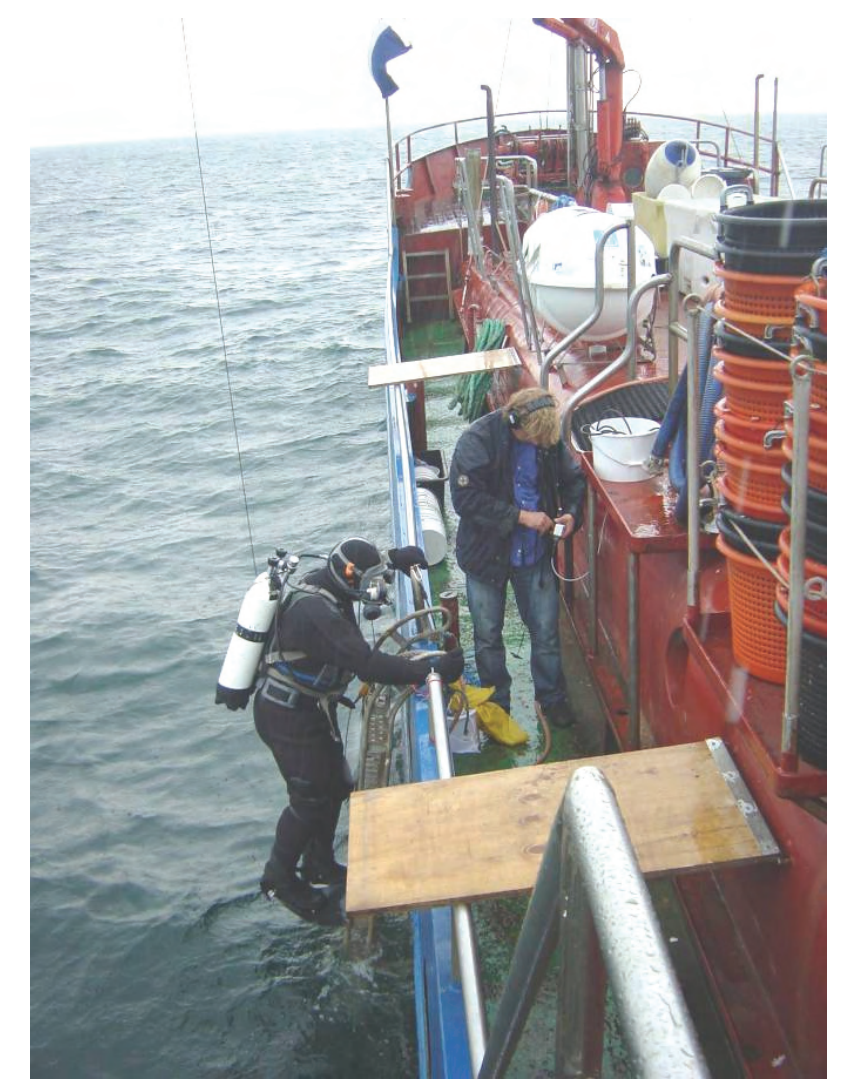

The research vessel has anchored on a stone reef in Kattegat and the diver is entering the water. Sampling is done by National Environmental Research Institute (NERI) as part of the National Monitoring Programme. 



\section{Aim}

The overall aim of this project is to identify, sample and intercalibrate one or several macroalgae indicators used in national monitoring programmes of the Nordic countries (Finland, Denmark, Sweden and Norway) and metrics suggested for boundary setting protocol (by Denmark, Sweden and Norway, NEA-GIG), to harmonise and bridge over Nordic algal monitoring methods in use.

The project aim is to provide a translation for harmonising the national monitoring data in retrospect as well as in the future. By this the project addresses multiple aims by the Nordic Council of Minster, specifically the "Harmonisering av det nordiska marina miljöskyddsarbetet och EU's Marina Strategi" (HLG) and "Vandrammedirektivet” (NMD), and contribution to development of intercalibrated EcoQO's (aims of "Uthålligt utnyttjande av havsresurserna"), models of the relationship between nutrient load and effects on aquatic vegetation to be used as basis for reference condition and classification of EcoQO's ("Marin eutrofiering”) and not at least building a network of Nordic coastal monitoring expertise ("Biologisk mangfoldighed").

To achieve this goal an intercalibration workshop was arranged in 2007 in Norway (Homborsund lighthouse outside Grimstad) with invited macroalgal experts involved in national monitoring programmes, to test and compare national monitoring methodologies and suggested metrics of WFD intercalibration. The workshop included a practical diving exercise, communication of national methods and discussions to identify one or several macroalgae indicators for intercalibration. Based on this exercise two indicators "lower depth limit" (WFD intercalibration metrics) and "total cover" (by NERI) were chosen for further common work. A technical guideline for the indicator "total cover of erect macroalgel vegetation" (in short: "total cover") was elaborated (annex 1). The WFD intercalibration metrics "lower depth limit" is given in annex 2. The progress of the work has been followed up by to more workshops (in Denmark and Sweden).

The aim of this report is to assess if data derived form the different national monitoring programs show similar behaviour with respect to light penetration as the main governing mechanism for the depth distribution of total cover and species specific lower depth limit. 



\section{Material and methods}

\subsection{Total cover of erect macroalgae}

In this project we have focussed on data collected in the open part of the Norwegian south coast by Norwegian institute for water research, the open part of the Swedish west coast in Skagerrak by University of Gothenburg, all open inner parts of Danish waters by The National Environmental Research Institute, Aarhus University, The Askø area near Stockholm by University of Stockholm and the archipelago of Finland by Finnish Environment Institute and University of Helsinki.

The Danish monitoring programme has included a direct diver judgement of the percentage "total cover of erect macroalgal vegetation" of suitable stable hard substrate since 1993. This means that there exists a long time series on some of reef locations and more scattered information from a larger amount of other locations (table 3.1). The metric " $5 \%$ vegetation lower limit" was calculated by interpolating a depletion curve for area covered between the fixed depths used at the monitoring stations

The Norwegian monitoring has not included total cover until the beginning of this project. This means that the dataset is restricted to 2007 and 2008. All data are given for hard stable substrate suitable for macroalgal vegetation.

Data from the Swedish west coast in Kattegat-Skagerrak are restricted to 2007 as "total cover" was not estimated in previous years. The metric "Max depth" of selected species is based on merged data from field records and image analysis. The " $5 \%$ vegetation lower limit" was calculated by linear interpolation of a depletion curve for area covered between the fixed depths used for area measurements. Both entries are given as mean values of transect occurrences. All data are given for hard stable substrate suitable for macroalgal vegetation.

Total cover data on hard stable substrate from the Askø area on the Swedish east-coast has not been monitored before this project. However "total cover" was estimated as the cumulative sum of individual species cover based on the experience (Krautsky pers com.) that the vegetation is only slightly multilayered from water depth below $3 \mathrm{~m}$ (se later). The sum total vegetation cover on hard substrate was also estimated assuming different cover degrees on different substrate types based on experiences (Krautsky pers com.). Assuming those approximations on total cover on suitable substrate resulted in dataset covering a long time span. The depth limit of 5\% cover of selected species was extracted from the data set.

The Finish dataset did not include "total cover" before the specific sampling in 2007. It is however possible to estimate the "total cover" 
value as the cumulative sum of individual species covers based on the experience (Ari Ruuskanen pers com.) that the vegetation is only slightly multilayered on water depth chosen for this analysis (like in the Swedish Askø area). The registration of species specific vegetation cover has also changed from frame area to suitable hard substrate in 1999, and as a result of this data from the early period has to be recalculated based on the amount of hard substrate within the frame. Deepest registration with minimum 5\% cover degree of selected species was extracted from the final dataset.

Half of Finnish data was collected from exposed archipelago and half from moderately exposed archipelago: There are four geographical locations approx $100 \mathrm{~km}$ apart (Tvärminne, Inkoo, Pernaja and Kotka) along the Gulf of Finland. An overview of sampling stations used in this analysis is given in figure 3.1 as well in table 3.1.

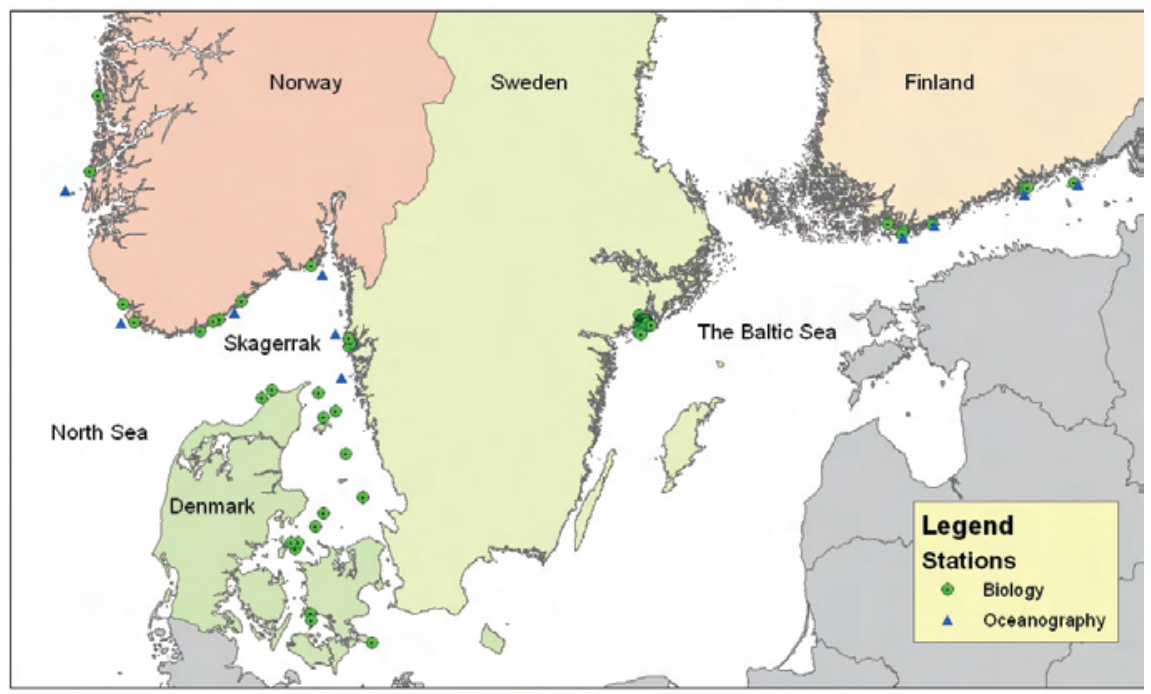

Figure 3.1 Map of sampling stations. Macroalgae stations = green circles. Oceanography stations = blue triangles.

Table 3.1 Sampling stations of macroalgal vegetation used in the analysis.

\begin{tabular}{llrrrl}
\hline Nation & Area & $\begin{array}{r}\text { No. } \\
\text { Locations }\end{array}$ & Depth range & $\begin{array}{r}\text { Sampling } \\
\text { years }\end{array}$ & Main sampling month \\
\hline \multirow{2}{*}{ Norway } & Skagerrak & 5 & $5-30$ & 2 & June \\
& North Sea & 4 & & 15 & June \& August \\
Denmark & $\begin{array}{l}\text { Skagerrak, Kattegat } \\
\text { and Belt Sea area }\end{array}$ & 24 & $6-24$ & 1 & August \\
& Skagerrak & 6 & $5-20$ & 20 & June-September \\
\multirow{2}{*}{ Finland } & Baltic Propper & 30 & $3-26$ & 7 & June-August \\
& Baltic Proper/ & 7 & $3-11$ & & \\
\hline
\end{tabular}




\subsection{Physio-chemical variables}

Spatial variations in algal variables were related to the physio-chemical variables salinity, nutrient concentration, chlorophyll concentration and Secchi depth. These data were sampled at sites situated in the vicinity of vegetation sites. In some cases an average of several stations was used and in others one physio-chemical stations were used for several vegetation stations.

\subsubsection{Norwegian data}

Norwegian physio-chemical dataset was drawn from the oceanographic part of the Norwegian monitoring programme with 3 stations in Skagerrak and 2 stations on the west coast of Norway (North Sea). The sampling frequency is every second week and sampling and chemical analysis are performed according to standard guidelines. The oceanographic stations were matched to the macroalgae stations.

\subsubsection{Danish data}

Danish algal data were matched with physio-chemical data stored in NERI's database and sampled by the Danish counties, NERI as well as SMHI. Sampling and chemical analysis were performed according to common guidelines (Andersen et al. 2004). The typical sampling frequency range between weekly and monthly but some stations especially in the open waters has a lower frequency, especially on Secchi depth measurements that depends on daylight.

\subsubsection{Swedish data}

Monthly measurements of hydrographical and water chemistry data from the National and the SMHI off-shore monitoring programs covering the time period from august 2006 to july 2007 and the water column between 0-30 m were retrieved from the SHARK database hosted by the Swedish Meteorological and Hydrological Institute. A description of the sampling program can be found at SEPA [http://www.naturvardsverket.se/upload/02_tillstandet_i_miljon/Miljoovervakning/undersokn_typ/hav/vegbo tva.pdf]

\subsubsection{Finnish data}

Finnish data sets were obtained from SYKE database. Samplings were carried out on permanent sampling stations nearby the algae monitoring stations. Water samples for phycio-chemical analyses were collected 1-2 
times a month in January-March (if no ice occurred), and 2-4 times a month in April-August.

On overview over physico-chemical sampling stations is given in figure 3.1 (blue dots).
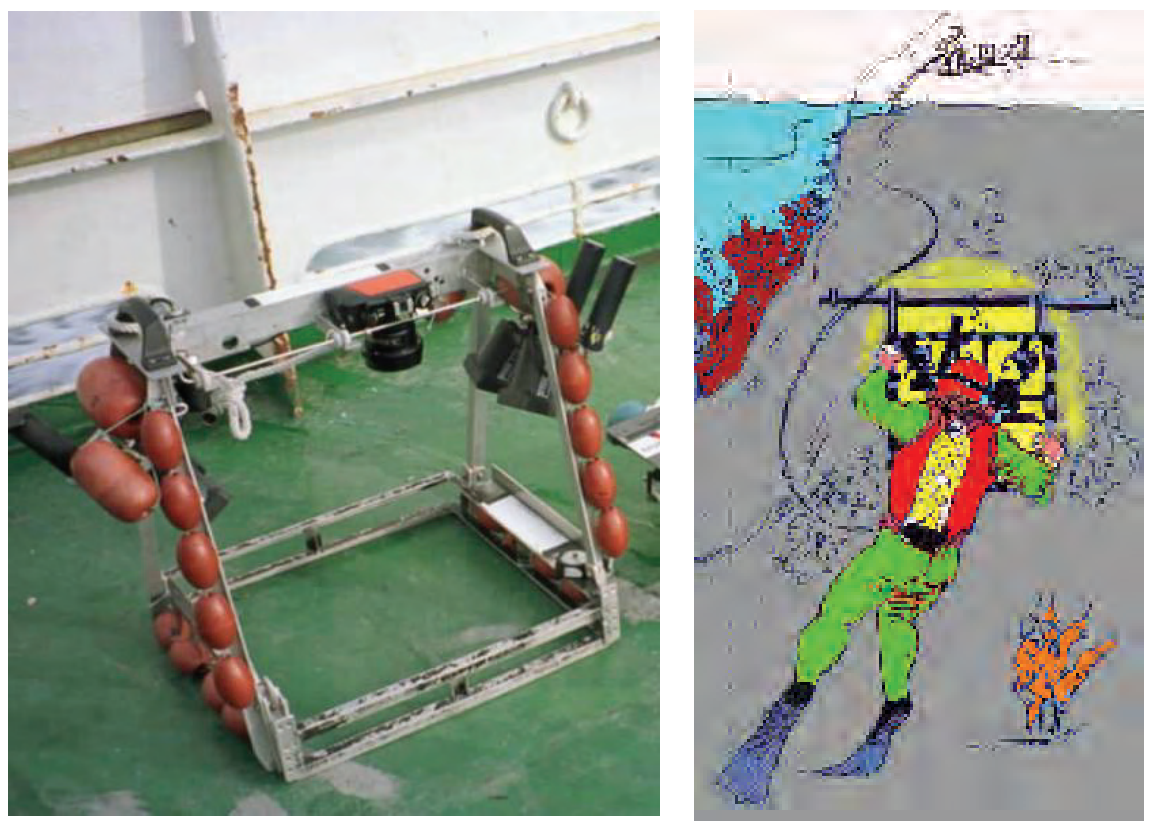

Photo-monitoring used in the Swedish National Monitoring programme. At fixed depths photos are taken of the bottom community. Each photo covers an area of $0.25 \mathrm{~m}^{2}$. (Photo: NIVA. Illustration: $P$ Wang, NIVA)

\subsection{Depth distribution of macroalgal species}

The Water Framework Directive metric "Depth limit of macroalgal species" use the depth extension of selected perennial macroalgal species as the biological quality element in response to environmental impacts. The species shown in table 3.2 were all selected by the Nordic "North East Atlantic group" and the "Baltic group" due to the following qualities: species where 1) perennial, 2) commonly occurring in the water types and 3) easy to determine (see Annex 2). 
Table 3.2 Selected macroalgae indicator species

\begin{tabular}{|c|c|c|c|c|c|c|}
\hline Finland: & coastal waters of Baltic Sea & & & & & \\
\hline Sweden: & c w of Baltic Sea & & & & & \\
\hline Sweden: & c w of Skagerrak-Kattegat & & & & & \\
\hline Denmark: & c w of Skagerrak-Kattegat & & & & & \\
\hline Norway: & c w of Skagerrak & & & & & \\
\hline \multirow[t]{6}{*}{ red algae } & Chondrus crispus & $x$ & $x$ & $x$ & & \\
\hline & Furcellaria Iumbricalis & $x$ & $x$ & $x$ & & \\
\hline & Coccotylus /Phyllophora* & $x$ & $x$ & $x$ & & \\
\hline & Rhodomela confervoides & $x$ & $x$ & $x$ & & \\
\hline & Delesseria sanguinea & $x$ & $x$ & $x$ & & \\
\hline & Phycodrys rubens & $x$ & $x$ & $x$ & & \\
\hline \multirow[t]{3}{*}{ brown algae } & Fucus vesiculosus & & & & $x$ & $x$ \\
\hline & Halidrys siliquosa & $\mathrm{x}$ & $\mathrm{x}$ & $\mathrm{x}$ & & \\
\hline & Laminaria saccharina & $\mathrm{x}$ & $\mathrm{x}$ & $\mathrm{x}$ & & \\
\hline
\end{tabular}

Note: * $=$ the complex of Coccotylus truncatus and Phyllophora pseudoceranoides

In theory lower depth distribution of macroalgal species reflects water transparency (water quality) if no other factors control the vertical distribution like sea-urchin grazing, species competition or unfavourable substrate limiting the distribution. Comparisons of present and historical data on depth distribution indicate reduced distribution due to reduced water transparency and/or increased nutrient load (Rueness \& Fredriksen 1991, Thorn et al 2006). But there have so far not been established any good relationship between nutrient load, water quality and the depth limit of the selected macroalgae. Therefore we selected this metric for further testing in this project as the metric seems easy to implement and the relation with water transparency is obvious. The lack of relationship will be discussed later as we experienced the same problem as the Nordic NEAGIG groups.

We decided to use the $5 \%$ cover degree as the lower depth species limit in favour of the maximum depth occurrence, because we believed that the maximum depth occurrence of a species was connected with much more uncertainty. Chapter 3.1 describes the method used on each data sets to produce the $5 \%$ depth limit, as this specific metric was not recorded directly in the monitoring programmes. 


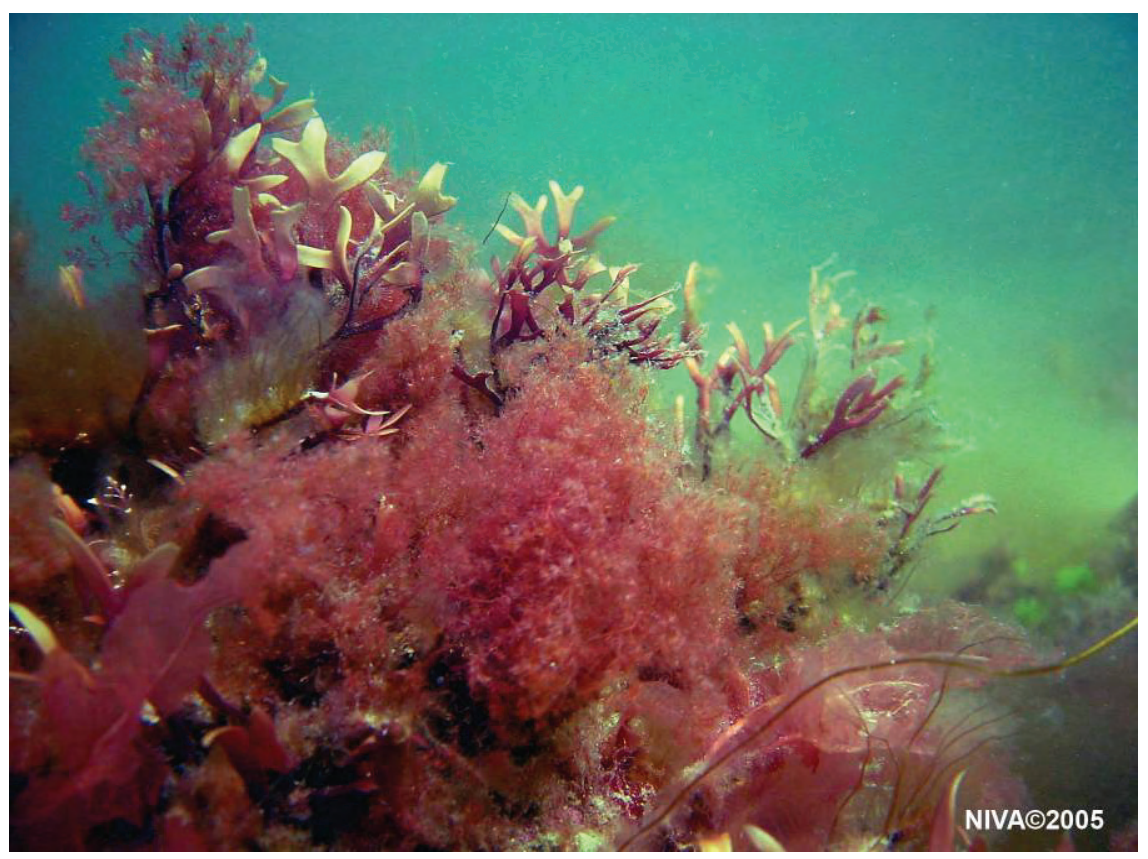

Red algae community with 2 of the 8 selected species: Chodrus crispus, and Deleseria sanguinea together with filamentous unknown red algae. Photo: F. Moy

\subsection{Data handling and harmonization}

The approach is to 1) normalise all cover data to represent total cover on suitable hard substrate, 2) to identify specific areas where data from macroalgae transects can be linked to water quality data measured at regular monitoring stations in the vicinity, and 3) to estimate total cover at a standard depth in order to accommodate depth differences between transects. This is done by an underlying model described in details in Carstensen et al, 2008 and visualized in figure 3.2. 


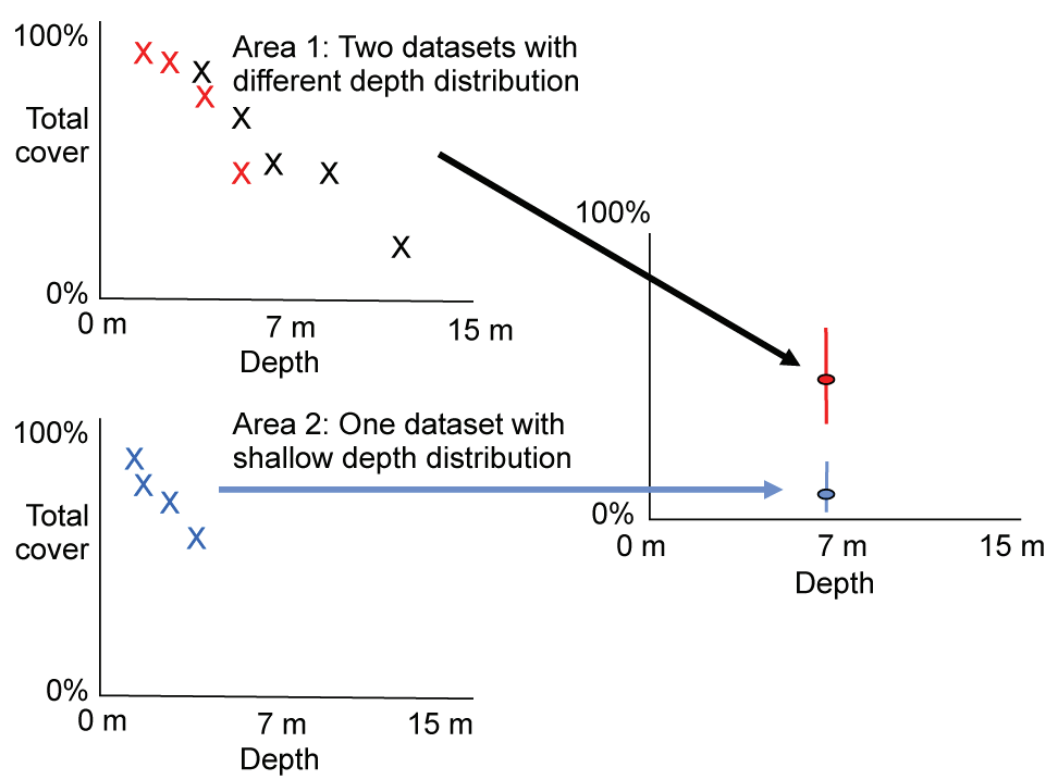

Figure 3.2 Examples on the data harmonization procedure resulting in an estimated marginal mean value of the selected indicator for two selected areas with confidence level. In this example from Carstensen et al (2009) a water depth of $7 \mathrm{~m}$ was chosen.

The outcome of this exercise is a data set linking annual and area-specific total cover estimated for a standard depth $(15 \mathrm{~m})$ with annual means of water quality variables in the 6 months (January-June) prior to macroalgae monitoring (typically between May and September). Due to differences in the data collection and the availability of total cover data, different models were developed to obtain the annual mean values (see description below for each model).

For the water quality data a generic model was applied taking into account variations between stations within the area (variable), months (January-June), and years of sampling. In general, longer time series existed for the water quality data and all these data were used to obtain better estimates of the seasonal variation (months) and variation between stations. The model employed was:

$$
X_{i j k l}=\operatorname{station}_{i}+\text { year }_{j}+\text { month }_{k}+e_{i j k l}
$$

and from this model marginal mean values for yearj were computed. $\mathrm{Nu}-$ trient and chlorophyll a concentrations were log-transformed prior to the analysis. Annual means of water quality data are only shown in relation to macroalgae data. 

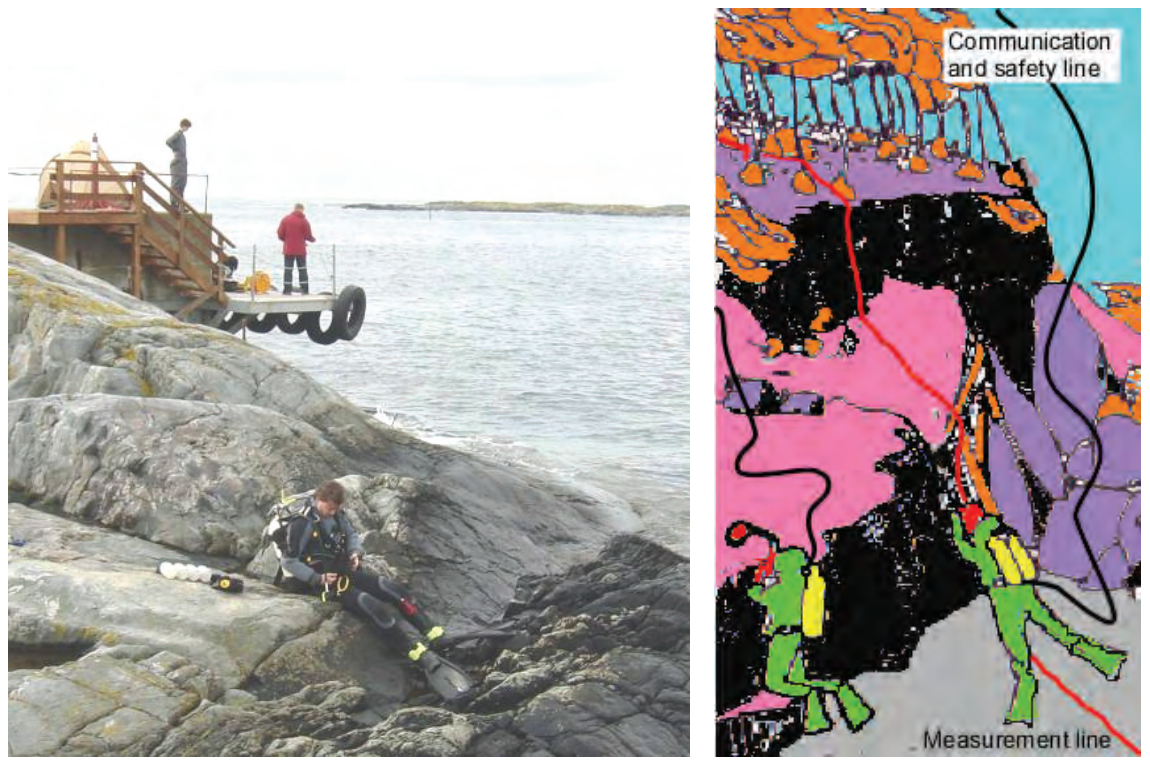

Diving exercise at the workshop. The diver team include besides the diver, a line-man handling the communication cable, a writer recording the obersvations on paper and tape, a standby rescue diver and the dive-leader supervising the operation. (Photo: NIVA, Illustration: P Wang, NIVA) 


\section{Results}

\subsection{Total cover of macroalgae}

\subsubsection{Finnish archipelago}

A total of 245 cover observations were obtained from the southern Finnish archipelago coast, representing 7 areas (Brännskär, Bålaskär, Granbusken, Pitkäluoto, Ryssholm, Västrä Källskär, and Ämmärukka, figure 4.1) and 7 years (1996, 1998, 2001, 2002, 2003. 2005, and 2007). Data were collected in the months of June-August. Cover estimates were provided for macroalgae (not normalised to suitable substrate), rock, boulder, stone, gravel and sand. Cover estimates were normalised to the total cover of suitable substrate, where it was assumed that rock, boulder and stone all comprised $100 \%$ suitable substrate, gravel comprised 50\% suitable substrate, and sand was not considered a suitable substrate. Most observations had suitable substrate close to $100 \%$.

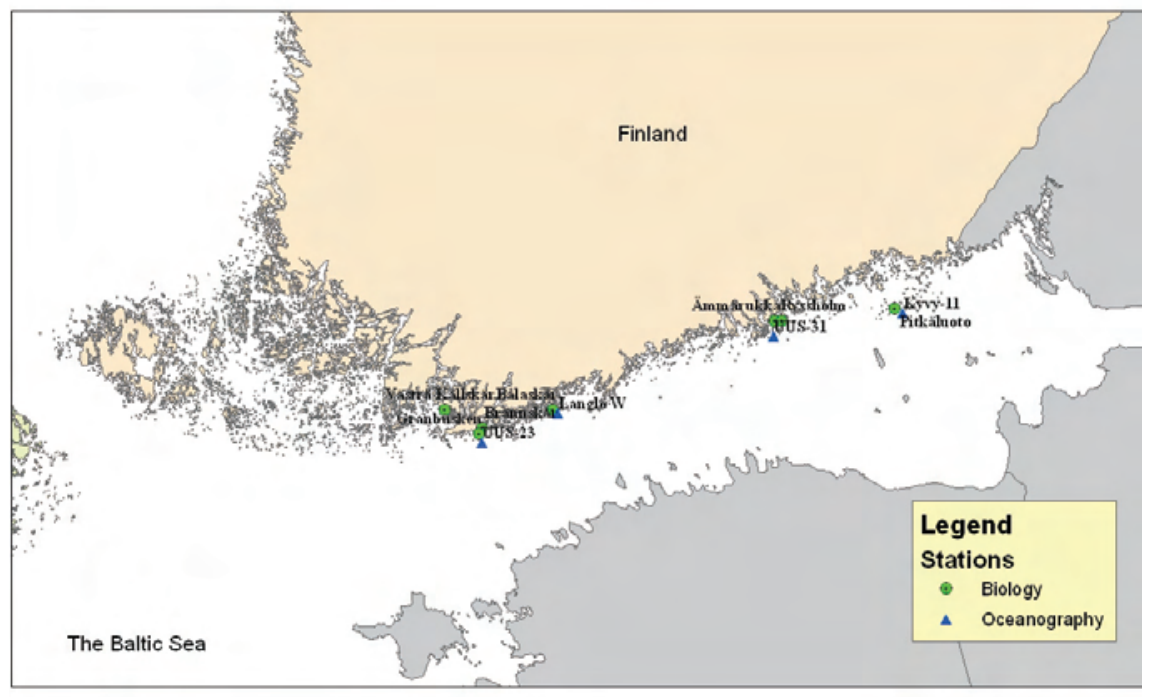

Figure 4.1 Map of Finnish stations.

Total cover observations obtained from shallow depths $(<3 \mathrm{~m})$ were not considered light limited but dependent on physical exposure and therefore this observations were not used in the model. After this screening of data 140 observations remained to be analysed with the model after the angular transformation, $\mathrm{f}(\mathrm{x})$, was applied:

$$
f\left(x_{i j k}\right)=\text { area }_{i}+a \times \text { depth }_{i j k}+\text { area }_{i} \times \text { year }_{j}+e_{i j k}
$$


where area $_{\mathrm{i}}$ described differences between the 7 areas, $\mathrm{a} \times \mathrm{depth}_{\mathrm{ijk}}$ described a declining functional relationship to depth of the observation, and $\operatorname{area}_{\mathbf{i}} \times$ year $_{j}$ described area-specific year-to-year variations in total cover. Annual means of total cover ranged from $75 \%$ down to $0 \%$ with a general decreasing tendency (figure 4.2). Only Brännskär showed improved total cover over time.

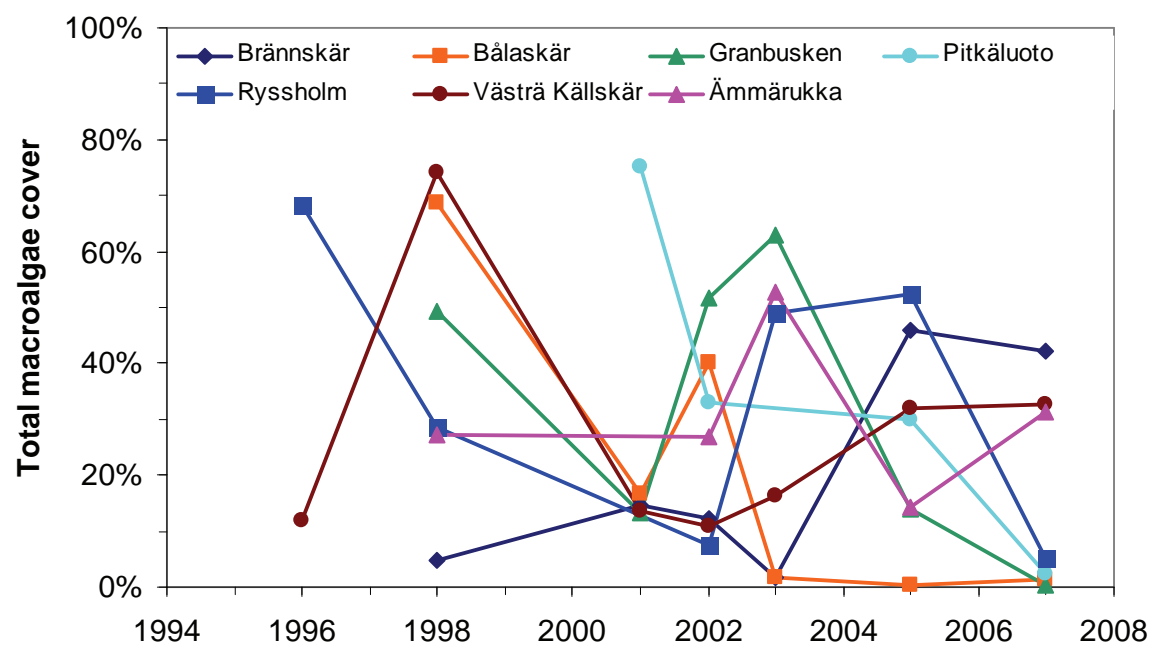

Figure 4.2 Finnish stations (upper) and area-specific annual estimates of total cover $(n=40)$ expressed for a standard depth of $15 \mathrm{~m}$ estimated by means of (2) (lower).

\subsubsection{Swedish east coast data}

The macroalgae data from the Askö area (figure 4.3) was a more condensed data set consisting of 6,884 observations. Similar to the Finnish data, data on total cover from Askö were not normalised to the suitable substrate, and in order to do this substrate categories 1-4 were assumed $100 \%$ suitable substrate, category 4 was assumed to represent $80 \%$ suitable substrate, categories 6 and 8 were assumed to represent $50 \%$ suitable substrate, category 7 was assumed to represent $30 \%$ suitable substrate, categories 13 and 14 were assumed to represent $10 \%$ suitable substrate and finally, categories $8,10-12$ were assumed to represent $0 \%$ suitable substrate. Using this substrate classification resulted in 699 observations representing unsuitable substrate (0\%) and these were therefore not used. The substrate classification was more variable than for the other intercalibration sites. Total cover from shallow depths $(<3 \mathrm{~m})$ was mostly determined by physical exposure and therefore these data were discarded, leaving 3,611 observations for the analysis. Total cover data was sampled between June and September. The Askö area was considered as a single area because all transects (most of them revisited regularly) were confined in a small area with just a single station to characterise the water quality. Total cover observations were modelled after the angular transformation as: 


$$
f\left(x_{i j k}\right)=\text { transect }_{i}+\text { year }_{j}+a \times \text { depth }_{i j k}+e_{i j k}
$$

where transect $t_{i}$ described differences between the 44 transects, year ${ }_{j}$ described the year-to-year variation in total cover common to all transects, and $a \times$ depth $_{\mathrm{ijk}}$ described an overall declining functional relationship to depth of the observation. Annual means of total cover ranged $1 \%$ and $43 \%$ with a tendency to increasing total cover from beginning of the 1990s (figure 4.3).
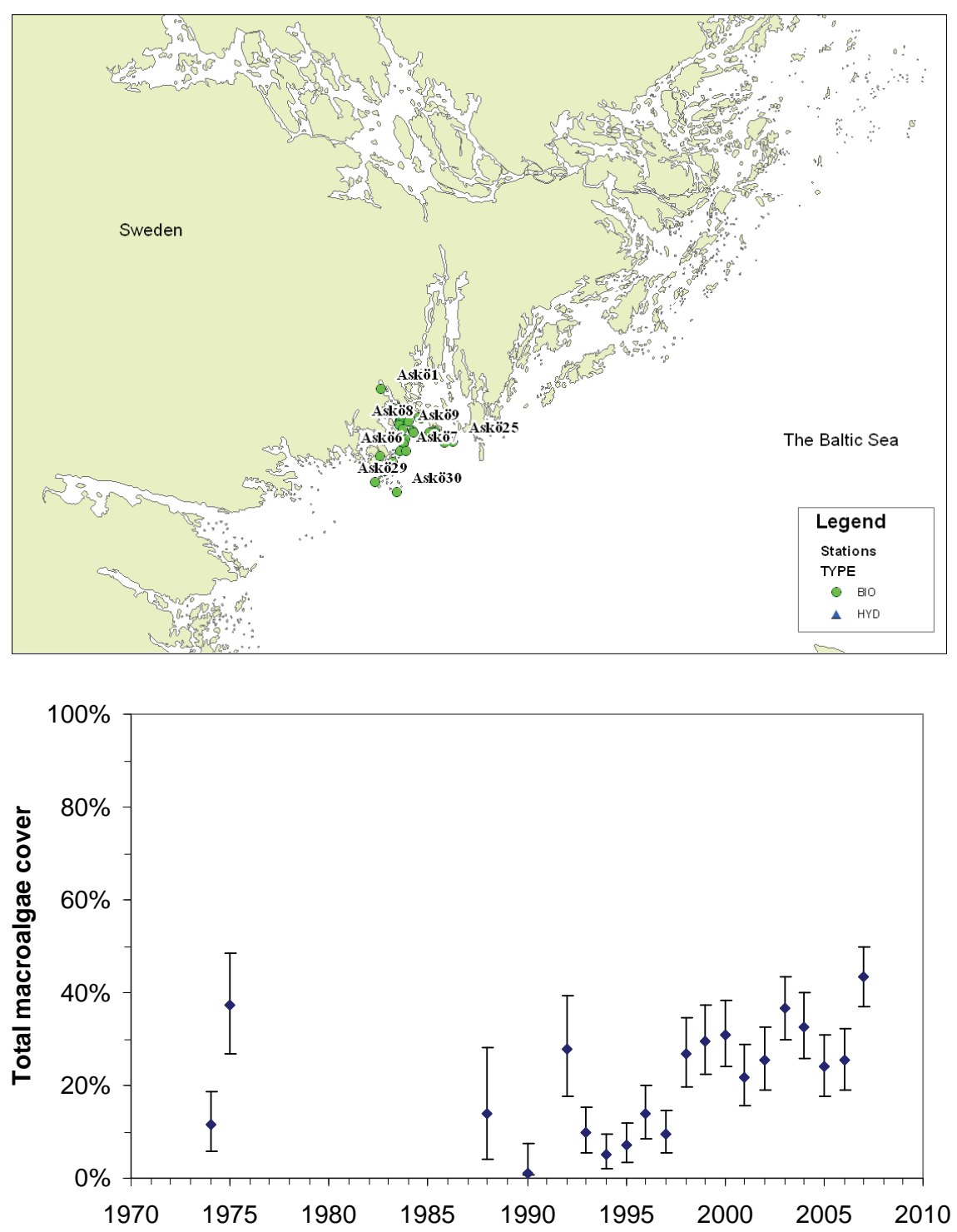

Figure 4.3 Askö stations (upper) and annual estimates of total cover $(n=20)$ expressed for a standard depth of $15 \mathrm{~m}$ in the Askö area estimated by means of (3) (lower).

\subsubsection{Danish data}

The Danish data set ( $\mathrm{n}=883$ observations) were sampled at 24 stone reefs and represented 15 years in total (figure 4.4). The stone reefs were mostly 
visited in June or August, but a few samples from May, July, September and October were also included. Total cover as estimated specific to the cover of suitable substrate and normalisation was therefore not needed. The stone reefs in Denmark are mostly location in open waters with high physical exposure and therefore observations at $6 \mathrm{~m}$ or above were discarded, leaving 808 observations remaining for the analysis. Another feature that characterises the Danish stone reefs is that macroalgae on several of them are heavily grazed by sea urchins, and the cover of sea urchins was also included in the data set. Total cover, after angular transformation, was modelled with a model similar to that applied to Finnish data:

$$
\begin{aligned}
f\left(x_{i j k}\right)= & \operatorname{area}_{i}+a \times \text { depth }_{i j k}+\text { area }_{i} \times y e a r_{j} \\
& 0.1 \%)+e_{i j k} \times \log (\text { sea urchin cover }+
\end{aligned}
$$

where area $_{\mathrm{i}}$ described differences between the 7 areas, $\mathrm{a} \times \mathrm{depth}_{\mathrm{ijk}}$ described a declining functional relationship to depth of the observation, $\operatorname{area}_{\mathrm{i}} \times$ year $_{\mathrm{j}}$ described area-specific year-to-year variations in total cover and $\mathrm{b} \times \log$ (sea urchin cover) described the grazing effect of sea urchins. There was a highly significant grazing effect of sea urchins $(\mathrm{p}<0.0001)$ and the annual means were standardised to a zero cover of sea urchins, similar to what is observed at the other intercalibration sites. The sitespecific trends showed commonalities, exemplified by high total cover in 1996 and 1997, which were two years with unusually low nutrient inputs (figure 4.5). The annual total cover means were mostly above $40 \%$, except for two areas along the Jutland west coast in the Skagerrak, where the strong Jutland current carries nutrients and sediments in a northwestern direction.

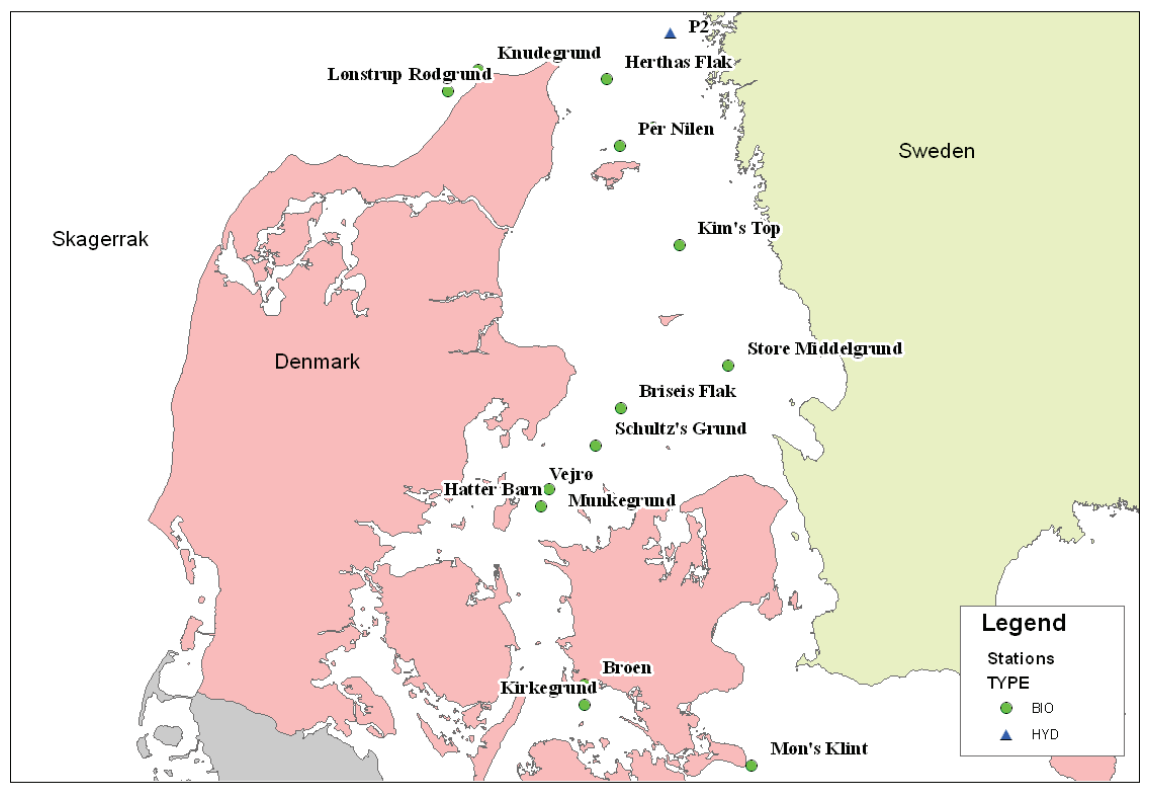

Figure 4.4. Map of Danish stations 


\subsubsection{Swedish west coast data}

Macroalgae data from the Swedish west coast comprised 840 observations of total algal cover. All data were sampled in August 2007 at 6 different stations (Byxeskär, Gråurn, Långö, Mittskär, Namnlösen, and Tån, figure 4.6). The relatively large amount of observations was due to the camera sampling method with 10 replicates at each depth. Total cover data were observed relative to the fraction of suitable substrate. The investigated areas were also exposed and therefore observations at depths above $5 \mathrm{~m}$ were discarded. The remaining 480 observations, after using the angular transformation, were analysed with a simple model without temporal variations:

$$
f\left(x_{i j k}\right)=\text { area }_{i}+a \times d e p t h_{i j k}+e_{i j k}
$$

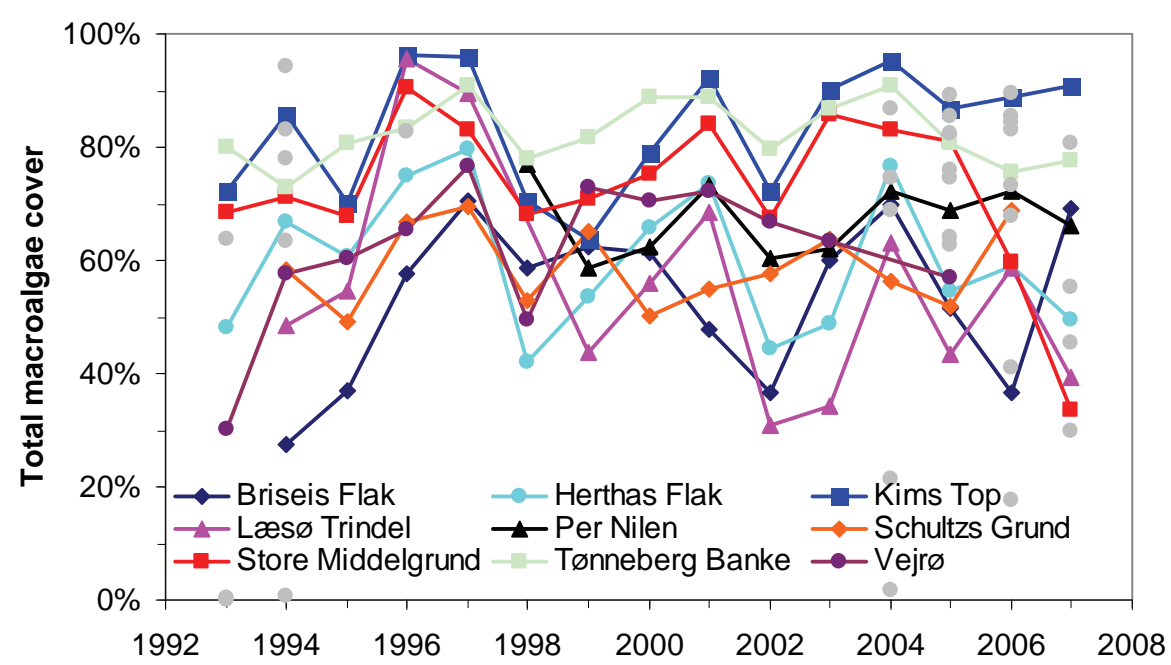

Figure 4.5 Area-specificc annual estimates of total cover $(n=155)$ expressed for a standard depth of $15 \mathrm{~m}$ estimated by means of (4). Continuous time series are shown for the 9 stone reefs with consistent monitoring, whereas the other irregularly sampled stone reefs are shown as grey dots. The 6 lowest total cover means $(<30 \%)$ from the irregularly monitored stone reefs are from two specific sites located in the Skagerrak (Knudegrund and Lønstrup Rødgrund).

where area $_{\mathrm{i}}$ described differences between the 6 areas and $\mathrm{a} \times \mathrm{depth}_{\mathrm{ijk}}$ described a declining functional relationship to depth of the observation. The output of this model was 6 area-specific estimates representing the year 2007 only. Mean cover estimates varied from 29\% at Namnlösen to $79 \%$ at Gråurn (figure 4.6). The range of total cover estimates were comparable to the Danish estimates for 2007 (figure 4.5), which appears reasonable given that most of the Danish stone reefs and the Swedish west coast transects are located in the same region (Kattegat and Skagerrak). 

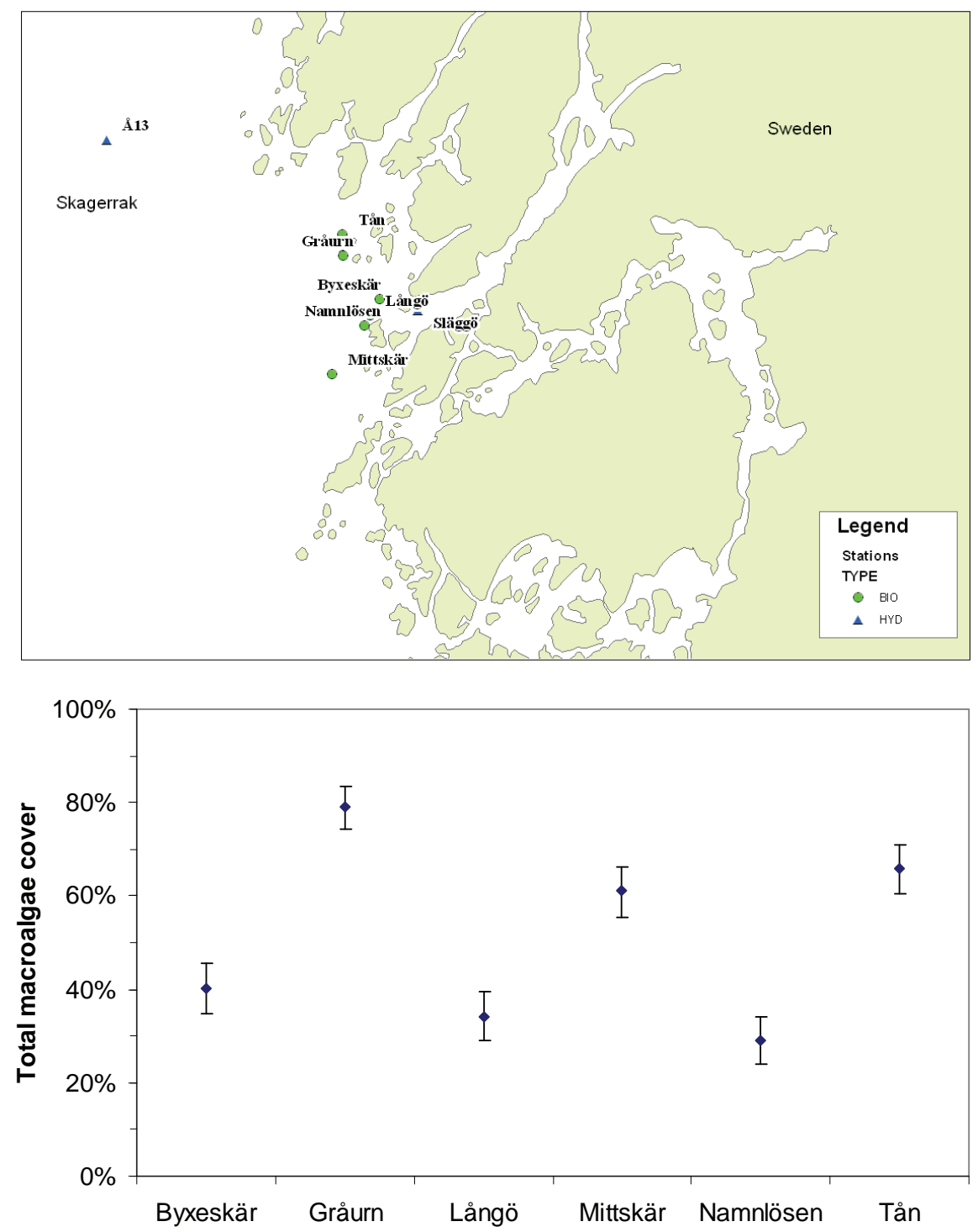

Figure 4.6 Swedish West Coast stations (upper) and total cover estimates $(n=6)$ expressed for a standard depth of $15 \mathrm{~m}$ in 2007 for areas on the Swedish west coast estimated by means of (5) (lower).

\subsubsection{Norwegian data}

The Norwegian data had a total of 261 observations from 9 stations from 2007 and 2008. Total cover data were monitored relative to the fraction of suitable substrate, and consequently no normalisation was required. Monitoring was carried out in June for both years of investigation.

The investigated areas were also physically exposed and therefore observations at depths above $5 \mathrm{~m}$ were discarded. The remaining 250 observations were analysed with a model similar to the Finnish data, after applying the angular transformation:

$$
f\left(x_{i j k}\right)=\text { area }_{i}+a \times \text { depth }_{i j k}+\text { area }_{i} \times \text { year }_{j}+e_{i j k}
$$




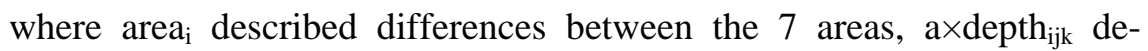
scribed a declining functional relationship to depth of the observation, and area $_{\mathrm{i}} \times$ year $_{\mathrm{j}}$ described area-specific year-to-year variations in total cover. There was a wide span in total cover means ranging from $4 \%$ at A03 in 2008 to 100\% at D25 in 2007 (figure 4.7). This range of the estimates covered a distinctive spatial gradient from A03 towards D25, and a significant decline $(\mathrm{p}<0.05)$ from 2007 to 2008 in all areas except C15 and C18.
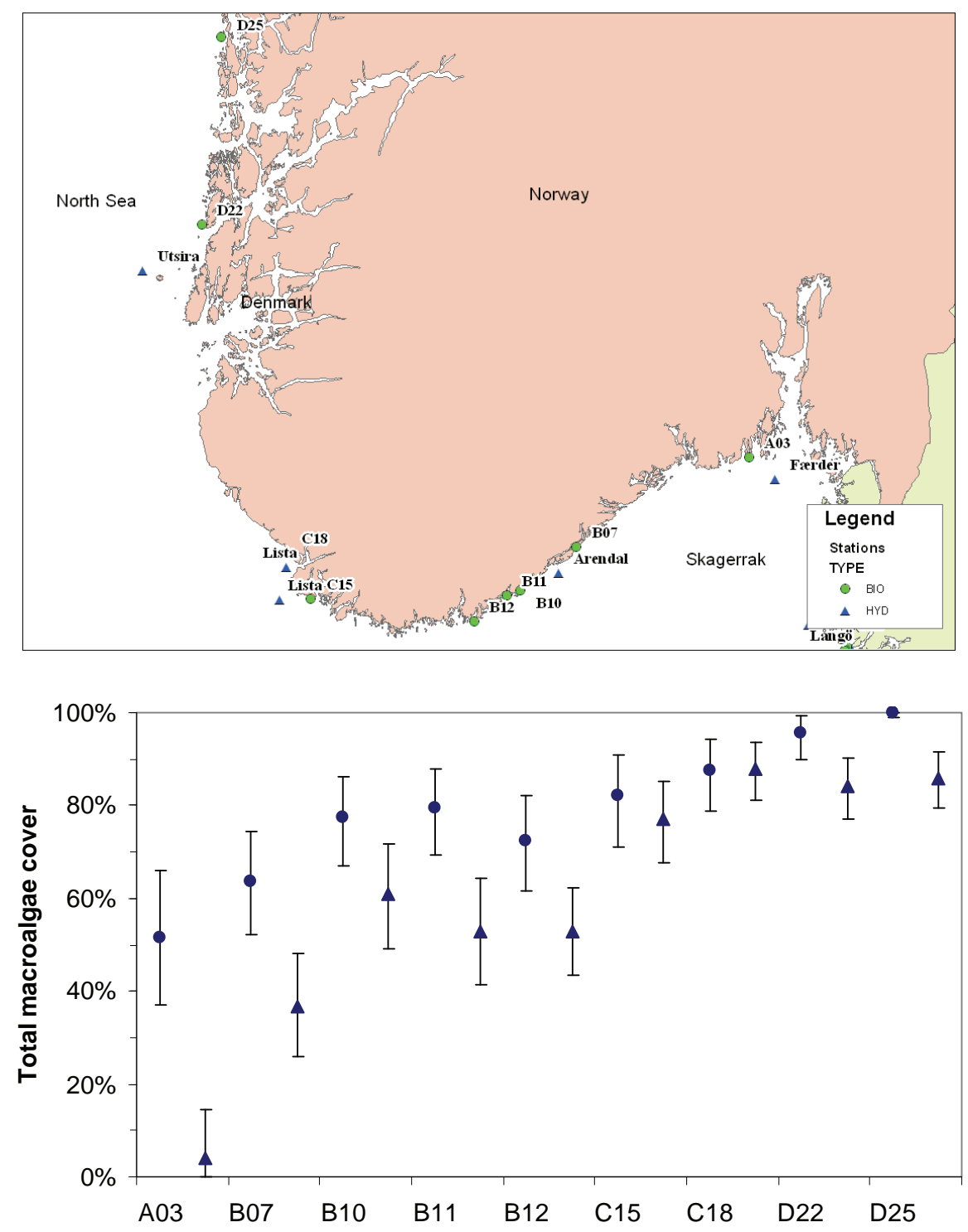

Figure 4.7 Norwegian stations (upper) and total cover estimates $(n=18)$ expressed for a standard depth of $15 \mathrm{~m}$ in 2007 (circles) and 2008 (triangles) for stations along the Norwegian southern coast estimated by means of (6) (lower). 


\subsubsection{Cross-system comparison}

The area-specific total cover estimates resulted in 239 annual means representing 46 areas and 21 years, although these were quite heterogeneously distributed between study sites (table 4.1). The parameters for the depth gradient varied by a factor of 2, with the steepest gradients observed at the Swedish west coast. The uncertainty of the Finnish depth gradient was substantially larger than for the other study sites due to lack of deeper observations and therefore a limited range for estimating the depth gradient.

Table 4.1 Summary of model results to estimate annual total cover means for the different study sites.

\begin{tabular}{lcrrrrr}
\hline Study site & $\begin{array}{r}\text { \#annual total } \\
\text { cover means }\end{array}$ & $\begin{array}{r}\text { \# of } \\
\text { areas }\end{array}$ & $\begin{array}{r}\text { \# of } \\
\text { years }\end{array}$ & $\begin{array}{r}\text { Depth } \\
\text { range (m) }\end{array}$ & $\begin{array}{r}\text { Depth } \\
\text { estimate (a) }\end{array}$ & $\begin{array}{r}\text { Residual } \\
\text { variance }\end{array}$ \\
\hline $\begin{array}{l}\text { Finland archipelago } \\
40\end{array}$ & 6 & 7 & $3.0-11.3$ & $\begin{array}{r}-0.056 \\
( \pm 0.0120)\end{array}$ & 0.08214 \\
Askö & 20 & 1 & 20 & $3.0-25.6$ & $\begin{array}{r}-0.048 \\
( \pm 0.0023)\end{array}$ & 0.1703 \\
Denmark stone reefs & 155 & 24 & 15 & $6.0-24.0$ & $\begin{array}{r}-0.080 \\
( \pm 0.0024)\end{array}$ & 0.05063 \\
Sweden W coast & 6 & 6 & 1 & $5.0-20.0$ & $\begin{array}{r}-0.105 \\
( \pm 0.0024)\end{array}$ & 0.05966 \\
Norway coast & 18 & 9 & 2 & $5.0-30.0$ & $\begin{array}{r}-0.060 \\
( \pm 0.0019)\end{array}$ & 0.04333 \\
\hline
\end{tabular}

The parameter estimate and the residual variance are estimated for the angular transformed observations.

The residual variance was large at Askö and in the Finnish archipelago. This is most likely due to the normalisation of total cover that introduces additional variation, particularly for Askö data where the cover of suitable substrate was estimated qualitatively only (different substrate categories). The residual variance for the Danish stone reefs, the Swedish west coast, and the Norwegian coast had similar magnitude, but it should be acknowledged that the Swedish residual variance also includes variation from the 10 depth replicates. If we split this residual variance into two components: 1 ) variation around the depth gradient (corresponding to the estimates from Denmark and Norway) (variance $=0.02146$ ) and 2) variation between replicates (variance $=0.04333$ ), then the variance for the depth-specific observation, average over the 10 replicates, equals 0.02579 . This variance is considerably lower than the residual variances obtained from the Danish and Norwegian data, suggesting that a more precise total cover estimate is obtained as the average of the 10 camera replicates than a depth-specific total cover estimate assessed by the diver ( $\sim 30-40 \%$ more uncertain). But it should also be noted that the Swedish west coast data set represent a relatively small area and homogenous waters compared to for instance the Norwegian data set.

The annual total cover means were investigated in relation to water quality variables, primarily Secchi depths. It was investigated if there would be bias in this relationship between the different study sites and 
monitoring carried out. It was only possible to analyse for an additive bias, as the variation range in Secchi depths within some study sites was too narrow to accurately estimate a relationship to Secchi depth, thereby resulting in quite diverse and unexpected relationships to Secchi depths. Annual means from two specific Danish areas in Skagerrak, Knudegrund and Lønstrup Rødgrund, were not used in the analysis, since these two areas deviated significantly from the other Danish areas due to the special hydrography of the Jutland west coast. The model employed was:

$$
f(x)=\mu+\text { area }_{i}+a \times \operatorname{secch}_{i-} \text { depth }_{i j}+e_{i j}
$$

where $f(x)$ is the estimated mean of the angular transformed total cover observations, area $\mathrm{i}_{\mathrm{i}}$ describes an additive bias across monitoring programs, and $\mathrm{a} \times$ secchi_depth $_{\mathrm{ij}}$ describes a generic relationship to secchi depths.

Analysing (7) resulted in a highly significant bias $(\mathrm{p}<0.0001)$ and investigating the parameter estimates clearly suggested that total cover means from Askö deviated significantly from all the other areas. Therefore, the model (7) was re-examined, excluding means from Askö. The outcome using this reduced data set was still a significant bias $(\mathrm{p}<0.0001)$ that derived from the Finnish total cover means. Thus, re-examining the model (7), excluding means from both Askö and the Finnish archipelago, resulted in a non-significant bias $(\mathrm{p}=0.1638)$, suggesting that total cover respond to secchi depths in a comparable way across the Danish, Norwegian, and Swedish west coast monitoring program reducing the number of areas in the model to three, all having the same gradient but different intercepts (figure 4.8).

The total cover in three areas can be described by following relationship to secchi depth:

- Skagerrak-Kattegat-Belt sea:

- Askø area

$y=\sin ^{2}(0,63+0,052 x)$

- Finnish archipelago

$$
\begin{aligned}
& y=\sin ^{2}(0,28+0,052 x) \\
& y=\sin ^{2}(0,23+0,052 x)
\end{aligned}
$$




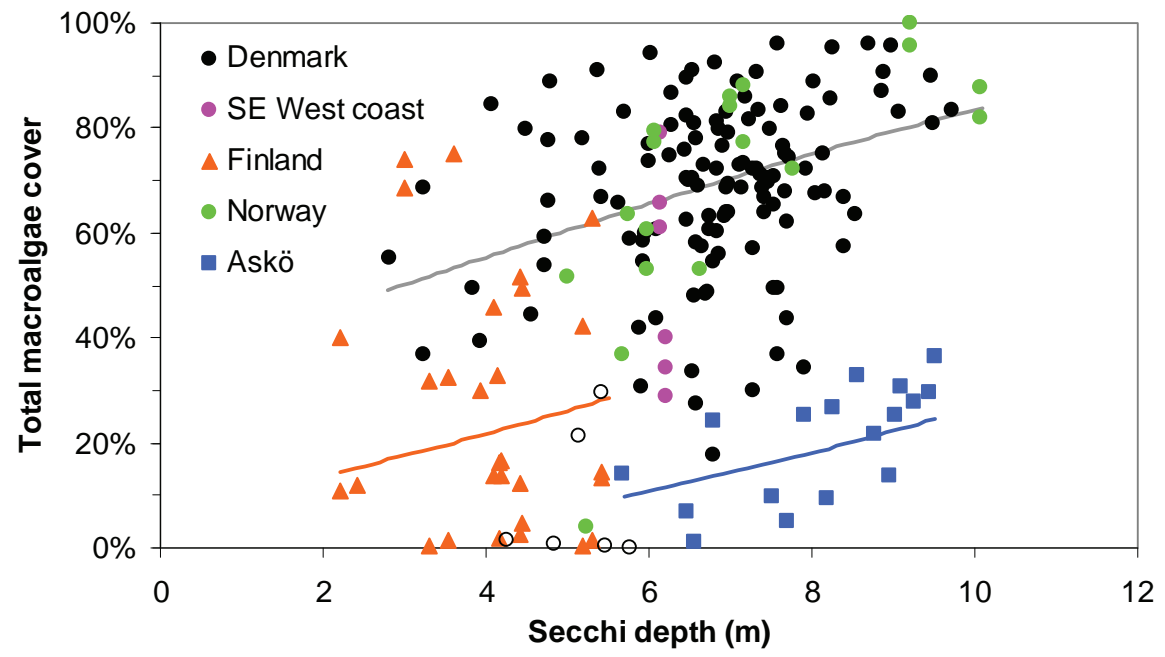

Figure 4.8 Estimated annual total cover at 15 m depth versus annual Secchi depths (JanJun). Gray solid line shows the combined model for Denmark, Norway and Swedish west coast, whereas separate models are shown for Finnish data and data from Askö. Open circles show annual means from Knudegrund and Lønstrup Rødgrund that were not included in the analysis. Total cover means and regression lines were found from the inverse angular transformation.

There was considerable scatter around the three estimated relationships between total cover and Secchi depths (figure 4.8). The least scatter was found for the Askö data. This is most likely due the problem of accurately characterising the water quality for the areas with macroalgae transects. For the Askö data there was only one area and therefore all scatter is principally temporal, i.e. uncertainty in the annual estimates. For the other study sites the scatter also include spatial differences, i.e. differences in how well macroalgae transects are linked to water quality stations as well as the quality of data behind the estimated marginal mean values of water quality variables. Estimated marginal means on Secchi depth less than $5 \mathrm{~m}$ is for example hardly reflecting the average values from January to June in open inner Danish waters.

The bias between the three relationships can be due to both differences in the total cover estimation method but also in the linking of water quality stations to macroalgae transects. Macroalgae transects from most data from Askö and half of the Finnish data are located in sheltered coastal areas with relatively shallow depths, whereas the water quality stations linked to these are located further offshore in deeper areas. Therefore, it can be questioned if the water quality stations are representative of the actual water quality at the macroalgae transects. For the Danish, Norwegian and Swedish west coast study sites the macroalgae transects were mostly located in deeper and more open water areas, suggesting that differences between water quality at the transects and water quality stations might be small. However, for some transects the nearest water quality stations were quite distantly located. Thus, differences displayed (figure 4.8) between the different monitoring programs is a com- 
bination of how well water quality and macroalgae transects are linked and differences in the method for estimating total cover. Comparable relationships for total macroalgae cover were obtained by substituting secchi depths with total nitrogen (TN) or total phosphorus (TP) concentrations, whereas poor relationships were obtained using dissolved inorganic nitrogen (DIN), dissolved inorganic phosphorus (DIP) or chlorophyll a (Chla) as the explanatory variable.

\subsection{Lower depth limit}

The relationship between water transparency and the depth limit of perennial macroalgal species is obvious and therefore is selected as a matrix for water quality boundary setting in the WFD (see annex 2: Protocol from the Nordic NEA-GIG). As experienced in the monitoring programmes, we have problems with assessing the deepest occurrence of a species because the abundance becomes increasingly sparse towards its depth limit. In this project to harmonize Nordic methods we therefore decided to used the 5\% cover of the species as the lower "depth limits", which is believed to easier to locate than the absolute depth limit. Absolute lowest depth distribution is also calculated.

Of the 9 species selected by the WFD 6 red algae and 2 brown algae were intercalibrated in this project (Chondrus crispus, Furcellaria lumbricalis, Coccotylus/Phyllophora, Rhodomela confervoides, Delesseria sanguinea, Phycodrys rubens, Halidrys siliquosa, Laminaria saccharina). Fucus vesiculosus was not intercalibrated since growth of bladder wrack in Skagerrak and Kattegat is limited to the intertidal due to biological control (species competition) of the lower growth limit. A review of WFD Metric: "Depth limit of macroalgal species" is given in Appendix 2 and the good-moderate boundary set for the selected species used in this work is shown in the table 4.2.

Table 4.2 Good-moderate boundary set for the selected species.

\begin{tabular}{|c|c|c|c|c|c|c|}
\hline Finland: & coastal waters of Baltic Sea & & & & & \\
\hline Sweden: & c w of Baltic Sea & & & & & \\
\hline Sweden: & c w of Skagerrak & & & & & \\
\hline Denmark & c w of Kattegat & & & & & \\
\hline Norway: & c w of Skagerrak & & & & & \\
\hline \multirow[t]{6}{*}{ red algae } & Chondrus crispus & 9 & - & 9 & & \\
\hline & Furcellaria Iumbricalis & 9 & - & 9 & & \\
\hline & Coccotylus /Phyllophora* & 18 & - & 18 & & \\
\hline & Rhodomela confervoides & 9 & - & 9 & & \\
\hline & Delesseria sanguinea & 18 & - & 18 & & \\
\hline & Phycodrys rubens & 17 & & 17 & & \\
\hline \multirow[t]{3}{*}{ brown algae } & Fucus vesiculosus & & & & 5 & 5 \\
\hline & Halidrys siliquosa & 8 & - & 8 & & \\
\hline & Laminaria saccharina & 9 & - & 9 & & \\
\hline
\end{tabular}

${ }^{*}$ Coccotylus $/$ Phyllophora $=$ the complex of $\mathrm{C}$. truncatus and $\mathrm{P}$. pseudoceranoides 
The Boundary setting protocol (WFD intercalibration technical report on Macroalgae in Coastal and Transitional Waters, see Annex 2) state that the Good/Moderate boundaries was set between 40 and $60 \%$ of the estimated reference values for the selected species and water types. The depth limits of the selected macroalgal species is the $5 \%$ cover degree lower depth distribution and this 5\% cover is more conservative than the WFD metrics "depth limit". Therefore this must be taken into consideration when comparing the results with the boundary settings. Also the intention in this work is not to evaluate the water quality, but to test and experience use of this common metrics.

\subsubsection{Depth distribution of 8 selected macroalgae species}

In figure 4.9 to 4.13 lower depth limit (5\% cover degree) is shown for Chondrus crispus, Phycodrys rubens, Furcellaria lumbricalis, Coccotylus/Phyllophora, Delesseria sanguinea, Rhodomela confervoides, Halidrys siliquosa and Saccharina latissima (Laminaria saccharina) in the period 1995-2008. As can be seen from the figures there is a large variation in lower depth distribution from year to year. This should be considered and compensated for before accepting the metric.

The red algae Chondrus crispus was only recorded in the Skagerrak region (Figure 4.9). Swedish data was from 2007 only (no variance). At the Norwegian stations there was a large variation between the stations and between the years and this variation may be caused by other factors than light limitation. The usefulness of Chondrus crispus may be dependent on abundance of other dominating macroalgae competing for space.

Phycodrys rubens (figure 4.9) was only recorded in Norway and Swedish west coast. The Norwegian data were better than the good-moderate boundary and the Swedish data were at the border.

The maximum depth distribution limit recorded (1995-2008) for Furcellaria lumbricalis (figure 4.10) is beyond the good/moderate boundary set for Skagerrak at $9 \mathrm{~m}$ depth for many of the stations, even in the Baltic. But median or average depth distribution seems to fail the criteria. This is another example of problems due to large year to year variance. Available substrate seems to limit the depth distribution at many stations in the Askö area.

Lower depth good-moderate boundary of Coccotylus truncate/Phyllophora pseudoceranoides (figure 4.11) in Skagerrak is set at $18 \mathrm{~m}$ and in average the Norwegian stations meets this limit. This taxa complex grows in Skagerrak, Kattegat and the Baltic and in low light conditions. For many of the stations, especially in the Askö area, Coccotylus/Phyllophora is limited by available substrate.

Delesseria sanguinea (figure 4.12) is abundant in the Skagerrak and Kattegat region. The variance from year to year is much less for this species, especially at the Norwegian stations, than for other selected species. 

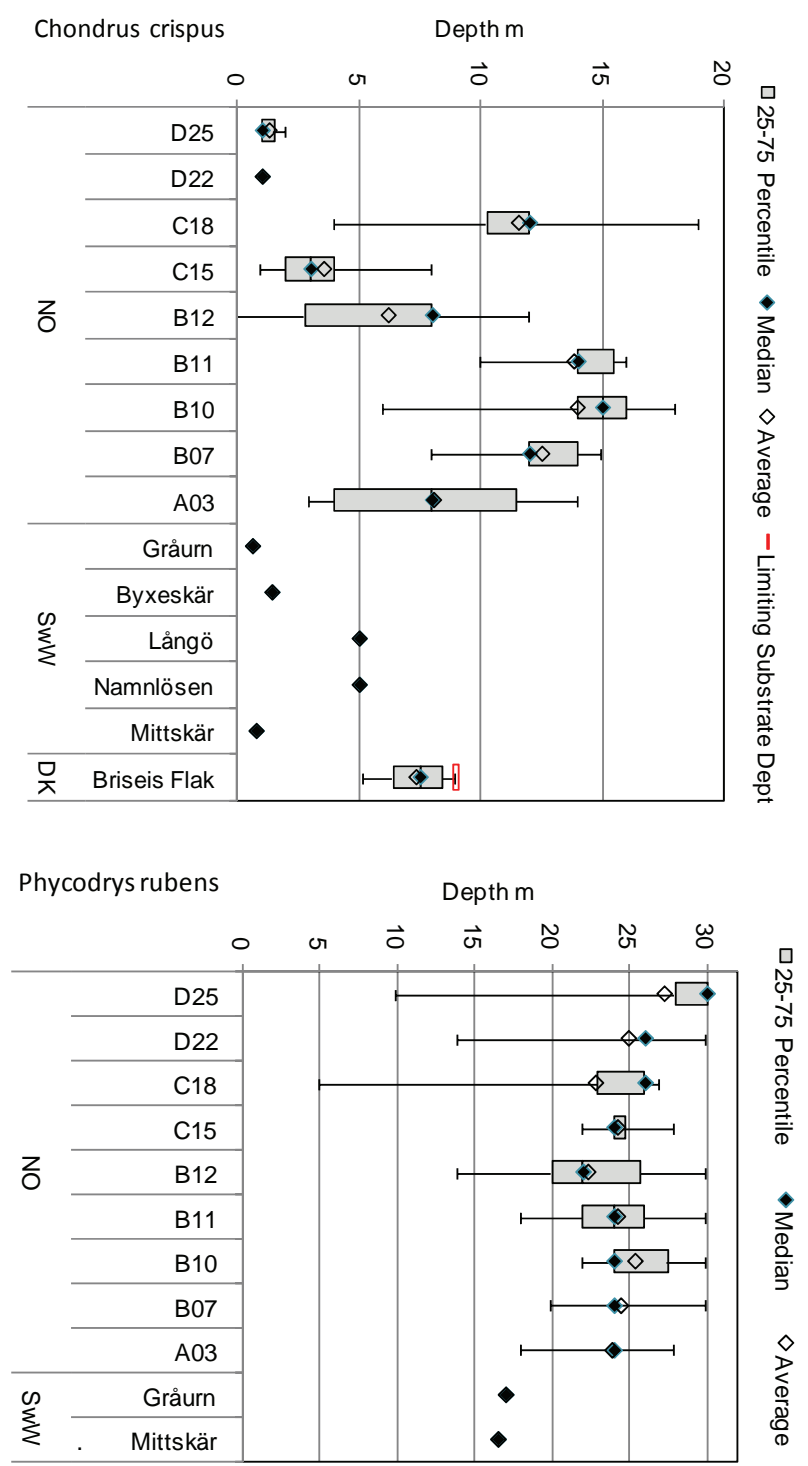

Figure 4.9 Lower depth limit of Chondrus crispus and Phycodrys rubens (5\% cover) at monitoring stations 1995-2008. (Swedish west coast only in 2007). Good-moderate boundary in the Skagerrak area is set at 9 and $17 \mathrm{~m}$ depth, respectively. Possible growth limitation by improper substrate is indicated by - (station Briseis Flak stops at $9 \mathrm{~m}$ ). Whiskers show lowest and highest value. 


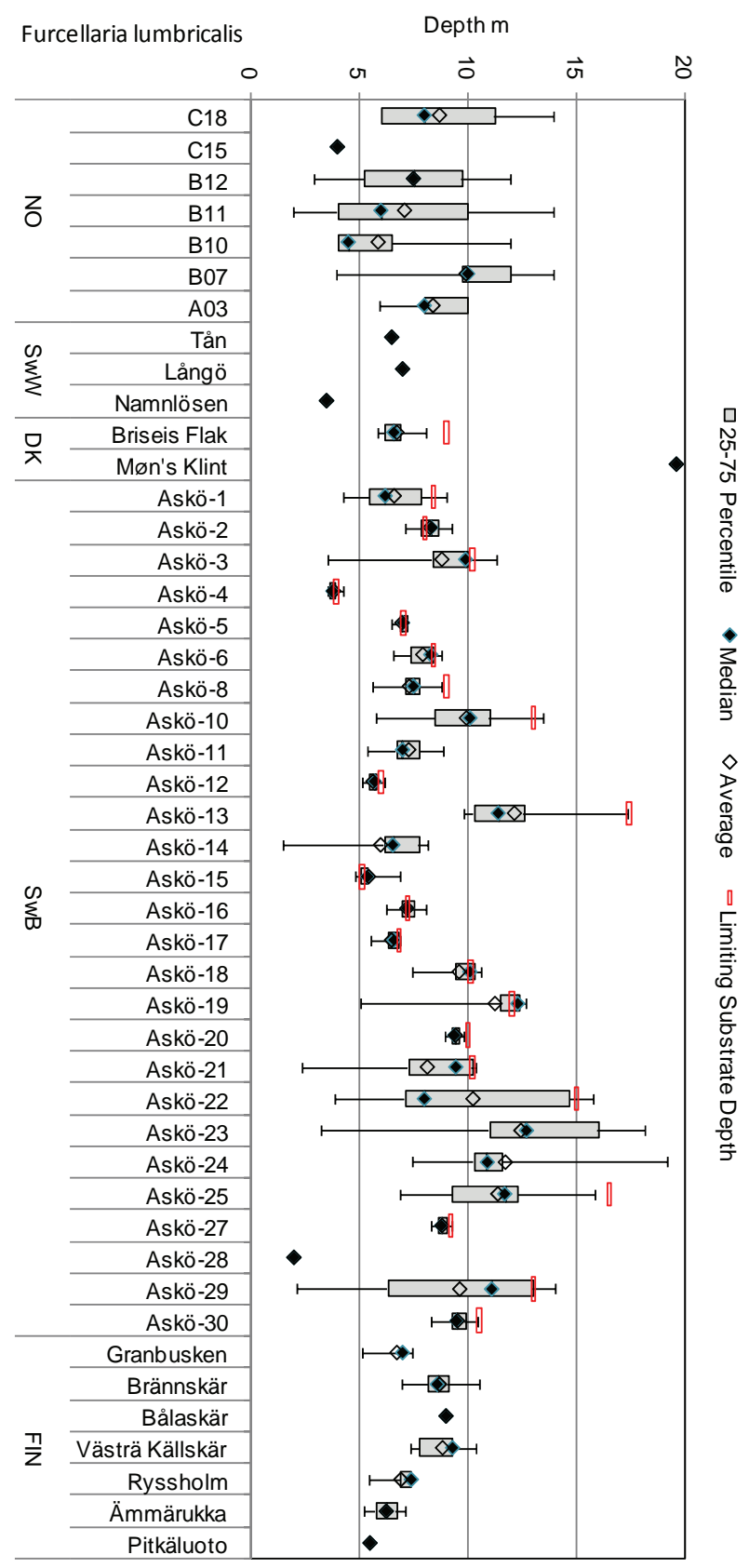

Figure 4.10 Lower depth limit of Furcellaria lumbricalis (5\% cover) at monitoring stations 1995-2008. Good/moderate boundary in the Skagerrak is set at $9 \mathrm{~m}$ depth. Possible growth limitation by improper substrate is indicated by - (average of transect depth). Whiskers show lowest and highest value. 


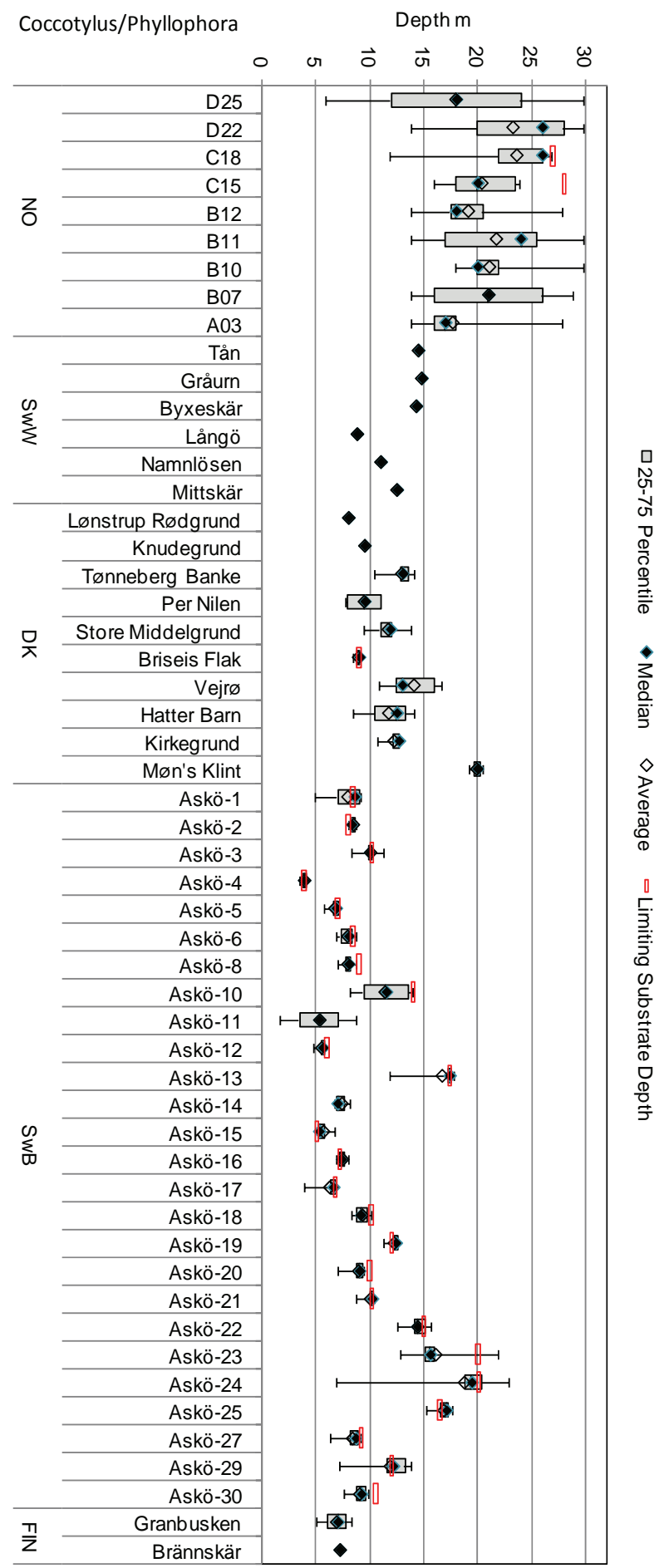

Figure 4.11 Lower depth limit of Coccotylus truncate/Phyllophora pseudoceranoides (5\% cover) at monitoring stations 1995-2008. Possible growth limitation by improper substrate is indicated by - (average of transect depth). Whiskers show lowest and highest value. 

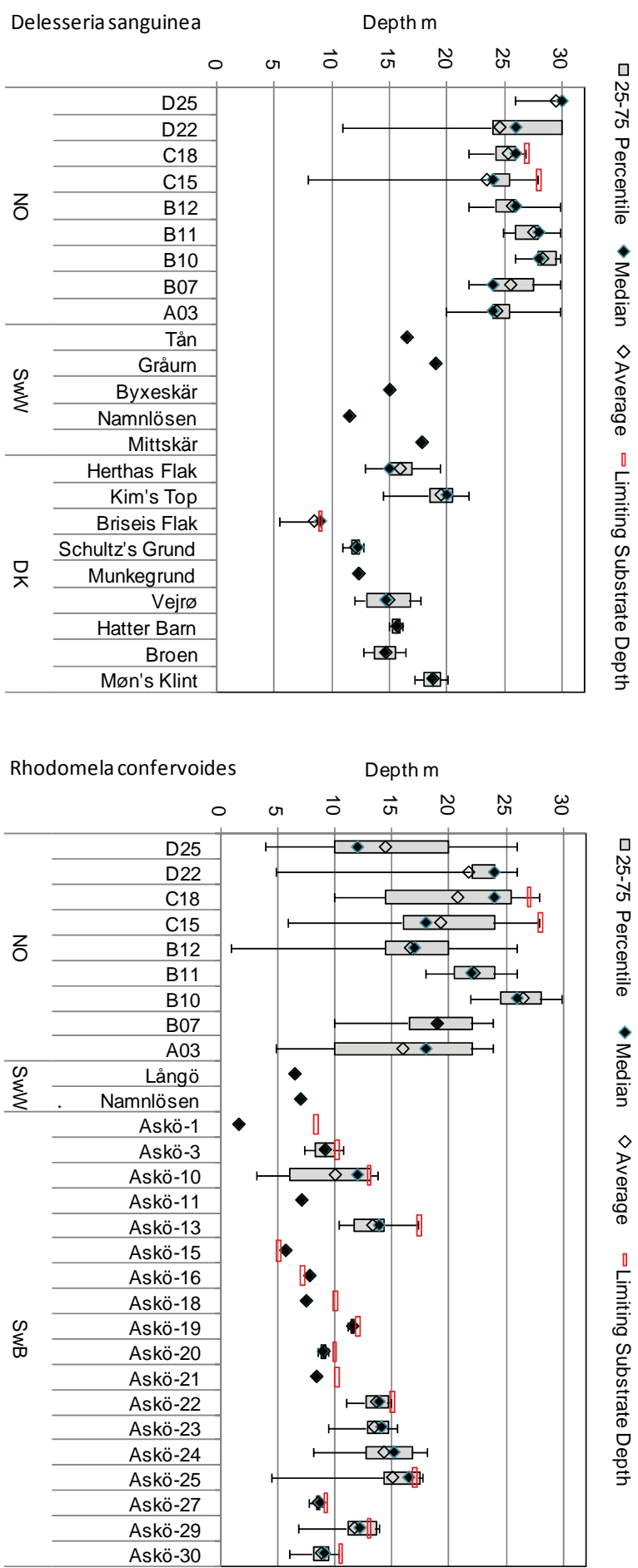

Figure 4.12 Lower depth limit of Delesseria sanguinea and Rhodomela confervoides (5\% cover) at monitoring stations 1995-2008. Good/moderate boundary in Skagerrak is set at 18 and $9 \mathrm{~m}$ respectively. Possible growth limitation by improper substrate is indicated by - (average of transect depth). Whiskers show lowest and highest value. 

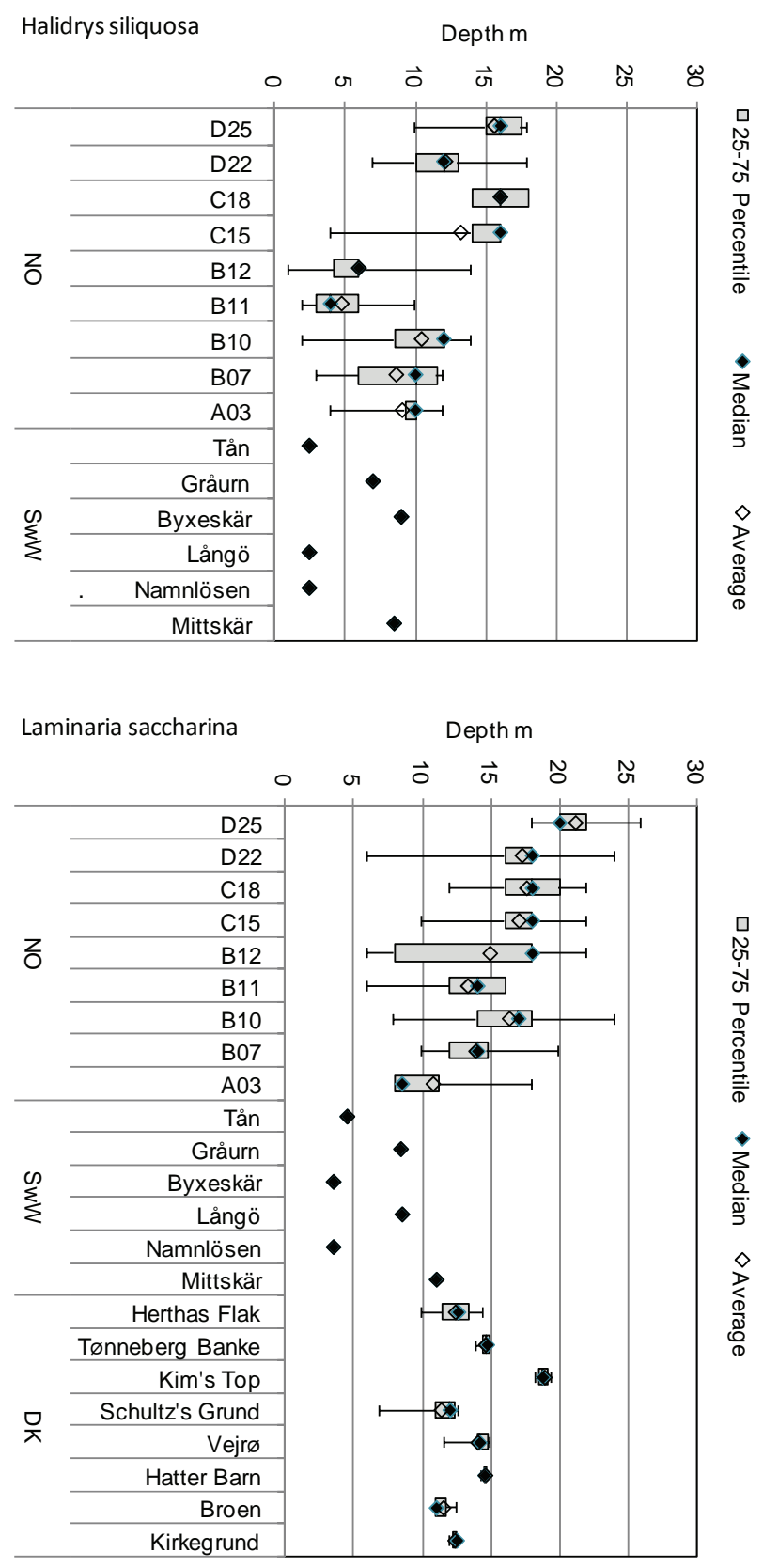

Figure 4.13 Lower depth limit of Halidrys siliquosa and Saccharina latissima (Laminaria saccharina) (5\% cover) at monitoring stations 1995-2008. Average value is shown as open diamonds. Good/moderate boundary in Skagerrak is set at 8 and $9 \mathrm{~m}$ respectively. Non stations were limited by improper substrate for these two species. Whiskers show lowest and highest value.

Saccharina latissima (Figure 4.13) is also abundant in the SkagerrakKattegat region and for all stations (except for Swedish west coast 2007 data) the $5 \%$ cover degree depth distribution was better than the Skagerrak criteria set at $9 \mathrm{~m}$ depth. The abundance of Saccharina was greatly reduced in the region after 1997-2002 (Moy et al. 2008) especially on sheltered stations and analyses of the Swedish data has shown reduced 
depth distribution after this period. Variance from year to year may be due climatic changes that influence the abundance and distribution of Saccharina in the Skagerrak-Kattegat region.

For the other selected species (Rhodomela confervoides, Halidrys siliquosa) variations were similar to species mentioned here. The year to year variations was large and average depth distribution did not meet the boundary settings for all species. This indicates that the water quality can not be judge be a single year only due to natural variation in lower depth distribution. Also for many stations in the Baltic lack of suitable substrate at deeper waters prevented the use of this metric.

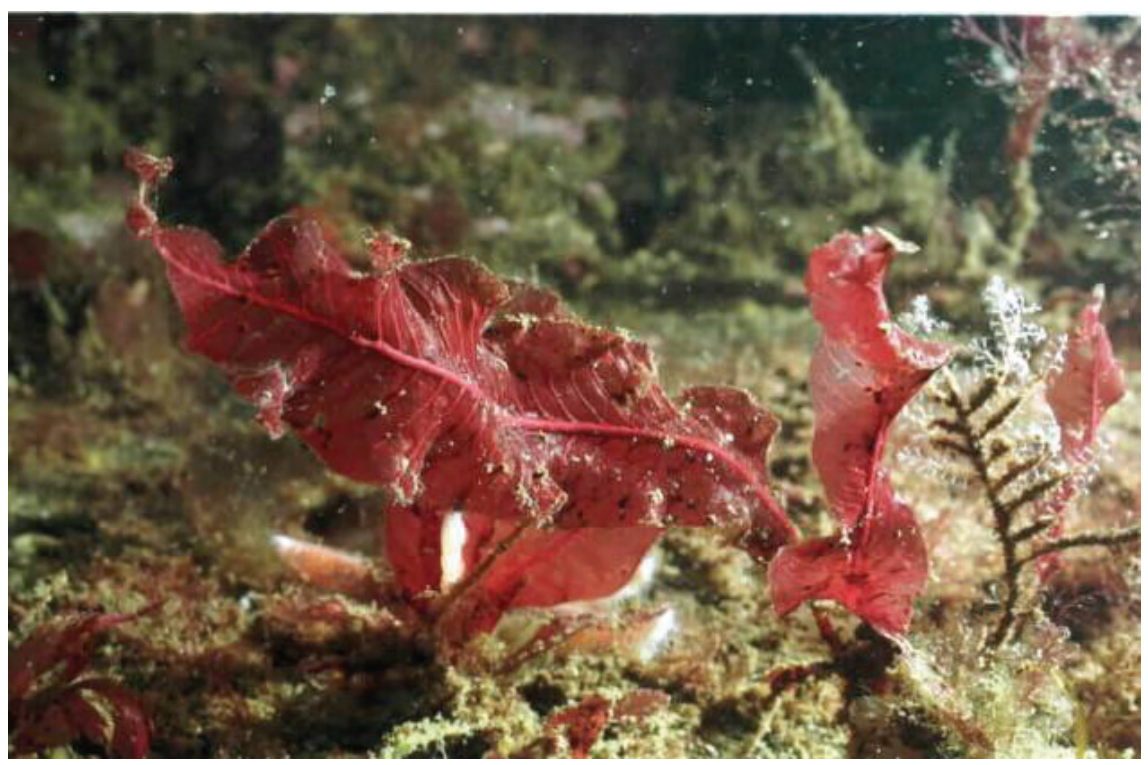

Delesseria sanguinea, one of the selected macroalgae species for monitoring lower depth distribution limit in the Skagerrak region (Photo: NIVA). 


\section{Discussion and Conclusions}

\subsection{Total algal cover}

Total cover estimations were most uncertain for Askö and also Finnish archipelago, because total cover had to be normalised to the fraction of suitable substrate at these study sites. The most precise depth-specific estimate of total cover is obtained from averaging over 10 camera samples, as carried out on the Swedish west coast.

Total cover estimates were significantly related to Secchi depths, but significant differences were found in this relationship between study sites. Though, there were no significant differences between the Danish, Norwegian and Swedish west coast relationships. The differences might be caused by a combination of different methodologies for assessing total cover and differences how well water quality can be estimated for the macroalgae transects. However the dramatic decline in salinity especially over the Gedser-Dars sill in the Belt Sea area and Drodgen Sill in Øresund restrict the number of algal species able to survive in the Baltic Sea and that might influence the total algal cover at low light levels in a negative way. The low salinity in the Baltic Sea at the same time has a positive influence on the survival of the blue mussels (Mytilus edulis) settling in the benthic vegetation as the low salinity prevents the predator the common seastar (Asterias rubens). Interactions between massive settlement of Mytilus and algal vegetation is demonstrated in Danish waters.

Water quality and macroalgae monitoring should be better coordinated with a close distance between stations and the pelagic sampling frequency should reflect the dynamic processes in the water column such that more precise functional relationships can be estimated.

Long-term trends in total cover (Danish and Askö data) suggest that macroalgae have a relatively fast response to changing water quality, and as such provide a good ecological indicator for assessing the effects of nutrient management.

\subsection{Lower depth limit}

Although the relationship between water transparency and the depth distribution limit of perennial macroalgal species is obvious, so far, doseresponse relationships between water quality expressed as either nutrient concentration or water transparency and the depth limit of the selected macroalgal species, has not been established by the Nordic NEA-GIG 
group (see Annex 2). They were not able to find discontinuities or thresholds which could be used to define the good/moderate boundary.

This lack of relationships may be due to (at least) two methodology limitations, also reported by the Nordic NEA-GIG group:

- The fact that observations along the depth gradient are typically interspaced by 2-3 m depth introduces an uncertainty of this magnitude on the estimates of depth limit. This is a large error given that many species don't penetrate very deep along the coasts of e.g Denmark.

- Assessing the deepest occurrence of a species is connected with much uncertainty, because abundance becomes increasingly sparse as the depth limit is approached, and time spent on searching as well as experience of the diver therefore influences the results. A more precise assessment of depth limits would require more observations along the depth gradient, e.g. every meter and it would then be preferable to define the depth limit as the depth of e.g. $5 \%$ cover which is easier to locate than the absolute depth limit.

In this project the metric "Depth limits of macroalgal species" was not directly obtained in the field but was calculated from the field recordings according to each nations monitoring methodology. In general the " $5 \%$ vegetation lower limit" was calculated by interpolating a depletion curve for area cover between the recoding depths used in the monitoring programmes. For Norway the " $5 \%$ vegetation lower limit" was set equal to "frequent" abundance.

The 8 selected species were Chondrus crispus, Furcellaria lumbricalis, Coccotylus/Phyllophora, Rhodomela confervoides, Delesseria sanguinea, Phycodrys rubens, Halidrys siliquosa, and Saccharina latissima.

Only the Nordic part of the NEA-GIG group, has suggested use of lower depth limit and therefore suggested depth criteria is only given for the Skagerrak region water types 8 (archipelago), 9 (fjords) and 10 (open coast). The work in this project has on the usefulness of this metric and not so much on stations that do or don't meet the good/moderate boundary criteria.

Many of the species at the Norwegian and the Swedish coasts of Skagerrak (Type 10, Open exposed coast) showed great differences in lower depth distribution, especially for species like Chondrus, Coccotylus and Saccharina, which showed reduced depth distribution on the Swedish exposed coast and this needs to be further investigated.

Reduced abundance and distribution of Saccharina has been reported from the Skagerrak region (Moy et al. 2008, Moy \& Christie submitted) and in that case, failing the boundary limit correctly indicates poor ecological quality and that attention is needed.

On exposed Danish stations in Skagerrak and northern Kattegat the observed lower limit for some species like the Coccotylus-complex and 
Delesseria were more shallow than the good/moderate boundary but for other species like Chondrus and Saccharina it was equal to or better. Overall it was expected that all species should be below the goodmoderate boundary, however the location of several stations far away from the coastal zone raise the question if the suggested boundaries can be used for those reef areas. Hard bottom stations in Denmark are mostly stone reefs on sandy bottom and suitable substrate may be a restriction.

Most worrying was the large year to year variations (year 1995-2008) found in the data sets, especially in the Norwegian data. For many species maximum depth distribution did meet the criteria, but median or average depth distribution did not. The large year to year variation (tabel is shown in Appendix 3) in the period analysed, indicate that the water quality cannot be judge by a single year alone. This year to year variation may be due to variation in many factors including water quality. Factors influencing the depth distribution must be evaluated before the lower depth limit is used to classify the water body.

The observed year to year variability and the different pattern between species also raise a fundamental question regarding the proposed boundary setting protocol. The variation was most likely also large in the "historic" datasets that was used for the proposed boundary setting.

The generally large variance in the Norwegian data may be due to the species composition with more dominance of canopy species like the kelp Laminaria hyperborea. The kelp may take out almost all light and restrict abundance of understory species like Chondrus crispus, Furcellaria lumbricalis, and Rhodomela confervoides. When biological factors like competition for space and light, and grazing from e.g. sea-urchins occur, use of depth distribution will be misleading. We recommend that species composition and abundance of the community is measured as baseline for use other metrics like the "lower depth limit".

Coccotylus/Phyllophora and Delesseria sanguinea grows deeper and with less light than most other macroalgae species and the lower depth distribution is therefore less influenced by abundance of kelp or other species. This may also be seen as less variance in the data (Figure 4.74.11) compared to the other selected species.

Depth distribution limit may also be used to define water quality in the Baltic, see figures of Furcellaria lumbricalis, Coccotylus/Phyllophora, and Rhodomela confervoides. Limitation in suitable substrate (as can be seen in the Askö data set) or restricted transect depth (as in the Finnish monitoring program before 2008) prevent full use of this metric.

The variance table shown in Appendix 3 indicate that the variance is almost equal for $5 \%$ cover degree depth distribution and the maximum depth distribution. This indicates that either method is equally good. If the Norwegian data set is subtracted (data set with the most extreme variance) the variance is generally slightly less (better) for the $5 \%$ cover depth limit compared to maximum depth limit. This support the hypothe- 
sis that $5 \%$ cover degree is easier to obtain than the maximum depth which could be more incidental. But $5 \%$ cover degree limit is more conservative than maximum depth, which should be reflected in the boundary setting protocol.

In conclusion, lower distribution limit seem to be a good metric to classify water quality and 5\% cover degree seems to be slightly better than maximum depth distribution, based on slightly better variance (except Norwegian data) 5\% cover degree is believed to be easier to obtain by the diver. Biological factors influencing depth distribution (like shading from kelp forest in the Norwegian data) must be evaluated before use of the metric. Lower depth limit are set by more factors than water quality and water quality based on lower depth limit therefore require a minimum set of species to be valid. One species alone is not good enough. Also the water quality cannot be judge by a single year alone but should be based on three or more years. 


\section{References}

Andersen JH, Conley DJ, Hedal S. 2004. Paleoecology, reference conditions and classification of ecological status: the EU Water Framework Directive in practice. Marine Pollution Bulletin 49: 283-290.

Carstensen J, Krause-Jensen D, Dahl, K, Middelboe AL. 2005. Development of macroalgal indicators of water quality In Dahl, K., Andersen, J., Krause-Jensen, D., Josefson, A., Kjerulf-Petersen, J., Hansen, O.S., Middelboe A.L. (Eds) Scientific and technical background for intercalibration of Danish coastal waters. National Environmental Research Institute, Denmark xx pp. - NERI Technical report no. 563. http://technical-reports.dmu.dk

Christiansen T, Christensen TJ, Markager S, Petersen JK, Mouritsen, LT. 2006. Limfjorden i 100 år. Klima, hydrografi, næringsstoftilførsel, bundfauna og fisk i Limfjorden fra 1897 til 2003. National Environmental Research Institute. - Technical report from NERI, no. 57, 81 pp. In Danish with English summary.

Clarke A, Juggins S, Conley DJ. 2003. A 150-year reconstruction of the history of coastal eutrophication in Roskilde Fjord, Denmark. Marine Pollution Bulletin 46: 1,615-1,629.

Dahl K, Lundsteen S, Helmig S. 2003. Stenrev - havbundens oaser. 1 Gads Forlag. - Miljøbiblioteket 2, 104 pp. In Danish. http://www2.dmu.dk/ 1_viden/2_Publikationer/3_miljobib/ rapporter/MB02.pdf

Dahlgren S, Kautsky L. 2004. Can different vegetative states in shallow coastal bays of the Baltic Sea be linked to internal nutrient levels and external nutrient load? Hydrobiol. 514: 249-258.

Duarte CM. 1991. Seagrass depth limits. Aquat. Bot. 40: 363-377.

Duarte CM. 1995. Submerged Aquatic Vegetation in Relation to Different Nutrient Regimes. Ophelia 41: 87-112.
Eriksson KB, Johansson G, Snoeijs P. 1998. Long-term changes in the littoral zonation of brown algae in the southern Bothnian bay. Eur. J. Phycol. 33: 241-249.

Eriksson KB, Johansson G, Snoeijs P. 2002. Long-term changes in the macroalgal vegetation of the inner Gullmar fjord, Swedish Skagerrak coast. Journal of Phycol. 38: 284-296.

Fredriksen, S., Rueness, J. 1990. The eutrophication status of Outer Oslofjord 1989. Subproject 4.1: Benthic algae in Outer Oslofjord. NIVAreport. OR-2388. 63pp. In Norwegian. http://www.niva.no/.

Hansson M, Håkansson B. 2006. Förslag till Vattendirektivets Bedömningsgrunder för pelagiala vintertida näringsämnen och sommartida effektrelaterade näringsämnen, siktdjup och klorofyll i kustvatten. Ej fastställd. SMHI rapport. In Swedish.

Hossain Z. 2004. The European Water Framework Directive - Testing the use of macroalgal depth limits as indicators of water quality. Prowork Project Work. Odense University, Denmark.

Karlsson, J. National monitoring data from 1994-1998. Övervakning av vegetationsklädda hårdbottnar vid svenska västkusten, Årsrapport 1999 inklusive bilagor. Tjärnö Marinbiologiska Laboratorieum och Botaniska institutionen, marin botanik, Göteborgs universitet, Sverige.

Kautsky L, Andersson C, Dahlgren S. 2004. Framtagning av nya bedömningsgrunder för kust och hav enligt ramdirektivets krav. Förslag till Ekologisk Kvalitetskvot (EQR) för den biologiska parametern - makrovegeation. Report to the Swedish EPA. In Swedish. 23pp.

Kautsky N, Kautsky H, Kautsky U, Waern M. 1986. Decreased depth penetration of Fucus vesiculosus L. since the 1940s indicate eutrophication of the Baltic Sea. Mar Ecol Prog Ser 28:1-8. 
Krause-Jensen, D., Carstensen, J., Dahl, K., Bäck, S., Neuvonen, S. 2009, "Testing relationships between macroalgal cover and secchi depth in the Baltic Sea”, Ecological Indicators, vol. 9, s. 1,284-1,287

Magnusson J, Johnsen T.M, Beyer F, Gjøsæter J, Lømsland E.R, Sollie, Aa, 1999. Pollution monitoring in the Inner Oslofjord in 1998. NIVA-report. OR-4058. 63pp. In Norwegian http://www.niva.no/

Magnusson, J., Bokn, T., Moy, F., Pedersen, A., Larsen, G. 1991. Pollution monitoring in the Inner Oslofjord in 1998. NIVA-report. OR-2711. 116pp. In Norwegian.http://www.niva.no/

Markager S, Storm LM, Stedmon CA. 2006. Limfjordens miljøtilstand 1985 til 2003. Sammenhæng mellem næringsstoftilførsler, klima og hydrografi belyst ved hjælp af empiriske modeller. National Environmental Research Institute. - Technical report from NERI, no. 577, 219 pp. In Danish with English summary. fagligerapporter.dmu.dk

Moy F, Christie H, Steen H, Stålnacke P, Aksnes D, Alve E, Aure J, Bekkby T, Fredriksen S, Gitmark J, Hackett B, Magnusson J, Pengerud A, Sjøtun K, Sørensen K, Tveiten L, Øygarden L, Åsen PA, 2008. Sluttrapport fra Sukkertareprosjektet. Sugar Kelp Project - Final Report. SFT-rapport TA2467/2008, NIVArapport 5709. $131 \mathrm{~s}$.

Moy FE \& Christie H, submitted. Large-scale shift from sugar kelp (Saccharina latissima) to ephemeral algae along the south and west coast of Norway. Marine Biology Research. Moy, F., Aure, J.(HI), Dahl, E. (HI), Falkenhaug, T. (HI), Green, N., Johnsen, T., Lømsland, E., Magnusson, J., Omli, L. (HI), Olsgard, F., Oug, E., Pedersen, A., Rygh, B., Walday, M. 2005. Long-term monitoring of environmental quality in the coastal regions of Norway. Annual report 2004. NIVA-report. OR-5026. 92pp. In Norwegian http://www.niva.no/

Nielsen R, Kristiansen A, Mathiesen L, Mathiesen H. 1995. Distributional index of the benthic macroalgae of the Baltic Sea area. Acta Bot Fenn 155: 1-51.

Nielsen SL, Sand-Jensen K, Borum J, Geertz-Hansen O. 2002b. Depth colo- nization of eelgrass (Zostera marina) and macroalgae as determined by water transparency in Danish coastal waters. Estuaries 25: 1,025-1,032.

Nielsen SL, Sand-Jensen K, Borum J, Geertz-Hansen,O. 2002a. Phytoplankton, nutrients and transparency in Danish coastal waters. Estuaries 25: 930-937.

Pedersen M, Snoeijs P. 2001. Patterns of macroalgal diversity, community composition and long-term changes along the Swedish west coast. Hydrobiol. 459: 83-102.

Pedersen, A., Oug, E., Green, N. 1989. Blooms of the planctonic algae Chrysochromulina polylepsis. Regrowth and recolonization of communities along the Norwegian Coast. NIVAs survey in june 1989. Main report. NIVA-report. OR-2395. 228 pp. In Norwegian.

Petersen, J.K., Andersen, J.H., Dahl, K., Hansen, O.S., Josefson, A.B., Karlsson, J., Loo, L.-O., Magnusson, J., Moy, F. \& Nilsson, P. 2006: Reference conditions and EQO's for aquatic vegetation and macrozoobenthos. Copenhagen: Nordic Council of Ministers. TemaNord 2006:510 : 138 pp. Available at: http://www.nmr.dk/pub/miljo/ miljo/uk/TN2006510.pdf

Rueness, J, Fredriksen, S. 1991. An assessment of possible pollution effects on benthic algae of the outer Oslofjord, Norway. - Oebalia 17 (suppl.): 223-235.

Sundene O. 1953. The algal vegetation of Oslofjord. Mat. -Naturv. Klasse. No. 2,244pp.

Torn K, Krause-Jensen D, Martin G. 2006. Present and past depth distribution of bladderwrack (Fucus vesiculosus) in the Baltic Sea. Aquatic Botany 84: 53-62

Valiela I, McClelland J, Hauxwell J, Behr PJ, Hersh D, Foreman K. 1997. Macroalgal blooms in shallow estuaries: Controls and ecophysiological and ecosystem consequences. Limnol. Oceanogr. 42:1105-1118.

Walday, M. Moy, F. Green, N. 2001. Monitoring of the Grenlandfjords. Hard bottom communities 1998-1999. NIVA-report. OR-4360. 89 pp. In Norwegian. http://www.niva.no/

Wallentinus, I. 1991.The Baltic Sea gradient. In: Mathieson, AC and Nien- 
huis, PH eds. Intertidal and littoral ecosystems. Ecosystems of the World. 2,4:83-108. Elsevier, Amsterdam. Øresundsvandsamarbejdet - Öresundsvattensamarbetet. 2004. Jämförelse mellan “urtida” och "nutida” näringsnivåer i

Öresund - beräkningar utförda med

MIKE3-modell. www.oresundsvand.dk 



\section{Appendix 1: Technical Guideline for collecting "total erect macroalgal cover”}

\section{Short definition of the indicator}

Total vegetation cover is the overall cover of all erect macrophyte species (not crusts) fixed to stable hard substrate. The value of the indicator has a range from 0 to $100 \%$.

\section{“Sampling” methodology}

\section{Visual judging}

The cover is judged by divers looking at the seabed in a more or less 90 degree angle from the water surface (figure 1A and 1B). Special attention is needed when judging thin filamentous algal sitting as "tuff" directly on hard substrate at deep water. First of all fine sediment (dust) often has to be carefully brushed away to get the full impression of cover. The real problem or challenge is however to judge how much those small tiny treads cover if they are standing side by side.

Figure 1 and 2 illustrates the judging of vegetation cover from two angles and the results are given in table 1 . In this case we only focus on total cover of erect macrophytes meaning that allowing multiple layers of algal will only be expressed as on cover. Note that this is different to the cumulative sum of individual algal species cover, which could exceed $100 \%$.

On boulders and stone reefs vegetation from one stone covering the neighbouring stone is included in the total vegetation cover. This is also the case at a seabed with "mixed substrate" were hard stable substrate are separated by gravel or sand course sand. This is illustrated in figure 2 were the "sampling area" is restricted to 2 stones.

\section{Depth measurement}

Total vegetation is given for a specific depth (+/- $1 \mathrm{~m}$ depth interval or smaller). Depth is adjusted for changing water levels like tides. 


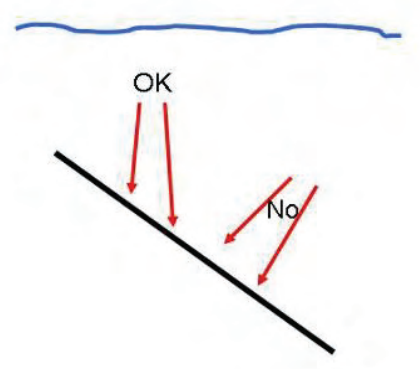

Figure 1 A. Judgement angle at slopes
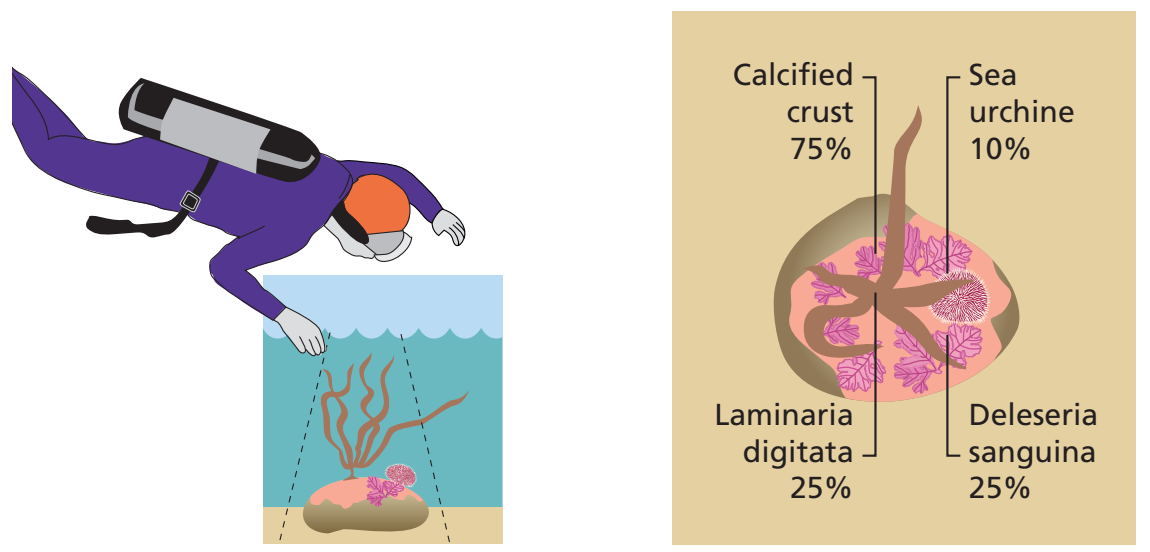

Figure 1B: Focus area for sampling total vegetation cover (left) and the same stone seen from above (right). Cover data are reported in table 1.

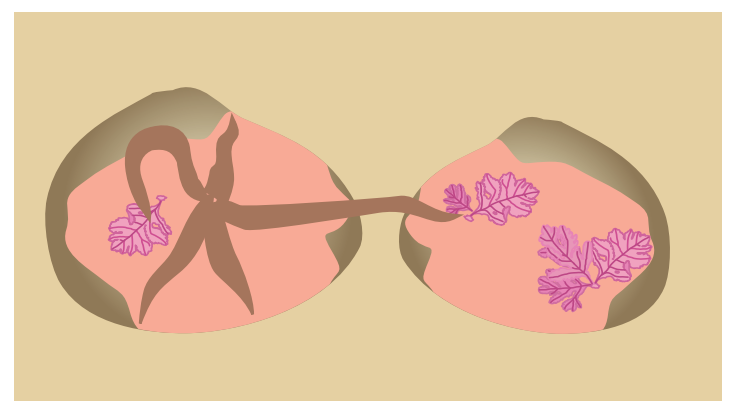

Figure 2. Judging total erect vegetation cover on stable hard substrate on stone reefs. In this case Laminaria from the left stone contribute to the cover of the right stone as well.

Table 1. Example of cover data. Species cover and total cover of erect macroalgal are judged in the field and cumulative cover is aggrgated data based on species.

\begin{tabular}{llr}
\hline Field data & & \\
\hline Species cover & Calcified crust & $75 \%$ \\
& Deleseria sanguinea & $25 \%$ \\
& Laminaria digitata & $25 \%$ \\
Total cover of erect macrphytes & Sea urchine & $10 \%$ \\
Aggregated data & & $40 \%$ \\
\hline & & \\
& & $50 \%$ \\
& Cumulative cover of erect macrophytes. & $125 \%$
\end{tabular}




\section{Sampling "substrate"}

Sampling is restricted to suitable hard stable substrate. Suitable hard stable substrate includes solid rock and stable boulders or smaller stones. The size of stones regarded as stable hard substrate can often be judged by presents and development of per-annual epibenthos and macrophytes (the biological components should be comparable with the components on larger objects). If this is not the case then a minimum size class is chosen based on experience (expert judging) including consideration about exposure and depth.

If substrate in general is too small to host the expected vegetation then sampling is not done.

If boulders and stones gets too scattered it influence the cover degree in Danish waters. $10 \%$ hard stable substrate within the "sampling area" should be the minimum level for collecting data and this information (cover of hard stable substrate) should be collected as well.

Sampling on biogenic hard substrate like Modiolus modiolus and Mytilus edulis shall be avoided as this kind of substrate seems to influence the vegetation cover (at least in Danish waters).

\section{Sampling area}

A sampling area of $>10 \mathrm{~m}^{2}$ is recommended however the area should reflect patchiness in the vegetation.

\section{Slopes and shadow effects}

The present model developed for Danish waters does not include effects of shadow caused by steep slopes and it might be problematic to include more parameters for the time being. For this reason focus in this NMR intercalibration project should be to sample data on locations/stations without slope effects (preferable $<30$ degree average angle to the horizontal axis in the sampling area) and other factors like hangouts than influence light penetration to the sampling area. The slope angel is measured as indicated in figure 3 .

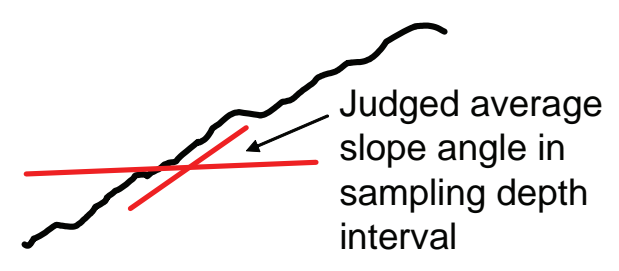

Figure 3. A rough estimate of the slope in the sampling area is judged as the angel from the horizontal axis. 


\section{Biological factors interacting with algal cover}

Presents of sea urchins and drifting algal mats both measured as \% cover of suitable hard substrate has proven to influence vegetation in a significant negative way in the latest model (under preparation) Effects of Mytilus edulis cover as competitor for substrate not as substrate (present in higher number only in the Baltic area and not monitored for more that tree years) were not significant.

\section{Sampling depth}

Total cover of erect macroalgal vegetation often show a distribution with less than $100 \%$ cover near the water surface, $100 \%$ cover in the "intermediate" depth and then decreasing cover at deeper water. (Figure 4) It is important to focus the sampling effort at deeper water as the indicator in this context should reflect light limitation linked to water quality and not the degree of exposure in the surface water. Sampling depth giving cover data within the interval $15 \%-85 \%$ in an "average year" regarding water quality is preferable as it allows detection of both improvements and loss in algal cover due to changing levels of eutrophication.

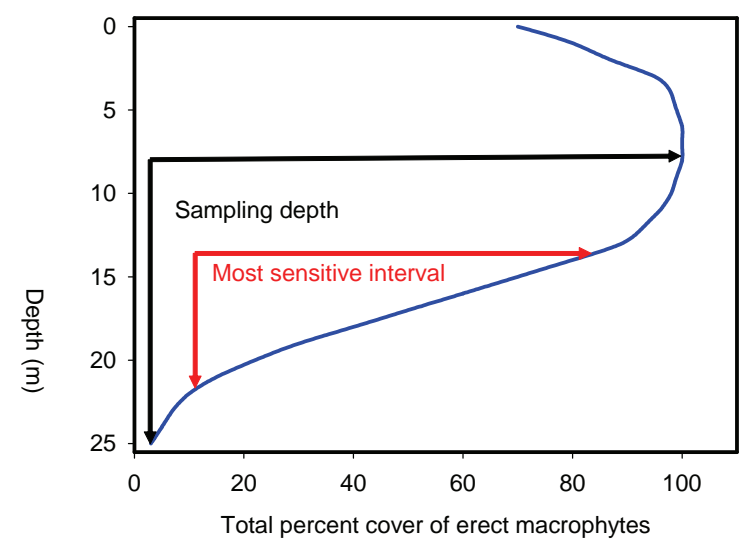

Figure 4: Illustrates the vertical focus area (depth) for sampling total vegetation cover and the depth were judged cover data are expected to provide the best input to recognize changes in the water quality. The actual depth intervals will of course be depended on the water quality at the sampling site.

\section{List of information's and sampling parameters to report:}

\section{General information regarding the Location}

Name

Position: degree, minutes and decimal minutes (WGS-84)

UTM Zone

Name of nearest relevant water chemistry station 
Station (depth relevant informations)

Depth (x,x meter)

Cover of hard stable substrate (\%) (should be $>10 \%$ of the seabed)

Slope angle (Degree)

Downward slope direction (in 360 degrees)

Area judged $\left(\ldots \mathrm{m}^{2}\right)$

Total vegetation cover (\%)

Cover of (Mytilus, sea urchine, drifting algal or other factors effecting vegetation cover) (\%)

\section{Suggestion for data delivery format}

\begin{tabular}{lrrr}
\hline General information regarding the Location & & & \\
\hline Name & Kim's Top & Kim's Top & Kim's Top \\
\hline Position Long. (WGS-84) & 1157.999 & 1157.989 & 1157.931 \\
Position Latt. (WGS-84) & 5653.768 & 5653.766 & 5653.76 \\
UTM Zone & 32 & 32 & 32 \\
Name of nearest relevant water chemistry station & 427 & 427 & 427 \\
\hline Station (depth relevant informations) & & & \\
\hline Depth (X,X meter) & 15 & 17 & 20 \\
Cover of hard stable substrate (\%) (should be >10\% of the seabed) & 100 & 95 & 80 \\
Slope angle (Degree) & 10 & 10 & 15 \\
Downward slope direction (in 360 degrees) & 270 & 270 & 270 \\
Area judged (... m2) & 25 & 25 & 25 \\
Total vegetation cover (\%) & 95 & 80 & 45 \\
Cover of Echinus esculentus & 1 & 2 & 2 \\
Cover of Metridium senile & & 10 & 1 \\
Cover of .....XXXXX & & & \\
\hline
\end{tabular}





\title{
Appendix 2: WFD Metric: "Depth limit of macroalgal species”
}

\author{
Based on: \\ WFD intercalibration technical report \\ Part 3 - Coastal and Transitional Waters \\ Section 4 - Macroalgae \\ and \\ Boundary setting protocol \\ for intercalibration of macroalgae \\ in the North East Atlantic Region \\ (NEA GIG)
}

\section{Short definition of the indicator}

The metric "Depth limit of macroalgal species" use the depth extension of selected perennial macroalgal species as the biological quality element in response to environmental impacts. The selected species shown in table 1 are all 1) perennial, 2) commonly occurring in the type and 3) easy to determine.

Table 1. Selected macroalgae indicator species

\begin{tabular}{|c|c|c|c|c|c|c|}
\hline Finland: & coastal waters of Baltic Sea & & & & & \\
\hline Sweden: & c w of Baltic Sea & & & & & \\
\hline Sweden: & c w of Skagerrak-Kattegat & & & & & \\
\hline Denmark: & c w of Skagerrak-Kattegat & & & & & \\
\hline Norway: & c w of Skagerrak & & & & & \\
\hline \multirow[t]{6}{*}{ Red algae } & Chondrus crispus & $\mathrm{x}$ & $x$ & $\mathrm{x}$ & & \\
\hline & Furcellaria Iumbricalis & $x$ & $x$ & $x$ & & \\
\hline & Coccotylus /Phyllophora* & $x$ & $x$ & $x$ & & \\
\hline & Rhodomela confervoides & $x$ & $x$ & $x$ & & \\
\hline & Delesseria sanguinea & $x$ & $x$ & $x$ & & \\
\hline & Phycodrys rubens & $x$ & $x$ & $x$ & & \\
\hline \multirow[t]{3}{*}{ Brown algae } & Fucus vesiculosus & & & & $x$ & $x$ \\
\hline & Halidrys siliquosa & $x$ & $x$ & $x$ & & \\
\hline & Laminaria saccharina & $x$ & $x$ & $x$ & & \\
\hline
\end{tabular}

Note: Coccotylus /Phyllophora ${ }^{\star}=$ the complex of Coccotylus truncatus and Phyllophora pseudoceranoides

Remarks of the use of the metrics

Although the relationship between water transparency and the depth limit of perennial macroalgal species is obvious, so far, poor dose-response relationships between water quality expressed as either nutrient concentration or water transparency and the depth limit of the selected macroal- 
gal species tested have been found. The Nordic NEA-GIG group found no discontinuities/thresholds, which could be used to define the good/moderate boundary. The only distinct theoretical threshold is at a very deteriorated stage (e.g. poor/bad boundary) when the benthic vegetation has disappeared and no depth limit exists.

This lack of relationships may be due to (at least) two methodology limitations:

- The fact that observations along the depth gradient are typically interspaced by 2-3 m depth introduces an uncertainty of this magnitude on the estimates of depth limit. This is a large error given that many species don't penetrate very deep along the coasts of e.g Denmark.

- Assessing the deepest occurrence of a species is connected with much uncertainty, because abundance becomes increasingly sparse as the depth limit is approached, and time spent on searching as well as experience of the diver therefore influences the results. A more precise assessment of depth limits would require more observations along the depth gradient, e.g. every meter and it would then be preferable to define the depth limit as the depth of e.g. 5\% cover which is easier to locate than the absolute depth limit.

\section{Skagerrak-Kattegat}

The metric "Depth limit of macroalgal species" of water types NEA 8, 9 and 10 (North East Atlantic water types) describes the depth extension of selected perennial macroalgal species in Scandinavian coastal waters. The species selected for each type are all 1) perennial, 2) commonly occurring in the type and 3) easy to determine. The metric is affected by nutrient concentration and water transparency (Kautsky et al. 2004). Depth limits of macroalgae as a group (Nielsen et al. 2002b) and depth limits of selected macroalgal species (e.g. Kautsky et al. 1986, Kautsky et al. 2004) have been shown to respond to changes in nutrient concentration and water clarity. Selected species are shown in table 1.

Salinity also affects competition among species and thereby the occurrence and depth distribution of the individual species (e.g. Nielsen et al. 1995, Pedersen and Snoeijs 2001, Torn et al. 2006). In areas containing large salinity gradients, relationships between depth limits and nutrient concentration/water clarity should therefore be developed for specific salinity regimes.

The algae also demand hard substratum for attachment, so the metric is only applicable in areas where hard substratum occurs to the maximum water depth where light allows growth. Moreover, the metric should only be applied in relatively deep areas where water depth in itself does not limit depth penetration of the algae. 


\section{Relationships between water quality and the depth limit}

The relationships between water qualities expressed as either nutrient concentration or water transparency and the depth limit of the selected macroalgal species was tested by the Nordic Intercalibration Group, and so far a dose-response relationships seem to show no discontinuities/thresholds, which can be used to define e.g. the good/moderate boundary. The only distinct theoretical threshold is at a very deteriorated stage (e.g. poor/bad boundary) when the benthic vegetation has disappeared and no depth limit exists. No distinct boundaries have been identified based on paired metric assessment. However, in general the doseresponse relationships on present-time data do not include a range of nutrient concentrations representing reference levels or high/good boundaries. Reference levels for the benthic vegetation indicators therefore have to be set using historical data, hind-cast modeling and/or expert judgement. As reference levels are likely to vary between areas, we suggest that the levels are defined for each area and that class boundary limits are defined as specified deviations from reference levels.

\section{Depth limits of macroalgal species}

Swedish historical data on depth distribution of individual macroalgal species are available for only one water body i.e. NEA 9 (Skagerrak fjords Norwegian and Swedish waters). This data set is from the inner Gullmar Fjorden, in 1941, at the Swedish Skagerrak coast (Eriksson et al. 2002). Norwegian historical data for lower depth limits were available for the two other water types e.g. NEA 8 (Skagerrak inner archipelago - Norwegian and Swedish waters) and 10 (Skagerrak exposed - in Norwegian and Swedish waters). The Swedish dataset is limited both in aerial cover and time but can be used to estimate the maximum historical depth distribution of some commonly occurring, easily recognizable perennial macroalgal species and thereby to define approximate reference depth limits for the type area represented by the data. The historical Norwegian datasets are, however, based on dredging and caution must be exercised. Hence, the historical data were used in combination with modeling (based on Secchi depths), present depth occurrence of the selected species in areas with low nutrient enrichment, and expert judgement to estimate reference depth limits for other water body types. The result from the the Skagerrak NEAGroup is presented in the table 5, 6 and 7. In Sweden reference depth limits have been defined for each of the selected species in each salinity regime in within the Swedish coastal water types (Kautsky et al. 2004).

In Table 5 depth limits in NEA9 areas are represented by the only area for which historical data is available, i.e. Gullmar Fjorden, one profile in 1941 and two recent Norwegian surveys. The high-good boundary (= reference condition) for depth limits of nine selected macroalgal species has been 
defined as a $17-33 \%$ deviation from the estimated reference levels. All depth limits are set by expert judgement for each of the nine selected macroalgal species since the few available data do not allow any good statistical treatment. Similarly, good-moderate boundaries have been set by expert judgement and represent a 42 to $50 \%$ deviation from reference levels.

In table 6 the lower depth limits have been estimated based on Sundenes historical data sets (Sundene 1953) and several recent data sets. As for NEA9 both the reference values and the boundaries are based on expert judgements. The historical values from Sundene (1953) are based on dredging and are therefore not as reliable as recent surveys carried out by use of diving. Hence, the new estimated reference values are estimated somewhere between Sundenes findings and recent observations. For some species the recent findings of lower depth limits exceeds those found by Sundene. In these cases the recent finding has been used in estimating a new reference value. The High/Good boundaries vary between 18 and 37\% of the estimated reference value and the Good/Moderate boundaries vary between 44 and $58 \%$ of the estimated reference values (Table 6).

Within NEA10 there are several extensive monitoring programs both in Norway and in Sweden that have made it possible to determine a lower depth limits for the same species as in NEA8 and 9. Fredriksen and Rueness (1990) compared the data sets collected at the same stations examined by Sundene in 1947-1952, and used both dredging and diving. The conclusions were that the lower depth limits have been reduced since Sundenes explorations. Both these reports have been compared with recent registrations and new reference levels have been estimated for all species. Within the Coastal Monitoring Program (1990-2006) some scattered individuals are found even deeper than the new reference values, however, these lower depth limits represent individuals that may not survive the over wintering, hence not a reference level for healthy and reproductive species. The High/Good boundaries vary between 24 and 29\% of estimated reference level and the boundary level of Good/Moderate between 40 and $50 \%$ of reference levels (Table 7)

Table 5. Estimated depth limits for NEA 9 - Skagerrak fjords - in Norwegian and Swedish waters.

\begin{tabular}{|c|c|c|c|c|c|c|}
\hline NEA9 Skagerrak fjords & $\begin{array}{r}\text { Walday et } \\
\text { al. } 2001\end{array}$ & $\begin{array}{r}\text { Magnusson } \\
\text { et al. } 1992\end{array}$ & $\begin{array}{r}\text { Eriksson } \\
\text { et al. } 2002\end{array}$ & NEW ref. & High/Good & $\begin{array}{r}\text { Good/ } \\
\text { Moderate }\end{array}$ \\
\hline Survey nr.: & 1 & 2 & 3 & & & \\
\hline \multicolumn{7}{|l|}{ Species } \\
\hline CHOCR & & 5 & 12.5 & 12 & $>10$ & 7 \\
\hline FURLU & & 3 & 15 & 15 & $>12$ & 8 \\
\hline HALSI & & & 12.5 & 12 & $>10$ & 6 \\
\hline LAMSA & 7 & 12 & 10 & 12 & $>8$ & 6 \\
\hline PHYP+COCTR & 17 & 13 & 11 & 14 & $>10$ & 8 \\
\hline $\mathrm{RHOCO}$ & 12 & 10 & 15 & 15 & $>12$ & 8 \\
\hline DELSA & 17 & 11 & 16.6 & 17 & $>13$ & 9 \\
\hline PHYRU & 14 & 9 & 16 & 16 & $>13$ & 8 \\
\hline
\end{tabular}


Table 6. Estimated depth limits for NEA8 - Skagerrak inner archipelago - in Norwegian and Swedish waters.

\begin{tabular}{|c|c|c|c|c|c|c|c|c|c|}
\hline $\begin{array}{l}\text { NEA8 Skagerrak } \\
\text { Inner Archipelag }\end{array}$ & $\begin{array}{r}\text { Walday et } \\
\text { al. } 2001\end{array}$ & $\begin{array}{r}\text { Magnus- } \\
\text { son et al. } \\
1992\end{array}$ & $\begin{array}{l}\text { Pedersen } \\
\text { et al. } 1989\end{array}$ & $\begin{array}{r}\text { Moy et } \\
\text { al. } 2005\end{array}$ & $\begin{array}{r}\text { Karlsson } \\
1994-98\end{array}$ & $\begin{array}{r}\text { Sundene } \\
1953^{*}\end{array}$ & $\begin{array}{r}\text { NEW } \\
\text { ref. }\end{array}$ & $\begin{array}{l}\text { Highl } \\
\text { Good }\end{array}$ & $\begin{array}{r}\text { Good/ } \\
\text { Moderate }\end{array}$ \\
\hline Survey nr.: & 1 & 4 & 5 & 6 & 7 & 8 & & & \\
\hline \multicolumn{10}{|l|}{ Species } \\
\hline $\mathrm{CHOCR}$ & 10 & & & 8 & 10 & 15 & 12 & $>8$ & 5 \\
\hline FURLU & 12 & 6 & & 3 & 12 & 20 & 16 & $>10$ & 7 \\
\hline HALSI & 4 & & 6 & 8 & 10 & 5 & 10 & $>8$ & 5 \\
\hline LAMSA & 12 & 10 & 16 & 6 & 8 & 13 & 16 & $>10$ & 7 \\
\hline PHYP+COCTR & 20 & 12 & 20 & 16 & 9 & 35 & 22 & $>18$ & 12 \\
\hline RHOCO & 12 & & & 16 & 12 & 14 & 16 & $>12$ & 7 \\
\hline DELSA & 22 & 15 & 16 & 16 & 20 & 35 & 25 & $>18$ & 12 \\
\hline PHYRU & 16 & 14 & 16 & 14 & 18 & 20 & 18 & $>15$ & 10 \\
\hline
\end{tabular}

Walday et al. 2001 is from Grenlandsfjord 1998-1999, Magunsson et al. 1992 is from Oslofjord 1990, Pedersen et al., is from Chysochromulina surveys in 1988 and 1989 . Moy et al. 2005 is from the Norwegian Coastal Monitoring Program from 1990-2005, Karlsson 1994-998 is from the Swedish coastal monitoring program from 1994-1998 and Sundene 1953 is from surveys in outer Oslofjord in 1947 to 1952. New reference is based on expert judgement and all these reports mentioned. * uncertainty of viability as dredging was used in collection the seaweeds.

Table 7. Estimated depth limits for NEA10 - Skagerrak exposed - in Norwegian and Swedish waters.

\begin{tabular}{|c|c|c|c|c|c|c|c|}
\hline $\begin{array}{l}\text { NEA10 Skagerrak } \\
\text { exposed }\end{array}$ & $\begin{array}{r}\text { Moy et } \\
\text { al. } 2005\end{array}$ & $\begin{array}{r}\text { Fredriksen \& } \\
\text { Rueness } 1990\end{array}$ & $\begin{array}{r}\text { Sundene } \\
1953^{*}\end{array}$ & $\begin{array}{r}\text { Karlsson } \\
1994-98\end{array}$ & $\begin{array}{r}\text { NEW } \\
\text { ref. }\end{array}$ & $\begin{array}{l}\text { Highl } \\
\text { Good }\end{array}$ & $\begin{array}{r}\text { Good/ } \\
\text { Moderate }\end{array}$ \\
\hline Survey nr.: & 9 & 4 & 8 & 7 & & & \\
\hline \multicolumn{8}{|l|}{ Species } \\
\hline CHOCR & 18 & 0 & 18 & 16 & 18 & $>13$ & 9 \\
\hline FURLU & 13 & 14 & 20 & 14 & 16 & $>12$ & 9 \\
\hline HALSI & 14 & & 8 & 10 & 14 & $>10$ & 8 \\
\hline LAMSA & 20 & 13 & 16 & 14 & 16 & $>12$ & 9 \\
\hline PHYP+COCTR & 30 & 18 & 35 & 16 & 30 & $>22$ & 18 \\
\hline RHOCO & 24 & & 12 & 16 & 16 & $>12$ & 9 \\
\hline DELSA & 20 & 15 & 32 & & 30 & $>22$ & 18 \\
\hline PHYRU & 29 & 27 & 27 & & 29 & $>22$ & 17 \\
\hline
\end{tabular}

Moy et al. 2005 is from the Norwegian Coastal Monitoring Program from 1990-2005, Fredriksen \& Rueness 1990 is from surveys on Sundenes (1953) location in 1989. Karlsson 1994 is from the Swedish coastal monitoring program from 19941998 and Sundene 1953 is from surveys in outer Oslofjord in 1947 to 1952. New reference is based on expert judgement and all these reports mentioned. * uncertainty of viability as dredging was used in collection the seaweeds.

\section{Concluding remarks}

In summary, our findings suggest that depth limits of macroalgal species is not a strong indicator of water quality in Danish waters. Depth limits were generally weakly correlated with proxies of eutrophication. Secchi depth alone could explain only up to $33 \%$ of variations in depth limit of a given species. In many cases, depth limits were located at water depths receiving relatively high light levels and depth limits often showed marked variability between years. Moreover, depth limits often coincided with the maximum depth of suitable substratum. These findings all indicate that factors other than light contribute considerably to regulating depth limits. Lack of suitable substratum limit depth penetration in many Danish waters and is a major factor explaining why the selected algae often don't grow as deep as light levels allow. Even at many of the stone 
reefs which represent the best substrata for algal growth in Danish waters, the selected species were often recorded more or less to the maximum investigated depth of the reefs which coincided with the maximum depth of suitable substratum.

\section{The Baltic Sea - Finland and Sweden}

Macroalgae are only intercalibrated between Sweden and Finland for the types B0, B2 and B3. Macroalgae are not intercalibrated in the types B12, B13 and B14, as the depth limit of Fucus is determined by substrate and not by human impact.

The Baltic GIG has agreed that there are no sites as of today suitable for representing the biological reference sites due to the overall eutrophication of the Baltic Sea.

Based on literature surveys and historical data the distribution and depth ranges of macroalgae were evaluated. The literature covered the years starting around 1930s onwards. With the expert judgements the reference condition for macroalgae depth limit was established. In Finland the Fucus reference values were set using the literature values by Häyren 1930-1950, Andersson 1950s and Ravanko 1960s. In Sweden reference values are based on data from the 1940ies (Kautsky et al. 1986, Eriksson et al. 1998 based on data by Waern) and literature data from 1990ies from areas regarded as almost unaffected by nutrient enrichment.

No dose-response relationship has been developed so far to show discontinuities/thresholds, which can be used to define e.g. the good/moderate boundary.

Table 8. Sites B3, more sheltered

\begin{tabular}{lcccccc}
\hline Reference & Highest ref. v & High & Good & Moderate & Poor & Bad \\
\cline { 2 - 7 } & $($ meter $)$ & $(\mathrm{m})$ & $(\mathrm{m})$ & $(\mathrm{m})$ & $(\mathrm{m})$ & $(\mathrm{m})$ \\
\hline $\begin{array}{l}\text { Swe: Integrated costal } \\
\text { monitoring 1991-93 }\end{array}$ & & & & & & \\
Fin: Ravanko 1968 & & & & & & \\
Fucus vesiculosus & & & & & & \\
Sweden & 8 & $>6$ & $4-6$ & $2-4$ & $<2$ & Missing \\
Finland & 6 & $>6$ & $4-6$ & $2-4$ & $<2$ & Missing \\
\hline
\end{tabular}

Sites:

Sweden (national type 12) Yxlan

Finland (national type Ca Lounainen sisäsaaristo) Seili and Bågaskär 
Table 9. Sites B3, more exposed water

\begin{tabular}{|c|c|c|c|c|c|c|}
\hline \multirow[t]{2}{*}{ Reference } & Highest ref. v & High & Good & Moderate & Poor & Bad \\
\hline & (meter) & (m) & (m) & (m) & (m) & (m) \\
\hline \multicolumn{7}{|c|}{$\begin{array}{l}\text { Swe: Waern 1952, } \\
\text { Monitoring, H. Kautsky } \\
\text { Fin: Andersson } 1955 \\
\text { Purasjoki } 1935\end{array}$} \\
\hline \multicolumn{7}{|c|}{ Fucus vesiculosus } \\
\hline Sweden & 8 & $>8$ & $5-8$ & $3-5$ & $<3$ & Missing \\
\hline Finland & 10-11 & $>8$ & $5-8$ & $3-5$ & $<3$ & Missing \\
\hline
\end{tabular}

Sites:

Sweden (national type 14), Askö

Finland (national type Ea Lounainen välisaaristo) Långskär

Table 10. Intercalibration type B2. Description: Coastal waters of the Bothnian Sea, partly sheltered. Mainly hard bottom. Salinity is ranging from 4 to 5 PSU.

\begin{tabular}{lcccccc}
\hline Reference & Highest ref. v & High & Good & Moderate & Poor & Bad \\
\cline { 2 - 7 } & $($ meter $)$ & $(\mathrm{m})$ & $(\mathrm{m})$ & $(\mathrm{m})$ & $(\mathrm{m})$ & $(\mathrm{m})$ \\
\hline $\begin{array}{l}\text { Swe: Kautsky \& Foberg 1990 } \\
\text { Fin: Häyren 1950 }\end{array}$ & & & & & & \\
Fucus vesiculosus & & & & & & \\
Sweden & 9 & $>7$ & $5-7$ & $3-5$ & $<3$ & Missing \\
Finland & 7 & $>7$ & $5-7$ & $3-5$ & $<3$ & Missing \\
\hline
\end{tabular}

Sites: Sweden: (national type 16): Yttre Gävlebukten, Ljusnan-Voxnan, Harskärs-Trödjefjärden, Långvinds- and Skärsöfjärden. Finland (national type F Selkämeren sisemmät rannikkovedet): Rounakari 
Tabel 11. Intercalibration type B0. Description: Open coast. Salinity < 3 PSU. Ice cover $>150$ days.

\begin{tabular}{lrrrrrrr}
\hline Reference & Highest ref. v & High & Good & Moderate & Poor & Bad \\
\cline { 2 - 5 } & $($ meter $)$ & $(\mathrm{m})$ & $(\mathrm{m})$ & $(\mathrm{m})$ & $(\mathrm{m})$ & $(\mathrm{m})$
\end{tabular}

Swe: Kautsky \& Foberg 1990,

Rosemarin 1992

Fucus vesiculosus

$\begin{array}{lllllll} & 7 & >6 & 4-6 & 2-4 & <2 & \text { Missing }\end{array}$

Sites:

Sweden Gaviksfjarden (national type 18)

\begin{tabular}{lrrrrrrr}
\hline Reference & Highest ref. v & High & Good & Moderate & Poor & Bad \\
\cline { 2 - 5 } & $($ meter $)$ & $(\mathrm{m})$ & $(\mathrm{m})$ & $(\mathrm{m})$ & $(\mathrm{m})$ & $(\mathrm{m})$
\end{tabular}

Swe: Kautsky m. fl. 1997

Fin: Häyren 1957

Fucus vesiculosus

\begin{tabular}{lllllrr} 
Sweden & 6 & $>5$ & $4-5$ & $2-4$ & $0.5-2$ & Missing \\
Finland & 5 & $>5$ & $4-5$ & $2-4$ & $<2$ & Missing \\
\hline
\end{tabular}

Sites:

Sweden: Örefjärden, (national type 20)

Finland: No intercalibration site

\begin{tabular}{lrrrrrrr}
\hline Reference & Highest ref. v & High & Good & Moderate & Poor & Bad \\
\cline { 2 - 7 } & $($ meter $)$ & $(\mathrm{m})$ & $(\mathrm{m})$ & $(\mathrm{m})$ & $(\mathrm{m})$ & $(\mathrm{m})$ \\
\hline
\end{tabular}

Swe: Kautsky \& Foberg 1998

Fin: Häyren 1955

Fucus vesiculosus

\begin{tabular}{lrrrrrr} 
Sweden & 6.7 & $>5$ & $4-5$ & $2-4$ & $0.5-2$ & Missing \\
Finland & 6 & $>5$ & $4-5$ & $2-4$ & $<2$ & Missing \\
\hline
\end{tabular}

Sites:

Sweden: Holmöarna (typ 21)

Finland: Bergo but data collected in Rönnskär 


\section{Appendix 3: Tables of algal depth distribution (average, maximum and variance)}

Table 12: Average depth distribution of selected species of $5 \%$ cover degree and maximum depth and variance between years 1995-2008.

\begin{tabular}{|c|c|c|c|c|c|c|c|c|c|c|c|c|c|}
\hline \multirow[b]{2}{*}{ 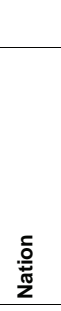 } & \multirow{2}{*}{$\begin{array}{l}\text { Species name } \\
\\
\end{array}$} & \multicolumn{4}{|c|}{ Coccotylus/Phyllophora } & \multicolumn{4}{|c|}{ Furcellaria lumbricalis } & \multicolumn{4}{|c|}{ Rhodomela confervoides } \\
\hline & & 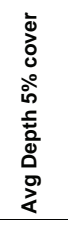 & 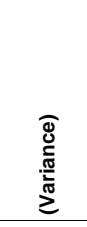 & 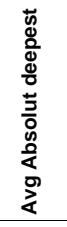 & 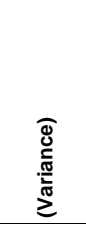 & 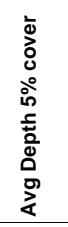 & 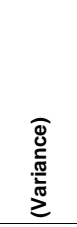 & 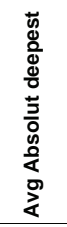 & 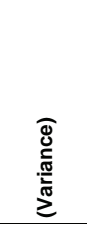 & 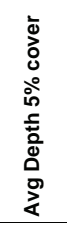 & 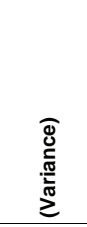 & 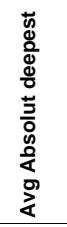 & 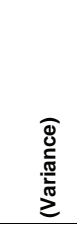 \\
\hline \multirow[t]{9}{*}{ NO } & D25 & 18.0 & $(288)$ & 17.0 & $(108)$ & & & & & 14.4 & $(74.8)$ & 19.8 & $(60.4)$ \\
\hline & D22 & 23.3 & (69.3) & 23.3 & (69.3) & & & & & 21.7 & $(42.5)$ & 21.2 & (33.9) \\
\hline & C18 & 23.7 & $(18.4)$ & 24.4 & (14.1) & 8.7 & (8.9) & 9.8 & $(12.4)$ & 20.7 & $(43.9)$ & 20.0 & $(47.8)$ \\
\hline & $\mathrm{C} 15$ & 20.4 & $(8.7)$ & 21.5 & $(9.0)$ & 4.0 & $(0.0)$ & 4.5 & (1.0) & 19.2 & $(47.5)$ & 17.8 & $(42.8)$ \\
\hline & B12 & 19.2 & $(13.4)$ & 18.5 & $(23.4)$ & 7.5 & $(40.5)$ & 7.5 & $(40.5)$ & 16.6 & $(57.5)$ & 15.4 & $(36.8)$ \\
\hline & B11 & 21.8 & $(24.6)$ & 22.0 & (29.5) & 7.1 & (13.1) & 8.5 & (16.9) & 22.1 & $(4.6)$ & 21.4 & $(17.5)$ \\
\hline & B10 & 21.1 & $(8.4)$ & 20.4 & $(30.3)$ & 5.9 & $(8.1)$ & 7.7 & (18.7) & 26.4 & $(6.3)$ & 24.0 & $(45.5)$ \\
\hline & B07 & 21.1 & $(29.3)$ & 21.6 & (32.6) & 9.9 & (7.4) & 9.6 & (10.8) & 18.9 & $(16.4)$ & 19.1 & $(11.5)$ \\
\hline & $\mathrm{A} 03$ & 17.7 & (14.1) & 18.0 & (15.4) & 8.4 & (2.8) & 10.0 & $(8.0)$ & 15.9 & (43.1) & 17.2 & (39.7) \\
\hline \multirow[t]{10}{*}{ DK } & Lønstrup Rødgrund & 8.0 & & & & & & & & & & & \\
\hline & Knudegrund & 9.5 & & & & & & & & & & & \\
\hline & Tønneberg Banke & 12.9 & (1.1) & 14.2 & $(0.5)$ & & & & & & & & \\
\hline & Per Nilen & 9.0 & (3.4) & & & & & 10.1 & $(2.1)$ & & & & \\
\hline & Store Middelgrund & 11.2 & (1.9) & 19.0 & $(19.7)$ & & & & & & & 16.4 & (13.6) \\
\hline & Briseis Flak & 8.9 & $(0.0)$ & & & 6.4 & $(0.7)$ & 8.6 & $(0.9)$ & & & & \\
\hline & Vejrø & 13.6 & (5.4) & 16.7 & $(10.0)$ & & & 11.1 & $(19.0)$ & & & & \\
\hline & Hatter Barn & 11.7 & $(8.6)$ & 16.0 & $(2.0)$ & & & & & & & & \\
\hline & Kirkegrund & 12.2 & $(0.9)$ & & & & & & & & & & \\
\hline & Møn's Klint & 20.0 & $(0.8)$ & 20.6 & & 19.6 & $(0.0)$ & 19.0 & $(5.4)$ & & & & \\
\hline \multirow[t]{24}{*}{ SwB } & Askö-1 & 7.9 & $(2.2)$ & 7.9 & $(2.0)$ & 6.6 & (3.4) & 6.5 & $(2.1)$ & 1.6 & & 4.9 & (8.5) \\
\hline & Askö-2 & 8.4 & $(0.1)$ & 8.4 & $(0.1)$ & 8.1 & (0.5) & 8.4 & $(0.4)$ & & & & \\
\hline & Askö-3 & 10.5 & $(1.4)$ & 10.5 & (1.4) & 9.0 & (4.5) & 9.6 & $(1.7)$ & 10.0 & $(2.8)$ & 10.0 & (2.8) \\
\hline & Askö-4 & 3.9 & $(0.0)$ & 3.9 & $(0.0)$ & 3.8 & (0.1) & 3.9 & $(0.1)$ & & & & \\
\hline & Askö-5 & 6.9 & $(0.4)$ & 6.9 & $(0.4)$ & 7.0 & (0.1) & 6.9 & $(0.4)$ & & & 6.0 & \\
\hline & Askö-6 & 7.9 & $(0.6)$ & 7.9 & $(0.5)$ & 7.9 & (0.5) & 8.2 & $(0.3)$ & & & 7.5 & (0.6) \\
\hline & Askö-8 & 8.0 & $(0.3)$ & 8.0 & $(0.3)$ & 7.3 & (1.0) & 7.0 & (1.5) & & & & \\
\hline & Askö-10 & 11.3 & $(5.0)$ & 11.7 & $(4.2)$ & 9.6 & (5.1) & 11.3 & $(5.9)$ & 9.7 & $(18.6)$ & 10.8 & (15.3) \\
\hline & Askö-11 & 7.0 & (12.4) & 8.3 & $(0.9)$ & 7.5 & (1.0) & 7.9 & (1.6) & 7.3 & $(2.0)$ & 8.7 & (7.8) \\
\hline & Askö-12 & 5.6 & $(0.2)$ & 5.6 & $(0.2)$ & 5.7 & (0.1) & 5.7 & $(0.1)$ & 6.0 & & 6.0 & $(0.0)$ \\
\hline & Askö-13 & 16.4 & (3.7) & 16.4 & (3.8) & 11.4 & (9.2) & 12.9 & $(6.6)$ & 13.0 & $(5.5)$ & 14.0 & (4.5) \\
\hline & Askö-14 & 7.4 & $(0.5)$ & 7.4 & $(0.5)$ & 5.9 & (5.4) & 6.3 & (6.9) & & & 8.1 & \\
\hline & Askö-15 & 5.7 & $(0.7)$ & 5.6 & $(0.5)$ & 5.4 & $(0.2)$ & 5.4 & $(0.2)$ & 5.2 & $(0.3)$ & 5.2 & (0.3) \\
\hline & Askö-16 & 7.4 & $(0.1)$ & 7.4 & $(0.1)$ & 7.2 & $(0.2)$ & 7.2 & $(0.2)$ & 7.6 & $(0.1)$ & 7.5 & (0.1) \\
\hline & Askö-17 & 6.3 & $(0.9)$ & 6.1 & (1.3) & 6.5 & $(0.2)$ & 6.5 & (0.1) & 5.7 & & 6.7 & $(0.0)$ \\
\hline & Askö-18 & 9.3 & $(0.8)$ & 9.6 & $(1.0)$ & 9.7 & (1.0) & 10.2 & $(0.1)$ & 8.9 & $(3.6)$ & 10.2 & (0.0) \\
\hline & Askö-19 & 12.2 & (0.1) & 12.2 & (0.1) & 11.1 & (4.3) & 11.6 & (1.7) & 11.5 & $(0.1)$ & 11.8 & (0.1) \\
\hline & Askö-20 & 8.8 & (1.2) & 8.8 & (1.2) & 9.3 & (1.0) & 9.6 & $(0.5)$ & 9.2 & $(0.7)$ & 9.4 & (0.9) \\
\hline & Askö-21 & 10.0 & $(0.2)$ & 10.0 & $(0.2)$ & 7.6 & (10.7) & 8.1 & (6.0) & 6.8 & $(19.6)$ & 8.9 & (1.3) \\
\hline & Askö-22 & 14.5 & $(0.6)$ & 14.5 & $(0.6)$ & 9.3 & (20.6) & 10.6 & (22.7) & 13.2 & $(5.5)$ & 14.4 & $(0.7)$ \\
\hline & Askö-23 & 15.9 & $(4.5)$ & 16.4 & $(8.5)$ & 11.5 & (26.3) & 16.0 & (22.9) & 13.5 & (2.8) & 14.6 & (6.9) \\
\hline & Askö-24 & 18.4 & $(17.3)$ & 18.4 & (17.3) & 11.7 & $(9.5)$ & 14.6 & (13.6) & 14.5 & $(10.2)$ & 16.2 & $(14.8)$ \\
\hline & Askö-25 & 16.8 & $(0.5)$ & 16.8 & $(0.5)$ & 10.8 & (8.2) & 13.0 & $(7.0)$ & 15.0 & (14.1) & 15.5 & (12.7) \\
\hline & Askö-26 & & & & & & & 10.4 & & 5.4 & & 5.1 & $(0.2)$ \\
\hline
\end{tabular}


Table 12(cont.): Average depth distribution of selected species of $5 \%$ cover degree and maximum depth and variance between years 1995-2008.

\begin{tabular}{|c|c|c|c|c|c|c|c|c|c|c|c|c|c|}
\hline \multirow[b]{2}{*}{$\begin{array}{l}\sum_{\text {L }} \\
\text { L }\end{array}$} & \multirow{2}{*}{ 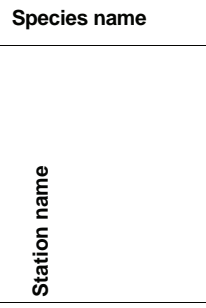 } & \multicolumn{4}{|c|}{ Chondrus crispus } & \multicolumn{4}{|c|}{ Delesseria sanguinea } & \multicolumn{4}{|c|}{ Laminaria saccharina } \\
\hline & & 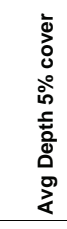 & 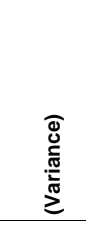 & 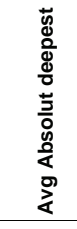 & 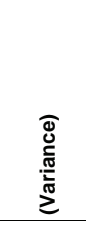 & 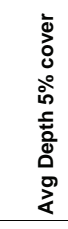 & 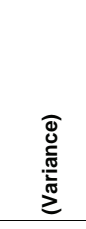 & 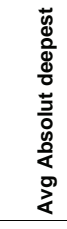 & 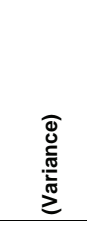 & 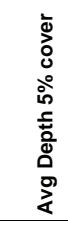 & 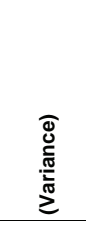 & 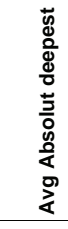 & 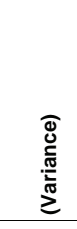 \\
\hline & Askö-27 & 8.3 & $(0.7)$ & 8.3 & $(0.7)$ & 8.8 & $(0.3)$ & 8.9 & $(0.3)$ & 8.7 & $(0.5)$ & 8.7 & $(0.5)$ \\
\hline & Askö-28 & & & & & 2.0 & & 2.0 & & & & 5.2 & $(6.8)$ \\
\hline & Askö-29 & 11.9 & $(2.9)$ & 12.1 & $(3.2)$ & 9.4 & $(15.2)$ & 10.1 & $(16.0)$ & 11.9 & $(4.7)$ & 12.0 & $(2.8)$ \\
\hline & Askö-30 & 9.0 & $(0.5)$ & 9.0 & $(0.5)$ & 9.6 & $(0.4)$ & 9.6 & $(0.4)$ & 9.1 & $(1.9)$ & 8.8 & $(2.7)$ \\
\hline \multirow[t]{7}{*}{ FIN } & Granbusken & 6.9 & $(2.6)$ & & & 6.7 & $(0.8)$ & & & & & & \\
\hline & Brännskär & 7.2 & & & & 8.7 & $(2.2)$ & & & & & & \\
\hline & Bålaskär & & & & & 9.0 & $(0.0)$ & & & & & & \\
\hline & Västrä Källskär & & & & & 8.8 & $(1.5)$ & & & & & & \\
\hline & Ryssholm & & & & & 6.9 & $(0.9)$ & & & & & & \\
\hline & Ämmärukka & & & & & 6.3 & $(1.8)$ & & & & & & \\
\hline & Pitkäluoto & & & & & 5.5 & & & & & & & \\
\hline \multirow[t]{9}{*}{ NO } & D25 & 1.3 & $(0.2)$ & 1.3 & $(0.2)$ & 29.4 & $(1.8)$ & 29.9 & $(0.1)$ & 21.1 & $(7.1)$ & 23.6 & $(12.8)$ \\
\hline & D22 & 1.0 & $(0.0)$ & 1.0 & $(0.0)$ & 24.6 & (37.3) & 25.0 & $(40.5)$ & 17.2 & $(25.4)$ & 17.2 & $(25.4)$ \\
\hline & C18 & 11.6 & (13.5) & 11.4 & (10.7) & 25.3 & $(2.8)$ & 25.3 & $(2.8)$ & 17.6 & (11.8) & 19.3 & (15.0) \\
\hline & C15 & 3.5 & $(4.3)$ & 3.4 & $(3.1)$ & 23.4 & $(22.9)$ & 23.4 & $(22.9)$ & 17.0 & (11.5) & 17.3 & $(8.8)$ \\
\hline & B12 & 6.2 & $(16.2)$ & 6.4 & (19.2) & 25.6 & $(4.9)$ & 24.2 & (32.3) & 14.9 & (42.1) & 14.6 & (50.3) \\
\hline & B11 & 13.9 & $(4.0)$ & 13.9 & $(4.0)$ & 27.5 & $(2.3)$ & 25.9 & $(45.5)$ & 13.3 & (10.6) & 15.4 & (12.1) \\
\hline & B10 & 14.0 & (11.1) & 14.5 & $(9.3)$ & 28.3 & (1.8) & 28.5 & $(1.7)^{\prime}$ & 16.3 & (17.8) & 15.7 & (30.7) \\
\hline & B07 & 12.5 & $(3.8)$ & 13.3 & $(1.2)$ & 25.5 & $(6.3)$ & 26.4 & $(5.8)$ & 13.9 & $(7.8)$ & 13.9 & (13.4) \\
\hline & $\mathrm{A} 03$ & 8.1 & (18.8) & 10.6 & $(27.3)$ & 24.3 & $(5.5)$ & 24.4 & $(5.0)$ & 10.8 & (23.6) & 11.5 & (19.1) \\
\hline \multirow[t]{6}{*}{ SwW } & Tån & & & 11.0 & & 16.5 & & 20.0 & & 4.5 & & 10.0 & \\
\hline & Gråurn & 0.6 & & 0.6 & & 19.0 & & 20.0 & & 8.4 & & 8.4 & \\
\hline & Byxeskär & 1.4 & & 5.0 & & 15.0 & & 20.0 & & 3.5 & & 8.0 & \\
\hline & Långö & 5.0 & & 6.0 & & & & 16.8 & & 8.5 & & 8.0 & \\
\hline & Namnlösen & 5.0 & & 4.8 & & 11.5 & & 16.4 & & 3.5 & & 8.8 & \\
\hline & Mittskär & 0.8 & & 0.8 & & 17.8 & & 20.0 & & 11.0 & & 7.6 & \\
\hline \multirow[t]{13}{*}{ DK } & $\begin{array}{l}\text { Lønstrup Rødgrund } \\
\text { Knudegrund }\end{array}$ & & & & & & & & & & & & \\
\hline & Herthas Flak & & & & & 15.6 & $(3.0)$ & 19.8 & $(0.4)$ & 12.4 & $(2.5)$ & 14.4 & (3.3) \\
\hline & $\begin{array}{l}\text { Tønneberg Banke } \\
\text { Per Nilen }\end{array}$ & & & 14.2 & $(1.2)$ & & & & & 14.2 & $(0.8)$ & 14.0 & $(0.6)$ \\
\hline & Kim's Top & & & & & 18.9 & $(4.6)$ & 22.0 & $(0.0)$ & 18.0 & $(2.7)$ & 18.2 & $(1.2)$ \\
\hline & Store Middelgrund & & & 14.0 & $(2.3)$ & & & & & & & & \\
\hline & Briseis Flak & 7.6 & $(2.1)$ & & & 7.9 & $(2.6)$ & & & & & & \\
\hline & Schult's Grund & & & 7.5 & $(1.6)$ & 11.6 & $(0.9)$ & 14.1 & $(5.7)$ & 10.2 & $(5.2)$ & 11.0 & $(0.8)$ \\
\hline & Munkegrund & & & & & 12.3 & & 11.0 & & & & & \\
\hline & Vejrø & & & 11.2 & $(8.2)$ & 14.5 & $(3.4)$ & 17.6 & $(7.0)$ & 13.6 & $(1.4)$ & 14.0 & $(2.7)$ \\
\hline & Hatter Barn & & & 10.3 & $(0.0)$ & 15.7 & $(0.8)$ & 17.0 & $(0.0)$ & 14.6 & $(0.0)$ & 16.0 & $(2.0)$ \\
\hline & Broen & & & 10.2 & $(0.9)$ & 14.7 & $(6.8)$ & 15.0 & $(0.0)$ & 11.5 & $(0.8)$ & 14.4 & $(9.6)$ \\
\hline & Kirkegrund & & & & & & & & & 12.3 & $(0.1)$ & & \\
\hline & Møn's Klint & & & & & 18.8 & $(4.2)$ & & & & & & \\
\hline
\end{tabular}

Note: Sweden's data from the west coast was from 2007 only and is not included in the variance tables. 
Ved Stranden 18

DK-1061 København K

www.norden.org

\section{Nordic intercalibration of hard bottom macroalgae monitoring methodologies}

\section{Algamony}

The aim of the ALGONOMY project was to harmonise Nordic macroalgae monitoring methodologies and to agree on common metrics that without extensive cost could be implemented in the national monitoring programmes. This report gives a description of the macroalgae monitoring methods used in Finland, Sweden, Denmark, and Norway and of the two common metrics "total algal cover" and "lower depth limit of macroalgal species" that was implemented to intercalibrate between the Nordic countries. Total cover estimates were significantly related to water clarity and provides a good ecological indicator for assessing the effects of nutrient management. Lower depth distribution limit is a good metric for classification but is set by more factors than water quality. In general, there is a need for better coordination between macroalgae and water quality monitoring with regard to geographic distance and sampling frequency to reflect processes and relationships. 